
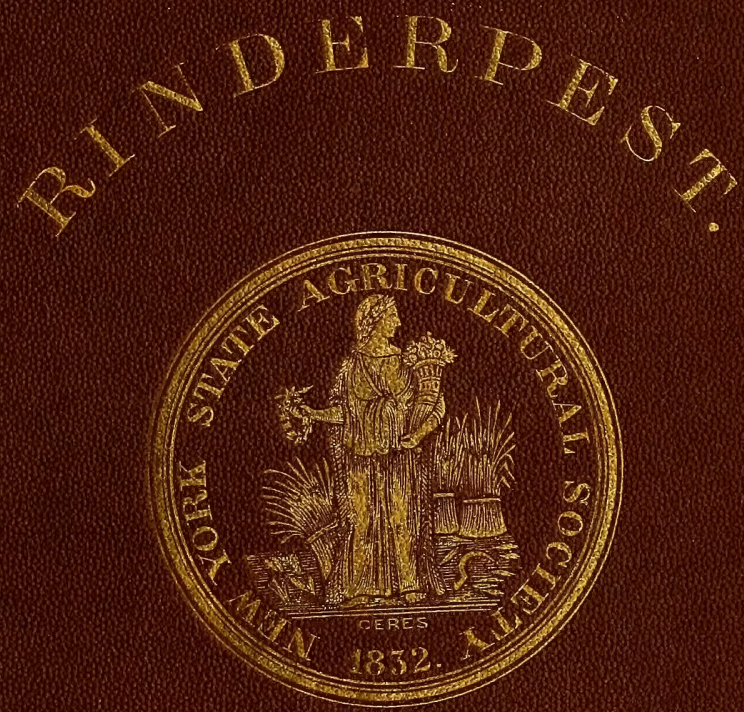

7. $3.00 \mathrm{dat}$ 


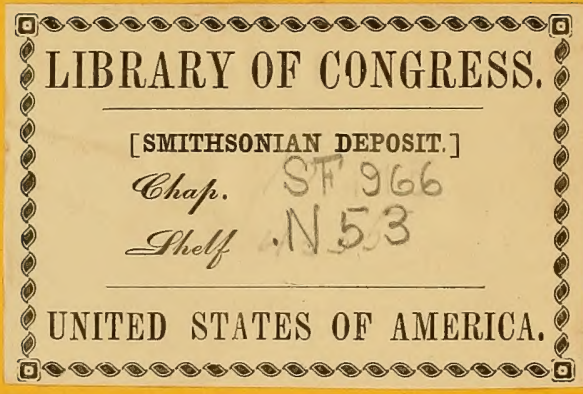











\section{FIRST AND SECOND REPORTS}

OF THE

SPECIAL COMNITTEE APPOINTED BY TIIE EXECUTIVE BOARD

OF THE

N. Y. STATE AGRICULTURAL SOCIETY,

ON THE

STATISTICS, PATHOLOGY AND TREATMENT OF THE EPIZOÖTIC DISEASE

KNOWN AS THE

\section{RINDERPEST.}

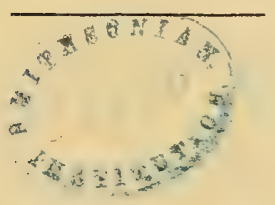

ALBANY :

WEED, PARSONS AND COMPANY, PRINTERS. 


\section{New York State Agriculrural Societr, ? Anndal Meeting, February 15th, 1866.}

Mr. JUDD, as Chairman of the Special Committee appointed on the subject of the Rinderpest, presented the following resolution, which was unanimously adopted :

Resolved, That the Executive Committee of the New York State Agricultural Society are requested to give special attention to the progress of the Rinderpest in foreign countries, and to the danger of its introduction bere. That they be empowered to use such measures as they may deem expedient for obtaining and publishing information in regard to the ravages and character of the disease, preventives and remedies to be used, etc., and that if, in their judgment, it at any time appears necessary or desirable, they are authorized to employ one or more competent persons to make investigations and procure reliable information either at home or abroad.

ExectTIVe Board, February 15th 1866.

Mr. CoNGer moved the following resolution, prefacing its presentation with the expression of his desire that the President of the Society might be named as Chairman :

Resolved, That the subject of the Rinderpest be referred to a committee of five to prepare from foreign papers and other sources a general outline of the statistics and pathological character of the disease, with such suggestions as to remedial or preventive methods, as may be deemed advisable for the farmers of the State to pursue in the treatment of the disease, in the event of its appearance in this country during the ensuing year.

The resolution was adopted, and the President, Mr. Gould, Hon. A. B. Conger, Dr. Julien T. Williams, L. H. Tucker and M. C. Weld were appointed the Committee. 


\title{
FIRST REPORT.
}

\author{
$\left.\begin{array}{c}\text { New York State Agricultural Societr, } \\ \text { Executive Board, March 29th, 1866. }\end{array}\right\}$
}

The committee of the Society appointed to investigate the statistics and pathology of the Rinderpest, and to suggest preventive and remedial methods for the protection of the State from its ravages, beg leave, by way of preliminary report, and in brief outline, to submit to the consideration of the Executive Board, those facts and conclusions which, in the judgment of the committee, justify the establishment by law of an efficient system of sanitary measures to prevent the introduction and dissemination of this terrific malady.

Your committee have had access to many foreign journals, agricultural and medical, which in every issue are filled with statements of the destructive career of this plague, and mostly, with humiliating admissions of general failure to arrest its spread or establish any efficient system of cure. Your committee have also been favored through the Secretary of the Society, with copies of the first and second reports of the commissioners, appointed by Royal Commission to investigate the origin and nature of the cattle plague; and the reports prepared on the pathological appearances and symptoms of the disease by Dr. SurakT, of Edinburgh, which were with great kindness and dispatch forwarded to the Secretary by Prof. Joun Wilson, F. R. S. E., Professor of Agriculture in the University of Edinburgh.

It appears that as far back as October 21 st, 1865 , a period of rather more than four months after the introduction of this disease into Islington, 14,083 animals had been attacked; 6,711 had died; 5,119 slaughtered; only 707 had recovered, and 1,546 remained under treatment. Since that time the statistics of enumerated cases had disclosed the appalling figures of 9,120 attacked in one week, ending 
January 6th, 1866, and at a later period over 13,000 in one week; in all, officially reported up to January 27th last, 120,740. It is believed, however, that at least two hundred thousand animals infected with this plague had been destroyed. Although at the last accounts, the rate of mortality had decreased, still the highest proportion of recoveries was only twelve in each one hundred cases.

In Belgium, where a vigorous system of quarantine had been instituted, and immediate slaughter of animals suspected to be suffering with the premonitory symptoms secured; only three hundred and six cases occurred, seventeen of which died, the rest being summarily disposed of by public authority. One case lately occurred at Antwerp, being traced to a smuggled cow. The market was at once closed, and all egress of cattle prohibited until further orders. The plague was thus successfully checked and Belgium has been free from its ravages ever since.

The disease entered France by one animal bought at Malines, and was arrested by the sacrifice of forty-three head of cattle. In November last, at the Jardin d'Acclimation, it made its appearance in the case of two gazelles, brought from India, which had been for three days in London. It spread rapidly among other animals at the garden, but was suppressed by the destruction of thirty-five ruminants of different species.

In Prussia, which has a long line of frontier, and is therefore greatly exposed from surrounding territory, where the disease has made extensive havoc, it has been kept at bay by the most determined action and instantaneous use of the knife.

Aberdeenshire, in Scotland, a county containing 150,000 head of cattle, adopting at the start a policy different from that pursued in England, has been quite exempt. It maintained a strict quarantine, and authorized summary destruction of all animals infected, under a system of compensation to the owners. Out of a fund of $£ 3,000$, raised by private subscription, $£ 1,400$ remained unexpended. Other parts of Scotland, which have neglected the precautions adopted in Aberdeen, have been frightfully devastated. Ireland, under a like system, principally of quarantine, established also with reference to persons employed about diseased cattle, has been untouched with these calamities.

The disease appears, from these statistics, and by a general admission of all writers on the subject, to be not only of a fatal, but of a highly infectious and contagious character. It is not only propagated in animals of the bovine race from one to another, but also to all classes of ruminants. The contagion is also conveyed in the clothes 
and by the persons of those employed in taking care of, or even of inspecting the diseased subjects. No remedial agencies have as yet been discovered which would justify for one moment the abandonment or neglect of preventive measures. Public policy and private interest alike demand that the pest should, if possible, be stamped out.

Your committee believe that the introduction of this disease into the State of New York, which contains over two millions of horned beasts and three millions of sheep, with no sanitary regulations established by law for its suppression, would result, if the ratio of mortality should be equal to that in England, in a loss to the people of this State of at least five millions of dollars.

Your committee, therefore, recommend that the Society should present a memorial to the Legislature, invoking in behalf of the great interests of the farmers of this State, summary and efficient action by which the disease may be prevented from coming within the borders of the State, and for its extirpation in any locality where it may, by possibility, be introduced; and to this end have prepared a draft of a bill* to be presented to the Legislature for its approval.

AN ACT to prevent the introduction and spread of the disease known as the Rinderpest, and for the protection of the flocks and herds of sheep and cattle in this State, from destruction by this and other infectious diseases.

The People of the State of Nero York, represented in Senate and Assembly, do enact as follows:

SECtion 1. It shall be the duty of the health officer of the port of New York, in addition to the duties now imposed on him by existing law, to examine and inquire whether any animals are brought in any vessels arriving at said port in violation of any regulation of law passed by the Congress of the United States prohibiting the importation of such animals.

§. Whenever any animal is brought as a ship's cow, with no intention of landing the same or of violating any such law or regulation of Congress as aforesaid, the same shall be carefully examined and kept in quarantine for the space of at least twenty-one days, and if any symptoms of the infection or incubation of the disease commonly known as the rinderpest, or of any other infectious or contagious disease, shall present themselves, it shall be the duty of the said health officer

*The bill prepared by the committee was, at the request of the Society, introduced into the Secate on the 31st day of March, by the Hon. Ezrs ConNexr, ex-President of the Society, and with slight amendments, became a law, being passed on the 20th of April, three-fifths being present; a copy of the law, as passed, being given in the-text. 
immediately to cause the said animal or animals to be slaughtered, and their remains boxed with a sufficient quantity of quick lime, sulphate of iron or other disinfectant, and with sufficient weights placed in said box to prevent the same from floating, and to be cast into the waters of the said port. It shall also be his duty to cleanse and disinfect by suitable agencies, the berth or section of the ship in which said animal or animals were lying or slaughtered, and also to cause the clothing and persons of all taking care of the same or engaged in such slaughter and burial, to be cleansed and disinfected.

§ 3. William Kelly, of Dutchess county, Marsena R. Patrick, of Ontario county, and Lewis $\mathbf{F}$. Allen, of Erie county, are hereby appointed as commissioners under this act, and with powers and duties as hereinafter enumerated.

$\S 4$, In the event of any such disease as the rinderpest or any infectious disease of cattle or sheep breaking out or being suspected to exist in any locality in this State, it shall be the duty of all persons owning or having any interest whatever in the said cattle, immediately to notify the said commissioners or any one of them of the existence of such disease; whereupon the said commissioners shall establish a sanitary cordon around such locality. And thereupon it shall be the duty of the said commissioners to appoint an assistant commissioner for such district, with all powers conferred by this act on the said commissioners or their agents or appointees, which said assistant commissioner shall immediately proceed to the place or places where such disease is reported to exist, and cause the said animal or animals to be separated from all connection or proximity with or to all other animals of the ruminant order, and take such other precautionary measures as shall be deemed necessary; and if, in his opinion, the said disease shall be incurable or threaten to spread, to cause the animals aforesaid immediately to be slaughtered, their remains to be deeply buried, and all places in which the said animals have been confined or kept, to be cleansed and disinfected by any of the agencies above mentioned; and also to cause the same to be carefully locked or barred so as to prevent all access to the same by any animals of a like kind for a period of at least one month. Any animal thus slaughtered shall be appraised under the supervision of said commissioners, and one-half of the value of said animal shall be paid by the State to the owner thereof.

$\S 5$. It shall be the duty of the said assistant commissioner, immediately on his being notified of his appointment, or at any time thereafter, of the breaking out of the said disease in any place contiguous to the same and within the county in which he resides, to give public notice of the same, in at least one newspaper printed or published in the said county, and to cause notices to be posted up in at least five conspicuous places in said neighborboed; and it shall be his duty to enjoin, in said notice and otherwise, all persons concerned in the care or supervision of neat cattle or sheep, not to come within one hundred feet of the said locality without the special permission of the said assistant commissioner.

$\S 6$. It shall be the duty of the commissioners appointed under this act, whenever they are advised that any such disease has made its appearance within the limits of the State, to publish in the State paper and in at least one paper published in 
any county where such disease exists, a statement of the methods approved by the New York State Agricultural Society for the treatment of cattle affected therewith, for the isolation of the same, for the disinfection of the premises or buildings in which said cattle are found affected as aforesaid, and for the preven. tion of the spread of the same through any agencies of whatever kind.

§7. The commissioners aforesaid and all such assistants as they may appoint, whenever in their judgment or discretion it shall appear in any case that the dis ease is not likely to yeld to any remedial treatment, or whenever it shall seem that the cost or worth of any such remedial treatment shall be greater than the value of any animal or animals so affected, or whenever in any case such disease shall assume such form of malignity as shall threaten its spread by processes either contagious or infectious, or otherwise, are hereby empowered to cause the said animals to be slaughtered forthwith and buried, as above provided, and to do all such things as are mentioned in the fourth section of this act.

§ 8. The said commissioners or their assistants are hereby empowered to enter upon and take possession of all premises or parts thereof where cattle so affected as aforesaid are found, and to cause the said cattle to be confined in suitable inclosures or buildings for any time requisite in the judgment of the said commissioners or their assistants, and prior to the slaughter and burial of the said animals and the full and complete disinfecting and cleansing of such premises; and all persons, whether owners of, or interested in such cattle or otherwise, who shall resist, impede or hinder the said commissioners or their assistants in the execu. tion of their duties under this act, shall be deemed guilty, and on conviction of the same, of a misdemeanor, and shall be punishable with fine not exceeding one thousand dollars, or imprisonment not exceeding the term of six months, or of both, in the discretion of the court before which they shall be adjudged guilty as aforesaid.

$\S 9$. The commissioners shall have power to establish all such quarantine or other regulations as they may deem necessary to prevent the spread of the disease or its transit in railroad cars, by vessels or by driving along the public highways; and it shall be proper for the Governor of the State, by public proclamation as aforesaid, to enjoin all persons concerned or engaged in the traffic or transit of cattle or sheep, not to enter upon any places or take therefrom any such animal or to pass through any such locality, and within such distances from the same as in the said proclamation may be prescribed.

$\S 10$. The sum of one thousand dollars, or so much thereof as may be necessary, is hereby appropriated to pay to the said commissioners for their services while actually engaged in the duties enjoined upon them in this act, at the rate of five dollars per day to each, and such further sums as may amount to their actual expenditures in traveling to and from the places they may be called upon to inspect or visit, and in the printing or publishing of all regulations or notices mentioned in this act. And the further sum of fifteen thousand dollars, or so much thereof as may be necessary, is hereby appropriated out of any money in the treasury, not otherwise appropriated, to pay for animals slaughtered by the provisions of this act, and the Comptroller is hereby directed to pay for the same on the warrant of the said commissioners. 
§11. The assistant commissioners are to receive for each and every day while actually engaged in duties provided by this act, the sum of three dollars per day, and all actual expenses and disbursements paid or incurred in the discharge of their duties as aforesaid, which said sums shall be a charge upon the county for which he is appointed, and shall, when duly audited by the board of supervisors of the said county, be paid by the county treasurer.

$\S 12$. The slaughtering of animals for beef after having been exposed to the contagion, or supposed to have been so exposed, may be permitted by the commissioners or prohibited by them, as they may judge proper.

$\S 13$. This act shall take effect immediately, and shall continue in force for one year. 


\title{
SECOND REPORT.
}

\author{
New York State Agricultural Roons, \\ Albany, June 15th, 1866.
}

The Committee of the Executive Board, in presenting their report on the remaining portion of the subject of the Rinderpest as referred to them, desire to acknowledge access to various other publications and treatises, on this and kindred diseases, than those mentioned in their preliminary report. Of these they would especially notice the essay of LAXARD, on the distemper of 1745-57; the report of JESSEN (now Counsellor of State and Director and Professor of the Veterinary College of Charkow) to the Russian Government, on the results of inoculation as a method of cure and extirpation of the disease; the inquiry into the Pathology and Treatment of the Cattle Plague, by Alfred C. Pope, Esq., and the Sequel to the Report made to the Lord Lieutenant of Ireland.

Others are referred to in the body of the report. They ought not, to overlook the elaborate treatise of JoHN GAMgee, Principal of the Albert Veterinary College, London, \&c., although the greater portion of this report was prepared for the press before access to his work. It exhibits large research and is of the highest value, when detailing his own independent observations or the investigations of others of equal science and repute. In addition to the topics discussed by other writers, this volume contains the debates of the International Veterinary Congresses (held at Hamburg in 1863, and at Vienna in 1865), on quarantine, diseases of cattle requiring police regulation, \&c. Appended are papers by Drs. Beate and CoBbold on the entozoa found in the muscles after death, \&c. It will be seen that we have drawn upon this volume by copious notes; that in our discussion of the pathology frequent reference has been made to GAMGEE's observations and those of his co-adjutors ; and that under the head of treatment, one of his remarkable experiments has been employed, as we trust, after a method which may result in robbing this plague of some of its terrors.

Of the works referred to in the first report, that of Dr. SuraRT, of Edinburgh, with its splendid pathological illustrations, has been most 
invaluable to your committee in the delineation of symptoms and morbid anatomy. These illustrations, with many of those of JEssEN and GAMGEE, have been copied and re-arranged, and will, doubtless, in their reprint, confirm to the eye of the reader the marked structural lesions of this disease.

Careful examinations have also been made of the description of the pathological lesions in cholera by PERIGOFF, and of those of diseases generally by LEBERT and others, in order, if possible, to attain some basis on which to rest the comparative pathology of the Pest.

A masterly article by EGAN, of Pesth, a practical agriculturist (æconom) of Hungary, who has had a large experience in the management of cattle and the treatment of this and other diseases which are rife in that region, is appended to the second report of the Royal Commissioners. It is to be regretted, that only that part of the article, as prepared by him, touching the Rinderpest, was forwarded by Lord Bloomfield for the use of the English Commission, as it is believed that EGAN's discussion of the various forms of Anthrax, and of the Epizoötic known in Hungary as the blood plague, would have thrown additional light on some portion of the labors of your committee.

With the materials before them, your committee have encountered a vast mass of variant statements and conflicting opinions as to observed phenomena, whether referring to symptoms, diagnostic signs, preventive or remedial agencies. Your committee have desired that their labors might lessen this confusion, and have aimed, in their classification of the various symptoms, to present the disease in its leading characteristics. Pursuing such a course, and seeking aid from the most recent investigations made by modern science on the action of blood-poisons and fungoid germs, your committee hope that their labors* may be of essential service to the Society, and through it to the State Commissioners, to whom, in the event of an outbreak of the Pest in this State, such vast interests have been intrusted.

In behalf of the committee,

A. B. CONGER.

\footnotetext{
* Much care has been given in the revision of the processes of Mr. ToLLE, the artist, to whose skill the lithographing in colors of the illustrations, has been committed. The time occupied in the attempt to make them faithful copies of the originals, the happy freedom which this country has enjoyed from any outbreak of this fearful pest, the desire of allaying apprehensions too easily excited, and the necessity of reprinting a large portion of the text to conform with the size ( 8 vo.) of the plates stricken off at a large expense, will account, in some measure, for the delay in issuing to members of the society, copies of this Second Report.
} 


\section{RINDERPEST,}

\section{ITS HISTORY, PATHOLOGY AND TREATMENT.}

Diseases of animals are either epizoötic or enzoötic. This classification corresponds to that of the maladies which affect the human race, epidemic and endemic.

The former of each class have been defined as dependent upon or originating in some particular condition (constitutioæris) of the atmosphere, and as attacking a number of individuals at the same time. Thus they differ from the latter of each class, which are described as of purely local origin, at least in the first instance, and as comparatively limited or isolated in their development.

Diseases, however, that are at first endemic or enzoötic, may break out at a time when their diffusion is favored by currents of the atmosphere; when its condition by lowering the tone increases the susceptibility of the patient; or when chemical or other changes affect its normal constitution, and so develop fresh food for the local malaria. Then, these diseases become epidemic or epizoötic.

Most of such diseases exhibit this further peculiarity of developing in their course a malignant rirus or miasm (perchance infinitesimal germs, with all the subtle rancor and prolific power of a fungous growth), which spread through or float on the atmosphere, intensifying the original power of the "materies morbi," whether originally local or not, and thus these maladies are infectious. But frequently it happens that the poison may be propagated by touch or direct applica- 
tion to absorbent surfaces, by inoculation or the like, and thus the disease may be not only infectious, but contagious also.*

We do not present this distinction as disposed to cope with any of the vexed questions in the schools, but simply (as the sequel will show the Rinderpest to be capable of propagation by both methods) to guard, in the case of this disease at least, against the erroneous impression that it must be communicable, if at all, in one way or the other, and cannot be by both. Before, however, demonstrating that the great variety of observed facts do not sustain any such delusive view, it is desirable to trace the pest from its earliest appearance to its present formidable development in Great Britain.

\section{HISTORY.}

The Rinderpest had its origin on the Asiatic part of the steppes of Russia, more, it is said, than one thousand years ago, and in the times of Charles the Great. These steppes (from the Russian word "step," signifying a desert or dry plain) are natural feeding grounds, not unlike the lands of Guienne in France, the heaths of Northern German5, and in many respects like the prairies of the Great West. In these steppes are now roving from eight to ten millions of cattle, more than half being reserved for market as fat cattle. Though the greater part of these immense ranges is more or less arid, that portion of the Asiatic steppe between the rivers Volga and Don is marshy and generally accounted to be the local source of the infection. Be this as it may, no part of the steppes, or it is said of Southern Russia (and the same may be affirmed of the Hungarian steppes, stretching

\footnotetext{
* The absence of any verb in the English language corresponding to the term contagion accounts for the use of the verb "infect," as indicative of the action of contagion as well as infection; hence these terms are frequently used as synonymous. Physiologists recognize the distinction aimed at in the text, though some using infection or contagion convertibly, attempt to make the necessary classification as immediate or mediate, contactual or remote. This may sorve for such diseases, on the one hand, as syphilis, framboesia, lepra, itch and the like, or for diseases transmissible from the lower animals, as hydrophobia, and on the other hand, for influenza, malarious or other fevers, \&c. But it does not serve as well as the distinction in the text for diseases whose poisonous principle is equally efficient, whether by immediate application to the skin, \&c., or by absorption through the atmosphere; as, for example, small-pox, hospital gangrene, plague, \&c., or of glanders, as an instance of transmissible disease.
} 
from Vienna eastward of Pesth) is wholly free at any time from this noxious distemper, although there are long periods when it is measurably kept in abeyance.

We may venture to doubt the reliability of the assertions made in regard to the antiquity of this pest in the steppes, hecause Professor Simonds admits, in his testimony before the Royal Commission (1st Rep., p. 7), that no symptoms of the disease, as it is said to have shown itself in the mediæval period, are sufficiently described to identify it with the malady as now existent. When the records of its identity were first made, or where they are to be found, we are at a loss to divine. We have met with no elucidation of these topics, nor of the kindred inquiry, whether the present disease is, by a law of modification operating from age to age, presenting, during its present cycle, a new phase or a totally distinct manifestation. And yet it is clear, that those who hold the theory of identity, if baffled in its maintenance by symptoms and morbid phenomena which show variance and disparity not only in degree but in kind, should be prepared to defend the theory of transition from one species of virulent brooding disease to another. But of this anon, when we come to the pathological investigation of the Pest.

As to its origin or its native home we are in less doubt. Professor Renault, president of the veterinary school of Alfort, in his memoir to the French minister of agriculture, has, after a thorough investigation, established the fact that this steppe-murrain never broke out spontaneously (i.e. as an enzoötic) in any country or locality but that of the Russian steppes, and, as we have before intimated, in the Asiatic part thereof.

He also asserts that its transmission to other parts of the civilized world has been directly by cattle contaminated with the poison when they left their native pastures; poison, as we may suppose, if not already brought in contact with the blood-corpuscles, at least lying ensconced in hair or on hoof, furtively araiting the fatal lick or smell that ensures its absorption by the system. It is very easy to imagine how a virus of this sort might, on this theory, work out all the 
terrible ravages that have actually resulted, when we understand that these cattle are moved from their pastures in immense droves, sometimes numbering one hundred thousand, and how, as they migrate towards the southern and western borders of Russia, developing and leaving behind them poisonous excretions, they thus distribute the plague throughout Polaud, Galicia and Hungary. Thence the passage to Western Europe is comparatively easy, unless the cordon has been tightly drawn or the pole-axe vigorously swung. Thanks to such methods established by decrees at Berlin during the present century, the disease has never (says Prof. Gerlach, 1st Rep., p. 25), when it has broken out in Poland, and sometimes appeared in Posen, Silesia and East Prussia, advanced since 1815 as far west as Brandenburgh.

In 1841 it penetrated into Egypt by cattle bought by the Pacha from Annatolia and Karamania, resulting in the desolating loss to that country of 350,000 cattle. During the Crimean war, and by the infection brought by Russian cattle into the Crimea, it was there fully developed; the French losing at Samsoun 8,000 out of 17,500 beasts, and the English 4,000 out of 10,000 , a loss ranging from 40 to 45 per cent. The mortality in some parts of Europe has risen to 94 per cent., and in some localties not a single animal was saved.*

As the present apprehension of the outbreak of this plague in this country has arisen from its recent spread in England and Scotland, we will now present an outline of its rise and propagation in those kingdoms.

It is generally known in this country that the farmers of Great Britain do not raise food enough for its population. But it may surprise many to learn that the annual value of produce imported, to supply this deficiency, is estimated on very accurate data, at uprvards of forty millions of pounds sterling. It is believed that the prominent items in this

\footnotetext{
* The number attacked in the Austrian dommions was 296,000, of which 152,000 died. In 1863 it again invaded Galicia (in which Country Prof. Srmonds first saw the disease in 1857), Hungary and its dependencies, fourteen per cent of all the cattle in those countries taking the infection, and the average mortality as given in Schmidt's Jahrbuch for 1865 was as follows: Hungary, 65 per cent; East Galicia, 77 per cent; Croatia and Slavonia, 81.6 per cent ; Military Frontier $\$ 3$ per cent; Moravia, 88 per cent; Lower Austria, 92 per cent; West Galicia, 94 per cent ; Burowina and Styria (in which but a comparatively small number were attacked), 100 per cent. (1st Rep., p. 11.)
} 
extraordinary expenditure consist of cattle, meat, butter, poultry, \&c. Most of the beef class of imports come through Holland and Belgium. Prior to 1865 but one importation direct from Russia is known to have been made into any port of Great Britain, and this into that of London on 4th July, 1860. But indirectly large numbers of Hungarian and Galician cattle have been brought to English markets; more of late years, as the completion of two great lines of railroads, which traverse Central and Southern Germany, and connect Hamburg and Rotterdam with Vienna and Lemburg, furnish quick transit for these supplies. (See 1st Report, p. 7.) The immunity which England has enjoyed, prior to 1865, in such importations, is traceable to the rigorous police measures established in Western Europe, and to the fact that the incubative stage of the Rinderpest rarely extends beyond a week.

But it seems that two importers of cattle, Messrs. Honck and Baker were induced by the representations of a Mr. Burchell, who subsequently acted as their agent, and, in expectation of a profit of one hundred per cent, to make a contract with the Esthonian Agricultural Society for a large number of sheep and cattle; the latter to weigh at least one thousand pounds each, and to be delivered at Revel after the ice had broken up in the Baltic. As some of the beeves offered did not come up to the contract weight, forty-six were sent down from the neighborhood of St. Petersburg, from which the agent was to choose. These being on their arrival much bruised, having been transported in four-horse wagons, and deemed by him not fit for the London market, three experts or judges were appointed by the local magistrates to say how many were in a suitable condition to take; and thirteen were so adjudged. These, with the Esthonian cattle which passed muster, made in all three hundred and twentytwo; but as one died in the yard before shipment, only three hundred and twenty-one sailed from Revel, on the $22 \mathrm{~d}$ day of May, 1865, in the "Tonning." This steam vessel landed at Copenhagen to await orders whether, in view of the then state of the markets, the owners desired her to proceed to 
London, Hull, or any other ports, and in obedience to instructions she put in for Hull; at which place she discharged, on the 28th day of May, three hundred and twenty cattle seemingly sound, and one which had sickened on the passage.* One hundred and forty-six of this number were sold for immediate slaughter at three different market towns, from none of which has any disease been traced; twenty were picked out by Mr. Baker to go to Gosport for like use and with a like result. The remaining one hundred and fifty-five arrived at London on 29th or 30th day of May, were placed in Mr. Honck's lairs, and sold in the Metropolitan market on the 1st of June. On inquiries addressed by the Royal Commission to the purchasers of these animals, they were all sound beef when slaughtered, as far as appearances could lead such judges to determine the fact.

We turn for a moment to another lot of eattle which have been supposed to have had considerable agency in disseminating the contagion throughout England. Twenty-three head of fat cattle were sent from Schiedam, in Holland, by a Mr. Defries, to his son a salesman in the Metropolitan market, which were sent into the market on 22d, 26th and 29th days of June, twelve of them thrice, the remaining eleven only twice. The markets of June being unusually dull, more animals than was customary were left unsold at the close of markets, and sent back to the yards where they lodged, which generally have sheddings attached, and are called lairs. This lot of twenty-three were placed in the lairs of a Mrs. Nichols at Islington, which adjoin the cattle yards used by many drovers bringing stock to the Metropolitan markets. As the prices offered for this lot of Dutch cattle were not satisfactory, they were, on the $2 d$ day of July, reëxported to Holland.

On the 27th day of. June, a cow belonging to Mrs. Nichols (who had at this date a herd of ninety-three, which, with

* Prof, GaMgee (in 1st Rep., 102), says that this one was kept by Mr. Bunchell on brandy and water during the passage to Hull, recovered from the attack, and was sold for £11. As confirmatory of the opinion that these animals brought down from St. Petersburg had the seeds of the Rinderpest in them, he has ascertained that a butcher at Revel was obliged to kill thirteen of those that remained. 
sixteen or seventeen more purchased subsequently, were all destroyed by Rinderpest), sickened and died, as was supposed by the owner from poison. Two cows which on the 19th of June* were purchased in the Metropolitan market by a Mr. Baldwin, of Hackney, died of the same disease, one on the 29th of June, and within twenty-four hours after she was observed to be ailing; and the other on the 5th day of July. These three cases were attended by Mr. Priestman, a veterinary surgeon, who with a son of Mrs. Nichols brought the stomach and intestines of a cow of the latter to Prof. Simonds at the college, on the 4th of July, for examination. The Professor was also requested to inspect the herd and the premises, which he did with great care; had another animal killed, and took its stomach and appendages and some water from a well recently opened, to the college for examination. On the 9th day of July he was fully satisfied that these animals and others reported at that date had died of the same disease which he had observed in Galicia in 1857.

Twenty-one of the Defries cattle died shortly after their arrival at Schiedam, it having been observed before their departure that they were out of health. Moreover the plague was communicated to the stock of a Mr. Vandervelden, grazing in a pasture adjoiningt that in which the Defries cattle had been placed; and the owner of the stock contaminated in this wise had, in utter ignorance thereof, sold upwards of twenty, which were exported to Norfolk.

To return to Mr. Baldwin's stock. In twelve days after his first loss his herd of twenty animals was reduced to ten, his saving up to that time of fifty per cent being attributable to the immediate slaughter of each animal on showing the first symptoms of the pest.

In a brief review of these statements (as it is impossible in this sketch, to give all the particulars which go to confirm

\footnotetext{
* Prof. GAMGEE states that the running from the eyes and nose, and the drooping and other primary symptoms, were observed in the market as ea:ly as the 14th of June, and gives the history of two Dutch cows bought there on the 19th, which went to Lambeth Walk, and communicated the disease in that neighborhood, one of them sickening shortly after the purchase (1st Rep., p. 103.)

$\uparrow$ Prof. Gerlacr states that this pasture was full one thousand paces from that in which the Defries cattle were placed.
} 
the conclusion) the only animals which could have conveyed Rinderpest directly to English stock were brought into the Metropolitan market; from which those that developed the contagion earliest were sent to three places, two in England and one in Holland, where it was definitely recognized. And although an interval of nineteen days has to be accounted for, there seems to be little difficulty in accepting the theory of Prof. Simonds (1st Report, 1-20), that the pestilence was in its state of incubation in one or more of the thirteen animals sent down from St. Petersburg to fill out the contract of the Esthouian Society; that it was developed in the lot brought to the Metropolitan market; thence spread to Mrs. Nichols' lairs at Islington, and to Mr. Baldwin's farm at Hackney, on or before the 20th of June, and throngh the Dutch cattle into Norfolk early in July. Even if the impression, as communicated by the English Consul-General at Hamburg (1st Rep., p. 7), and based upon the opinion of Mr. Schrader, a veterinary in the special employ of the Hamburg government, be correct, that the Rinderpest was developed by Hungarian cattle sent from Vienna to Utrecht early in May; this would require proof of the transmission of some of these cattle, or of others infected by them, to the Metropolitan market in order to account for the earliest observed outbreaks of the plague which we have given. If true, this theory would only show a double source of infection concentrating at a common point and thence to be diffused. Suffice it to say, that in a very short space of time from its outbreak in Islington, the Rinderpest appeared in Suffolk and Shropshire. Before the end of July it had invaded Scotland,* and by the 14th of October it had exteuded into twenty-nine counties in England, two in Wales and sixteen in Scotland, and resulted in six months in a loss of two hundred thousand animals, and within nine months of three hundred thousand at the lowest calculation ; an enormous

\footnotetext{
* Prof. Dick says that the infection in Edinburgh came from a herd of Dutch cattle brought down from London, two of which were bought by a cow-feeder named Ogg, and lodged in his byres; and that these developed the disease on the Sth of August, all the animals Ogg had dying except the two foreign cattle, which recovered. (1st Rep., p. 120.)
} 
havoc, resulting mainly from a neglect to establish, as has been shown in the preliminary report, efficient sanitary cordons.

It is conceded that it is by no means an easy task to trace with exactitude the subtle course of a pestilence which thus dashed with rapid and fatal strides through the herds of Great Britain as it had previously held on in its mad career on the Continent. Nor less difficult does it seem to arrange and classify the various statements given as to the mediate iustrumentalities of its spread. Too much concurrent testimony exists, however, of the poison being carried on the persons and clothes of attendants, diffused by excretions from the mucous surface, the skin and the bowels of diseased subjects; sometimes caught upon the wings of birds or elinging to their clars, so that falling plumes or alighting tracks might contaminate green pastures or farmsteads kept scrupulously clean-to cast a prudent doubt upon what would seem to partake only of the marvelous and fanciful. Proof may be deficient to show that in many cases the pest has been communicated, as some have affirmed, through the antenuæ of flies crowding together on the glairy mucus exuding from eyes, nostrils or vagina; or conveyed on the hair or feet of horses, cattle or dogs beyond the limits of developed contagion; or by like secondary agencies, and to a locality sufficiently remote, for its spread by gradual or ordinary diffusion. Yet it is asserted on evidence seemingly beyond impeachment, to wit, on the statement of the Governor of Silesia to Prof. Simonds (1st Rep., p. 3), that the outbreak in that province occurred in consequence of a carpenter's passing surreptitiously the frontier cordon from Galicia, in order to visit his father, and incautionsly mending a manger in the cow sheds; thus communicating the seeds of the disease, which in a few days broke out in what had been prior to that time a perfecty healthy district.*

\footnotetext{
* GAMGEE Was assured that a common cause of wide-spread outbreaks, was the practice of calling priests and people together, to pray in the cattle sheds, that the plague might be stayed, and the assembled people moving thence from farm to farm. He also quotes the anthority of VICQ D' AZYR, as to the infection of the 18th century, to show that where clothes of attendants on diseased cattle were placed on healthy ones, three animals out of six would be seized with the disease. (Cattle Plague, p. 37.)
} 
Also, it is gravely stated in a communication on the nature of this disease, transmitted to Lord Bloomfield, and by him to the Home Government, that with a straw from an infected stable, half a dozen healthy stables could be infected. All such statements may be grouped together as sufficient, if not incontestable, testimony of the ready communicability of this poison by contact, and other instrumentalities of contagion proper.

But when we learn that it is also conveyed by currents of the atmosphere, as in instances where, for a distance of three miles, it was carried by a strong prevailing wind (the air being charged with much moisture) from byres where the disease existed, to perfectly healthy herds; or where, from the same causes, it has overleaped all quarantine regulations, we have sufficient evidence of its dissemination by currents of the atmosphere, and thus being propagated in accordance with the laws of infection proper.*

We have adduced at this time these items of evidence as to the easy and rapid diffusion of the Rinderpest, in order to supply as best we may any seeming defect in the testimony laid before the English commission to make out the historical proof of the dissemination throughout Great Britain of the germs of this murrain from the Esthonian importation. We may thus seem to trench too rapidly upon a discussion properly pathological, and to anticipate the handling of our second main division to which we will at once proceed.

\footnotetext{
* Prof. Brown gives in his testimony (1st Rep., p. 21) an account of the ontbreak at Whitwell as from some beasts bought in the Metropolitan market, on the 1st of July, and its transference to Thimble Thorpe, a distance of three miles. as well as other places at least equally distant, where there "could not be traced any direct contagion, and no direct contact with diseased animals." He thinks it quite possible that the contagion conld be carried by flies. He was also cognizant of the attack on the stock of Miss B. Courrs and Lord Granville, in pastures quite private. In the first case there were diseased animals three-quarters of a mile off, and the outbreak occurred a short time after a thunder storm, when the wind blew from the infected places. Yet sheep in an adjoining pasture had been several times in the market. In the latter case, where only seven out of one hundred and thirty remained, Mr. PANTER, the bailiff, holding to the theory that the diseases of 1865 and $\mathbf{1 7 4 5}$ were the same, and with some show of consistency, because he believed that the pest broke out spontaneously in the London cow shed, during the hot weather of June; states that the nearest place where the plague existed prior to its discovery in the stables, under his care, was 400 yards off. He states also that pleuro-pneumonia was chronic on the farm, "Lord GraNville never having been a month without it in the last four years."
} 


\section{PATHOLOGY.}

This branch of our subject we propose to consider under the ordinary classification of Descriptive (A) and General (B), designing further to subdivide the former by treating first of the symptoms (A 1,) or descriptive appearance of the disease as it is manifested in the infected animal before recovery or death, and next of the morbid anatomy (A 2), or description of the lesions revealed by post mortem dissections. In a few cases, taken from Jessen's Report (Bericht . . . . Impfungen der Rinderpest) on the results of the inoculative methods, we have for convenience given the symptoms and post mortem revelations conjointly. Further historical reference to other murrains, and the consideration of their destructive characteristics as compared with the Pest, will be reserved for the general discussion.

As we derive our knowledge of the symptoms and morbid anatomy of this distemper from authorities recognized as such in England and on the continent, of whom we may enumerate Smart, Wood, Simonds, A. \& J. Gamgee, Simon, Pope, Gerlach, Egan and Jessen; where there are conflicting or independent statements, we will subjoin to such the name of each authority.

\section{(A 1.) SYMPTOMS.}

These will be arranged after the following classification of the several stages or periods of the disease: 1st. Incubation; 2d, External symptoms; 3d. The Congestive Period; and 4th. That of Resolution.

\section{1st Incubation.}

From the time of the first introduction of the poison into the system, until the development of the external symptoms, a period elapses of several days, which is known as the incubative stage of the disease. The time assigned by different authorities varies considerably, though there is but little doubt that we may fix this period in the majority of cases as one of six days. This is the time assigned by Smart and Wood. Egan states it from four to eight days. (2d Rep., p. 79.) 
The period of incubation varies according to the mode of the introduction of the poison; where the disease is inoculated, I believe it is four or five days ; but where it is caught in the usual manner, from eight to ten days. (J. Simon.)

In the inoculation cases which $I$ have had, it has usually averaged from six to eight days, and not beyond that. It cannot be longer than ten days, if ever so long. (J. Gamgee.)

It is seldom less than seven days, and it may be extended to fourteen or fifteen days, or perhaps to a longer period than that. (Simonds, 1st Rep., p. 16.)

The period of incubation is generally from five to seven days, though in rare cases it may be more. (Gerlach, from personal observation, 1st Rep., p. 20.)

The evidence as to the internal development of this disease in its primary stage, is drawn principally from postmortem observations of animals slaughtered soon after exposure to the contagion, and attests the fearful rapidity with which it is absorbed. And first it is stated that within thirty-six or forty-eight hours after inoculation, the blood is so thoroughly contaminated that a single drop is sufficient to develop the disease in all its malignity when employed as an inoculative medium, though Gerlach states that blood is rarely, if ever used, as the secretions of the eyes, nose and mouth are, in the remedial agency of inoculation. (1st Rep., p. 20.)

Invariably, in the early stage, even before the vulva and mouth have become affected, the lining membrane of the fourth stomach, and of the whole intestinal canal from that stomach downwards, shows appearance of disease. This is indicated by what is at first a mere blush of redness on the surface of the lining membrane, quite appreciable, however, when compared with the pale, fawn-colored appearance found in the healthy state. (Wood.)

The other stomachs soon sympathize with the condition of the fourth; the rumen or paunch, and second stomach or reticulum, are loaded with undigested food, and the third or many-plies is impacted with a mass which assumes the form of a large, round ball, and becomes, as the disease advances, a hard, dry mass. 


\section{D. EXTERNAL SYMPTOMS.}

As the incubative period declines, the primary symptoms visible to the eye occur in the following order:

a. Loss of appetite, exhibited first in aversion to all sorts of green food, and on the following day in indifference to food of any kind. At first the animal leaves a portion of its food, and then refuses it altogether.

b. Rumination. The animal now ceases to chew its cud, and then there is manifest

c. Constipation in its gradual development. The dung is of a dark color, sometimes covered with slime on its surface. [Many show signs of bellyache, by frequently looking round towards the tail and bending up the back.] (Egan.)

d. Diminution of the flow of milk (much greater than in pleuropneumonia. Priestman.)

External appearances are, first,

1. Depression in looks, standing in the same posture, with drooping head and reclining ears. These, with the horns and other extremities, show a loss of natural heat.

2. The first striking signs are manifest in a change of manner. Most commonly the beast is remarkably heavy and dull, hangs its head, lowers its ears, stays behind the herd, and when in the stable keeps away from the crib. (Egan.) Sometimes there is a shaking of the head to and fro. If you lift it up, it goes down again like a dead weight. (Ernes.)

3. Sometimes an animal will be excited, uneasy, shaking its head, stamping with its feet, lowing frequently, butting with its horns, and running away from the herd. If tied up in the stable, it tears away from its chain and rope, and continually endearors to go elsewhere. (Egan.)

4. Trembling motions now occur of the head and neck; the hairs bristle up, especially on the back and towards the shoulders; the insertions of the horns and ears are sometimes cold, sometimes warm; the palate is dry; the eyes shining, \&c. (Egan.) In the cases first observed in Englant by Professor Simords, there were not the same nervous twitchings about them that had been observed in Galicia. (1st Rep., p. 9.)

f. Respiration is slightly quickened, the expiration or outbreath is prolonged, and the pulse rises a few beats. (Smart.) Joined with a striking motion of the flanks and low groans, sometimes a 
short, dry cough supervenes, which is the cause of much uneasiness to the animal. (Egan.) In most cases a cough with great difficulty in breathing exists, the animal making more noise on expiration than in pleuro-pneumonia. (Gooch's account of symptoms of Dutch bullocks in Norfolk, communicated to Prof. Simonds, 1st Rep., p. 10.)

g. The Vulva (the external opening of the vagina or passage leading to the womb) assumes a reddish tinge (with generally a few bluish streaks-Wood), and the color deepens as the disease advances, these appearances furnishing in females the most reliable and distinctive external characteristics of the disease. (Smart and Wood.)

$h$. The Mouth shows a faint, red or purple line on the under gum along the roots of the teeth, closing up the column of primary symptoms within forty-eight hours. (Smart.) The buccal membrane, particularly at the junction of the interior of the lips with the gums, becomes abraded or excoriated-the membrane peels off in little irregularly shaped spots, presenting a mouse-eaten or mouse-gnawed appearance. The papillæ of the tongue and cheeks are enlarged. (Per Barron, V. S., Sequel, \&c., p. 26.)

In the vulva and mouth we have the distinctive sign of the Rinderpest; and in the latter the appearance can be readily distinguished from that observed in epizoötic eczema or mouth and foot disease.

\section{D. The Period of Congestion.}

This is the stage of the disease when the congestion, which has exhibited its earliest outbreak in the epithelial membranes covering the mucous surfaces of the fourth stomach and in part of the bowels, and then shown itself in the vulva and mouth, becomes active and pervades the entire system, showing in the first place a largely quickened action of the

a. Pulse. The number of pulsations in health may be rated at 40 to 45 per minute in the field, and 50 to 60 in the byre. The pulse now mounts up to 80, 90 and even 100 beats per minute (Wood); 60 to 110 (Smart). Thirst and loss of appetite become more marked.

b. Respiration becomes hurried, and frequently labored and noisy, instead of from 18 to 20 per minute as in health the inspirations range each minute from 40 to 60 and considerably higher (Wood); 36 to 70 (Smart). The respirations numbered 96 in an animal which recovered, and are often jerking in their character. (Pope.) 
c. Tempercuture of the body (externally) is lowered, and deficient, requiring the use of blanketing, and that the temperature of the byre should be raised to $70^{\circ} \mathrm{Fahr}$. (Smart:)

d. Vital depression is characteristic of this disease throughout its entire progress, and becomes manifest as the congestion is extending over the internal organs.

e. Exudations from the eyes (viscid, slimy tears-Egan), nose, mouth and vulva, form with rapidity, consisting of a glairy, ropy mucus, and indicating the extended congestion of the external membranes of these organs; those of the mouth and vagina exhibiting apthce. The conjunctivæ are congested, becoming, as the disease progresses, perfectly turgid; large plugs of dense ropy mucus being occasionally passed. The alie are more swollen and injected on their internal surface; externally copper-colored and livid looking patches are observable, about the fifth or sixth day, and in many instances a little earlier; the discharges become purulent alike from the canthi, the nostrils and the vagina. (Pope.)

An abundant yellow or bloody, stringy discharge comes from the nostrils, which gradually becomes white and fetid, and a tough viscid slime also flows from the corners of the mouth, and at the same time there are found on the mucous membrane of the mouth, especially between the under lip and gums, small blisters which often cover the whole inside of the mouth; the sick beast grinds its teeth, which are now very loose. (Egan.)

$f$. The anus is frequently very highly congested, presenting the appearance of intense hemorrhoidal congestions.

g. The urine is now not unfrequently loaded with blood, and is passed with considerable pain and difficulty. (Pope.)

\section{4th. The Period of Resolution.}

The congestion is frequently favorably resolved by nursing and judicious treatment; by the strength of natural constitution, overcoming easily at the outset the diffusion of the virus, and effecting what commonly passes for a light attack of the disease; or, as frequently happens in a preguant cow, by the concentration of the disease, in the foetus and uterine membranes, and consequent abortion.

In all such cases the animal begins to look cheery, carries its ears forward, begins to take food and chew the cud. The milk returns 
and gradually assumes its natural appearance. The distinctive appearances on the vulva and the inside of the mouth disappear very slowly. (Wood.)

The attacks (of pain, \&c.,) gradually subside, the skin becomes warm and remains so, appetite and rumination return, looseness diminishes, \&c.

In convalescence, a scabby cruption very often appears on the skin, accompanied by itching, especially on the nape of the neck or the sides of the neck, and on the back. (Egan.) This scabby eruption, sometimes also seen on the nostrils, and frequently met in other parts of the country, has not been seen in more than a dozen cases that have been treated homoeopathically in this neighborhood. (Pope.)

If, however, from the virulence of the attack, or the lack of sufficient constitutional power to resist the disease, or from neglect and injudicious treatment, the period of congestion is not relieved by any favorable indications, then follow the symptoms which result in death.

Sometimes in the natural course of the disease, more frequently perhaps from the injudicious use of irritant purgatives, the constipated state of the bowels is changed to a diarrhœic condition. The dung becomes soft and pappy, and at length liquid, not unfrequently colored with blood; it is usually voided with little effort in small and frequent passages. (Egan.) "Diarrhœa, often dysenteric in its character, or thin, watery and offensive in the highest degree, sets in, and exhaustion, accompanied by intense restlessness, follows, and death takes place from simple exhaustion. Sometimes where symptoms seem to have improved, the animal becomes suddenly more dull; the head drops, the eyes look heavier, the conjunctiva are almost livid, the teeth are ground, the animal butts at everything within reach, oftentimes becoming furious, and suddenly dies." (Pope.)

Again; diarrhœa might set in on the second or third day, and about the fifth day it is generally fatal; but it begins by nervous symptoms, and these are so strong at times that a cow might be found. dead in the morning without having been suspected to be ill at all. (Simonds.)

On the other hand, constipation is attended not unfrequently with great distention of the abdomen, becomes obstinate and aggravates all the other symptoms. Respiration is now slow, very laborious, moaning or grunting, and the pulse slow and small. The superficial membrane of the mouth peels off from the gums and lips, leaving the surface raw. A similar action occasionally takes place in the intes- 
tinal canal, resulting in a desquamation of its mucous surface in casts. In one case the entire epithelial lining of the small intestine, in a perfect tube, was passed from the bowel and has been preserved. (Smart.) The general weakness and leanness (of the body) makes rapid progress, the eyes sink in, the sight is weak, air tumors rise in the back under the skin, groans and difficulty of breath become continually more violent, the ichorous discharge from the open fundament flows involuntarily, and finally the beast cannot stand any longer, but lies on its side with its head turned, until at once, generally, between the fifth and ninth day (in very bad cases between the third and fourth) death comes on with convulsions. (Egan.)

The staring hide and arched back are not characteristic of the Rinderpest, but of pleuro-pneumonia; but they occasionally make their appearance when the pest is complicated with the latter disease. (Smart.)

On looking at the carcass the hair is seen bristling; a whitish slime appears at the corners of the eyes and nostrils, partly dried to a bark; the hind quarters are much swollen; the mucous membrane of the bowels projecting through the fundament is of a bluish red color, \&c. (Egan.)

We deem it judicious to add to the already extended account of general symptoms a few detailed cases taken from Jessen, of animals described numerically in his report; because the accuracy of his details (as to time at least) may be of future benefit in the study of individual cases should the disease break out in this country. We have also added to the description of symptoms in each case, the post mortem observations, that the symptoms and pathological appearances might be grouped together, and for the further reason that it may be desirable to separate the description of his inoculated cases from those given by Smart and others, and perchance distinguish between the English type of this murrain and that observed in some parts of the continent.

No. 6 was a steppe cow, seven years old, sickly before vaccination and in thin flesh. Woolen threads were saturated with the secretions (from eyes, \&c.) of a yearling calf, and inserted as a seton on both sides of the neck and before the shoulders.

Symptoms as follows: On 6th day, short, hacking cough. On 7 th day, loss of vivacity, drooping head and hanging ears; rumination 
ceased; shaking of head; gnashing of teeth; hair bristling and skin lying in folds. On the right side auscultation showed blowing murmurs; and percussion, dullness. On same evening, eyes and nose began to run; milk diminished and had strong salty taste; respiration and pulsation equal to 60 per minute. On sth day these rose to 80 ; secretions increased; ears and horns alternately hot and cold; mouth hot; chilliness over the whole body ; neither eat nor drank. On $9 t h$ clay, respiration 100, with sighing; left side of bowels tympanitic, but normal at six P. x., when pulse was 88; diarrhœa mixed with blood; aphthous appearance of vulva. On 10th day, pulse 108; respiration 50, and sighing; bloody diarrhœa; colliquations from nose and eyes; body cold, and death at six P. Mr.

Post-mortem. Besides ordinary external appearances, the veins of the brain were engorged; one of the lymphatics contained hard particles; hyperæmia in the base. Lungs full of air, not much reddened (emphysema in all the cellular tissues between the lobes) and contained many hydatids. Pericardium and heart normal. Arucous membrane of fourth stomach (PI. IV, fig 2) violet irr some places; in the folds ecchymoses shining through; duodenum not much reddened, and filled with bilious slime. Jejunum (Pl. VII, fig 1), colored blackish by pigment on the mucous membrane. Here and in the ileum the Peyerian glands raised and strongly injected. The capitlaries of the colon and coecum (Pl. VIII. fig 1, giving a view of the mucous membrane of the latter), were injected, showing a great many red points and streaks, which were also found in the rectum, but nowhere ulceration; many ecchymoses in the small bowels, visible inside and outside; mesenteric glands swollen and showing much pigment when cut through. In every one, as a proof of former ailment, chalky concretions from the size of a lentil to a pea. Liver full of hydatids; ovaries, kidneys and bladder normal and their mucous membranes healthy.

No. 14, a steppe calf of No. 6, nine months old, and placed beside his vaccinated mother, caught the infection naturally, and after twenty-seven days from first exposure seemed to have recovered, and was sent to a neighboring place to be herded with another lot of diseased animals. After twelve days it was started for home, and being led behind the wagon with a rope tied carelessly around its neck, it suffocated and was brought home dead.

Post-mortem. Lungs partly hepatized with some small ulcers; ventricles and auricles of the heart empty; paunch distended; third stomach hard, and when opened epithelial lining adhered to the food; 
fourth stomach not reddened, but close to the pylom there appeared a covered depression (with a light scab, which was loose at its periphery) with smooth rounded edges, apparently an ulcer (Pl. II, fig 2) beginning to heal; small bowels contained slime and bile; some intestinal glands showed hard elevations of the size of a pea having a hollow on the top; intestinal veins and those of the brain engorged; liver, kidneys, bladder and brain sound. The immediate cause of death was vascular apoplexy from strangulation. The calf, though apparently recovered from the pest, had not overcome its sequelce.

No. 8 was a two year old steppe ox, healthy and in fine condition, vaccinated on left shoulder with three woolen threads saturated with fluid from tears of a Rinderpest subject.

Symptoms as follows: On 6th day, loss of appetite; rumination suspended; ears and lips hot, the latter dry; P. Ir., loss of strength, with downeast looks. On 7 th day, lying down, with head stuck out and tears in the eyes; hair bristling; pulse 88; respiration 36 ; inspiration slow; expiration quick; dung softer; great loss of strength during night; at noon, gnashing of teeth and diarrhœa; pulse 92 ; respiration 40 ; at evening, shaking of head; deep sighing inspirations, with pawing of the fore feet. On 8 th day, does not eat; pulse 92 and small; respiration 40; tears flowing profusely; secretions from nose increased; gnashing of teeth and shaking of head more frequent; watery diarrhœa; increased debility and great thirst; pulse thinner; secretions stringy and thick; not so much head shaking; diarrhœa frequent, with no fœces and sour smell; month hot and covered with tough mucus. On 9th day, pulse 98 , small; stroke of the heart hardly perceptible; all symptoms exacerbated; mucous membrane of lips and anus full of erosions, on the first white, on the latter red, of varying size and form ; in the evening, pulse small and hardly to be felt; respiration 46, with heaving in the flanks; peculiar look of the dim eye ; frequent and severe shaking of the head; great thirst. On 10th day pulse 84 and fuller; respiration more quiet and 36 ; animal more lively and strives to eat; erosions around the anus spread to the scrotum; at noon, diarrhœa increased, animal hardly able to stand; pulse small and vacillating; respiration 44 ; he wants to eat but cannot chew ; in evening, great moaning, and gnashing of teeth more frequent. On 11th day, he is more lively ; eye more lustrous ; pulse more full, 84 ; respiration 36 ; desire for food and drink; death in the evening.

Post-mortem; made before the body was quite cold. Great emaciation; muscles of natural color; fat normal and soft; first and second 
stomachs and œsophagus filled with greenish colored fluid; cardium greatly distended; when cut, contents were observed to fill the entire cavity of the chest. In nostrils was seen a free-lying exudation, having several small branches as if from the bronchie. Cellular tissue of pericardium and mediastinum, and between the lobes of lungs distended with air. Lungs bright red, parenchyma normal; pericardium and heart healthy. In right ventricle very fluid red blood. Brain very soft; great deal of blood under the dura mater; no water in ventricles or spinal cavity; bowels pale externally; liver of normal color, very sanguineous ; gall bladder full of dark green gall; spleen full of blood and soft. First and second stomachs contained little food, but much water; membranes normal. Third stomach contained partly old, partly newly taken food (bran), perfectly normal. Fourth stomach full of soft food; membrane loosened, in parts injected, especially near the pylorus. The small bowels throughout showed in many places firm, elastic, fibrinous masses, yellow in color, products of the Peyerian glands. (Pl. VI, figs 1 and 2, giving sections of the duodenum, with one Peyer's gland and two follicles in fig 2.) The fibrinous masses were also on solitary glands of the thickness of a line or more; mucous membrane loosened and easily separated from the muscular coat. In cæcum, colon and rectum, no fibrinous masses. Mesenteric glands pale, enlarged and hard.

No. 32, a steppe calf of nine months old, which after inoculation was severely sick and died suddenly; symptoms not given.

Post-mortem. Mouth free from erosions; nostril somewhat reddened; chest showed a few emphysematous spots; heart full of coagula (clots); endocardium normal; liver rather soft, containing some fibrinous masses; gall-bladder full; spleen full of blood; kidneys normal; first and second stomachs full of soft food, but normal; third stomach of the form of a ball; food dry and dark green; epithelium not adherent; mucous coat of fourth stomach strongly injected, especially towards the pylorus, and contains thin, bilious slime, but no food; mucous coat softened; small bowels full of enormous fibrinous concretions. On Peyerian glands, thirty large plaques were counted, from. pylorus to crecum, covered with exuctations of three to four lines wide, sticking fast to the glands, even after sixteen hours maceration. Taken. off, the place corresponding to the glands was dark red. The whole formed a mass, flattened on both sides, of yellow or red color, with alternating elevations and depressions, and corresponding to the length of the agglomeration of the glands. Usually there was a large tail of three to four inches of light yellow exudation, showing in many 
places depressions, originating in the solitary follicles of the jejunum, which were reddened and hyperæmical (PI. VII, fig. 2). In the small bowels were many free exudations like polypus (Pl. VIII, figs. 2 and 3), all with these depressions. Before the bauhinian valve of the creum were pulpy, macerated glands, of one and one-half inches in length. Large bowels contained thin fluid, light yellow and grey slime. Their coats were softened, with red spots (injected vessels), especially where the rectum begins. Mesenteric glands enlarged-externally grey, internally dark grey-containing much fluid and yellow fatty exudations. Membranes of the brain and cerebellum strongly injected and softened.

\section{(A 2.) MORBID ANATOMY.}

On the dissection of the carcass, which is considerably distended with gases, a foul smell is experienced, which has a peculiar odor, and which is more intensely disgusting as the autopsy is extended into the abdominal cavity. It is highly characteristic, because if once experienced it cannot be mistaken for the exhalations consequent upon the examination of animals dying from any other disease. The pathological appearances which follow are principally those obtained by Dr. Smart from dissections made at the Edinburgh Sanatorium and at Tyne Castle, of over one hundred animals. Wherever other authorities differ from Smart, we shall, under each head, note the discrepant statements, as these clearly reveal modifications of the disease as observed by Smart, depending upon differences of nervous susceptibility of constitution, perhaps of climatic influences; different habits in regard to food, diet; previous or concurrent lesions of other diseases, \&c.

I. Mouth, Pharynx and Gullet. The gums, lips, hard and soft palates, the under surface and root of the upper surface of the tongue, the upper surface of the epiglottis, as also its membranous folds and the pharynx, are marked, to a greater or less extent, by an aphthous eruption (Pl. I, fig. 1), which is not ulcerous, as the subjacent membrane is entire.* The roughened and granulated aspect, as presented. to the eye, is readily scraped off and consists of accumulated epithe-

* A like eruption equally characteristic of the disease is found at the external opening (vulva) of the vagina. (Pl. II, fig. 1.) 
lium collecting on the surface of the membrane around the orifices of the follicles, and thus giving a punctated or honeycomb appearance resembling minute ulcers. The lesion does not extend beyond the pharynx (back mouth), into the gullet* (which exhibits no trace of disease), or into the air passages. The scaly epithelium from the under lip of a diseased cow, as highly magnified is presented in Pl. I, fig. 2, where some of it is rolled up into scrolls and cylindrical forms, and other parts show the proper flattened and nucleated appearance. There are also seen a few mucous corpuscles and some vegetable cells from the animal's food. The epithelial scales are very granular, showing the earlier processes of retrograde degeneration.

At the fauces, there is intense inflammation with an effusion of lymph, the parts being dotted over with a yellowish-white pigment. (From observations in Galicia, by Prof. Simonds, in 1857; 1st Rep., p. 5.)

The buccal membrane around the teeth is ulcerated looking, and stretching between each tooth is a kind of white secretion, which is easily removed and very fetid. (Per W. Pallin, V. S., Sequel, \&c., p. 53.)

II. The Stomachs. The first and second stomachs are generally . loaded and distended with food, a circumstance which indicates their suspended functional activity. No change of structure is observed in either organ, and their lining membranes are not reddened or congested. $\nmid$ Per contra, their membranes are friable, infiltrated and blood spotted here and there. (Egan.)

The third stomach, or omasum, exhibits, after careful search of its folds and in about one-half of the dissections, irregulart circular patches from the size of a pin's head to that of a twenty-five cent piece, which have bright red or scarlet margins, and in the larger patches inclose a central portion of a dirty yellow color and gangrenous appearance. (Pl. III, fig. 1.) This portion is slightly depressed, friable, quite bloodless, and the papillæ on its surface shrunken, especially towards the middle, but there is not any breach of substance.

\footnotetext{
* The tongue is foul with a greenish yellow deposit about its base, and this exudation sometimes extends down the oesophagus (gullet); so marked in one case that GAMGEE was induced to make a water sketch of this somewhat unusual condition. (Gamgee's Cattle Plague, p. 58.)

+ In protracted cases, the epithelium of the rumen has been seen to detach itself readily, or to be already removed on first examination, and ulceration has been witnessed. Both in the reticulum (2d stomach) and omasum is found, in some cases, a somewhat reddened mucous membrane beneath the epithelium, which sheds off too freely. (Gamgee's Cattle Plague, p. 59.)
}

¥ Such deeply reddened, more or less, circumscribed patches, have been observed by Prof. J. GAMGEE in pleuro-pneumonia and cases of chronic impaction of the third stomach. (Gamgee's Cattle Plague, p. 59.) 
The bright color of the outer ring, as shown by the microscope, is due not to ecchymosis but to the confluence of the congested papillary vessels (Pl. III, fig. 2), and thus explains the sharply defined marginate character of the patches. Their mode of extension is as follows: A single papilla is first attacked and its vessels become extremely congested (Pl. III, figs. 2a and 2b), as in fig. 2a (of the natural size, being more distinctly seen under high magnification in fig. $2 b$ ). The dark spots at the apex of the papilla indicate commencing gangrene, while the effused blood, stretching from it in every direction in curving filaments, shows the mode of attack upon the neighboring papillæ. As the congestion extends, the central papillæ show a circle of dull gangrenous appearance, the outer papillæ are engorged to the highest degree of vascularity, forming the scarlet-colored ring (Pl. III, fig. 1 ) and thus disorganization spreads from the center to the circumference.

The third stomach is usually full to swelling; it is sometimes firm and sometimes soft to the touch, and in accordance therewith the contents are sometimes solid and dry (often so much so as to be capable of being rubbed to powder), in cake-shaped layers, squeezed together between the compartments, and sometimes merely damp, pappy fodder. In the former case, the mucous membranes lining the walls of the stomach appear in places ragged and loose and sticking to the fodder; in the latter case, the mucous membrane is very much softened and the surface skin easily removable. (Egan.)

In some instances the purple circles so much spoken of can be observed, but it is a state which I believe exists also in other diseases. The epithelium peels off attached to the ingesta, which is found generally hardened between the folds, themselves injected, while the papillæ stand erect and prominent. (Pallin.)

The third stomach is affected with inflammation in patches. This inflammatory action often going on to a degree of intensity as ultimately to end in ulceration. (Simonds.) In most of the cases observed by J. Simon, there was considerably more affection of the third stomach than appears to be general, according to the German reports. The claret-colored patches and eventually sloughs were more frequent in England.* (1st Rep., p. 43.)

The abomason, or fourth stomach, is reddened in the earlier stages of the disease only a little more than in health, but the color deep-

* The abrasion of the epithelial membrane is not a diagnostic sign of this disease; nor is the peeling off and adhering to the plastic surface of the food to be confounded, as has been supposed by some, with the erosion of the mucous membrane.

The epithelium undergoes constant change in health, and can be readily stripped from the third stomach of a perfectly healthy animal freshly slaughtered. (Smart.) 
ens as the malady progresses, and becomes dusky red with interspersed claret-colored patches. (Pl. IV, fig. 1.) Its lining membrane* exhibits the following deviations from a healthy state: 1st. Its attachment to the muscular coat is generally loosened, and at many points destroyed. 2d. It is soft, easily breaks down under pressure, and where the change is furthest advanced, peels off as if cohering mechanically to its sub-mucous connections. $3 \mathrm{~d}$. Its epithelium is imperfect, and at many points quite absent, thus forming cracks on its surface. 4th. The high color of the tissue, as microscopically determined, is due, not as has been stated, to sub-mucous or intra-mucous extravasation, but to vascular congestion in its most extreme form ; the vessels being distended to their limits, but without rupture or dispersion of their contents unless artificially produced. 5th. In some instances, generally in cases examined a few hours after death, some small ulcer-like depressed abrasions have been found. These are not true ulcers, and do not penetrate beyond the epithelium. In other: instances black spots, without breach of surface and evidently due to pigmentation, were met with. (Smart.)

In simple cases, the fourth stomach is the principal seat of disease; the natural yellow or brown color of it is changed to a dark or mulberry shade; the lining membrane is thickened and corrugated, and in cases which have been long suffering, there are often patches resembling ulceration. A careful examination of this stomach proves the morbid condition not to be the result of inflammation, but depending entirely on an intense capillary congestion of the mucous coat, which is found raisec and separated from the muscular one beneath; ... the peritoneal covering of the stomach is generally healthy, proving the non-existence of inflammation. (Pallin.)

The rennet stomach (laabmagen) and the thin guts (dünndarm) always exhibit the most striking change; on the outer surface they are more or less discolored, covered with livid spots and bare places, and when cut up the mucous membrane appears dark red, and covered with a tough adhesive slimy fluid, discolored, frequently of a greenish black. (Egan.)

In the fourth stomach there is intense inflammation of the villous membranes in patches, and every now and then you see spots of ulceration. (Simonds.)

III. The Intestines. These show a like congestive vascularity,

* This is swollen, especially near the pylorus, and there is a singular mottled aspect, when closely observed, from the grayish epithelial deposit in the glandular openings. Erosions and ulceration are not uncommon. Dr. MURchison says: "The membrane is studded with numerous minute superficial ulcers like those erosions which are so common in the ordinary cartarrhal inflammation of the human stomach." (Gamgee's Cattle Plague, p. 59.) 
resembling the phenomena of muco-enteritis. Dr. Murchison's observations, however, make the inflammation of the small intestines usually most intense about the middle. The minuter vessels of the small intestines are completely injected, and can be seen by the naked eye in the arborescent forms of their intricate reticulations. (Pl. V, fig. 1.) When the capillary congestion is complete and is passing into the stage of destructive disorganization, there is shown a very characteristic mahogany appearance. (fig. 2.) In the large intestines the principal blood vessels of the mucous folds (rugæ) are mainly and in a higher degree affected, which gives to the gut a peculiarly striped aspect. (Pl. VII, fig. 3.)

In the duodenum we also find similar (inflammatory and ulcerous) indications of disease as well as in the other small intestines, particularly in patches; we observe now and then a tendency to ulceration or that there is ulcerction of Peyer's glands; but it does not appear to be an essential of the disease in its early stages. In the larger intestines are seen similar lesions to those in the smaller, and more frequently ulceration in the apex of the cæcum. The rectum may or may not be inflamed. Simonds.

The vascular* engorgement increases towards the terminal portion of the canal and the mucous folds of the rectum exhibit the tumid and deeply purple appearance of internal hæmorrhoids. (PI. IX, fig. 1.)

The entire canal of the intestines is more or less filled with fetid gases. (Egan.)

The ileum is affected similarly to the pyloric end of the stomach, thickened, \&c. That intensity of these appearances recurs in the cæcum. Here the red patches are visible, varying in intensity along the course of the large intestines until they reach the rectum, which is evidently another favorite abode of the disease, which is thickened, discolored and ulcerated, in advanced stages. (Pallin.)

The whole mucous lining of the bowels is unduly soft and its epithelium imperfect. There are no true ulcerations as in the ulcerative typhoid of man. Not unfrequently a viscid fetid mucus covers the membranous surface. The bowel is usually empty or its contents are fluid and slimy. The discharges contain bile, and are sometimes tinged with blood. Occasionally they resemble the rice-water stools of cholera. The feculent matter contained in the intestines (Mrs. Nichols' cow) was fluid, stinking, and of a dirty white color. (Simonds.) The ileo-cæcal valve is, as regards function, healthy,

* There are cases in which the intestinal mucous membrane is singularly free from disease. There are others in which the general blood extravasation has undergone a similar change, and acquired the color and character of a melanotic deposit. In these cases there is simply an open perforated aspect of Peyer's patches, and in others these glands seem to have disappeared altogether. (Gamgee, p. 60.) 
but its lining membrane, as also that of the creal appendage, is involved in the general hypervascularity.

There is no sloughing or invagination of the bowels, nor any desquamation of its mucous surface in the form of casts. The intestinal glands do not share to any marked extent in the altered condition of the membrane, except that they are obscured by its discoloration. They are never ulcerated, but exhibit the chronic tuberculous condition frequently met with in healthy animals. The mesenteric glands show no lesion of structure, but are bloodless and shrunken, and their lacteal vessels are generally empty.

IV. Kidneys, Bladder, Uterus, \&c. The pyramids of the kidneys are usually congested; the cortex is pale, but the structure entire. The lining membranes of the bladder and urethra, never seriously involved, present only the appearances when the organs are congested. The uterus exhibits no peculiar feature; the state of the vagina, and especially of the vulva, being highly characteristic, the aphthous eruption, as observed in the mouth, being apparent at the junction of the mucous membrane of the vulva with the integument.* (Pl. II, fig. 1.)

The labia superiorly are dry and corrugated, inferiorly coated with discharges thick and putrid, which, when removed, shows the papillary eruption of an aphthous nature. (Pallin.)

V. Henrt, Liver, Spleen. The condition of the heart is not peculiar, but such as is ordinarily induced by many exhausting diseases. Its muscular substance is relaxed and flabby; there is no valvular lesion or structural change. Ecchymosed patches are sometimes seen on the exterior of the ventricles. On the inner part of the heart, and on the left side in particular, petechiæ were present. (Simonds.) The large vessels and their lining membranes are healthy. The liver is of natural size, pale in color, but sound in structure. [The liver is generally friable and of a clay yellow. Egan.] The gall bladder is usually filed with bile, which is thin and of a light green color, and rarely patchy discolorations are found on its lining membrane. [It is much distended with thin, yellowish gall. Egan.] In one or two instances in Galicia we found ulceration of the mucous membrane of the gall bladder, and effusion of lymph into the gall ducts. (Simonds.)

The spleen is too pulpy, and breaks down under slight pressure.

* The mucous membrane of the organs of generation is always red, tumefied, and the epithelium undergoing changes as seen on the mucous surface of the organs of respiration and digestion. (Gamgee, \&c., p. 66.) 
The pulp is composed of broken down tissue and blood cells of a very dark color. It exhibits the same condition as in exhausting fever. The spleen is generally unchanged. (Egan.)

VI. Windpipe, Larynx, Lungs and Thoracic Cavity. The entire mucous membrane lining the respiratory passages is reddened and highly vascular, as in the earlier stages of acute bronchial catarrh. (Pl. IX, fig. 2.) It is sometimes nearly dry, but more frequently, especially in the smaller tubes, there is an abundance of frothy mucus (purulent-Egan) often of a slightly red color or tinged with blood. [It often appears to be free from inflammatory action, but is covered over with layers of lymph, frequently as thin as a sheet of paper. Simonds.] The membrane is entirely free of aphthous eruption, and there are but rarely indications of an effusive or depositive inflammatory condition. Exceptional cases have been observed in Vienna, and by Prof. Gambee, where a considerable deposit was observed in the trachea.* Only one case is to be found in all the museums of Europe where there has been, as in the exudation of croup, a solid fibrinous deposit in the trachea. (1st Rep., p. 110.) The air cells of the lungs in uncomplicated cases are healthy; any emphysematous condition being chronic and not superinduced by the disease. The lungs appear shriveled, pale or discolored, and sometimes much swollen. (Egan.) The serous membrane of the chest, as a rule, is likewise free from disease. (Simonds.)

VII. Brain and Spinal Cord. The cerebral membranes are much congested, not without vascular rupture or extravasation. There is no effusion on the brain, no congestion of the membranes of the spinal cord, the brain and cordbeing both perfectly healthy.

The brain gives no indication of disease; but in detaching the brain from the spine, we found nearly in every instance in Galicia a larger quantity of fluid than ordinary. (Simonds.)

Dupries, in post-mortems made in 1795 and 1814, with special reference to the lesions of the nervous system, invariably noted the following appearances: The spinal marrow softer and more injected than in health, especially in the lumbar region, so that when touched it appeared to be mere pulp. Serum limpid and transparent was found in the duplicatures of its investing membrane in great quantity, more abundant in the lumbar region. The cellular tissue of the

\footnotetext{
* Gayger has drawn out of the bronchial tubes imperfect and friable casts made by exudation which, when placed in alcohol, retained a considerable degree of solidity and firmness. In such cases the mucous membrane is all of a deep red color, with a dirty looking deposit on its surface, and a complete destruction of the normal ciliated epithelium. (Gamgee, p. 5\%)
} 
lumbar and sacral nerres, where they join the spinal cord, is ordinarily gorged with bloody serum, and in one case, in 1795, the nervous filaments were sprinkled with very small black ecchymoses. The brain is not so soft as the cord; most frequently it appears to be healthy; sometimes, however, more injected, and the meninges redder; the ventricles very often filled with an abundant lemoncolored serum. In one case, Dupries saw the arachnoid dotted with little black ecchymoses also found on the plexus choroides. Gamgee found usually redness of the meninges of the brain, and deeper redness of the cord, especially in cases where the breathing was very labored during life; and on puncturing the dura mater four to six ounces of serum escaped.

VIII. Urine, Blood and Milk. The urine in all cases contained albumen, in varying proportions, and in the majority of cases, blood cells also.

The blood, as in most cases in the vessels of a dead animal, remains fluid for a considerable period after death. (It sticks peculiarly to the hand. Higgins, 1st Rep., p. 119.)

On analysis- the blood was deficient in fluids and in its proper salts; with fibrine in excess. The blood of a healthy calf contained 4.53 parts of fibrine and 89.69 of corpuscles in 1000 parts. After disease, which was slight and induced by inoculation, the fibrine rose to 4.85 and the blood corpuscles to 117.7 in 1000 parts. In a bad case the fibrine amounted to 9.9 in 1000 parts. In three cases of analysis of urine, the coloring matter of bile was present; in one the bile acids were present and in one case examined for leucine and tyrosine, these constituents were not found. (A. Gamgee.)

The blood coagulates slowly but firmly out of the body. The clot resembles pitch, and in the fluid state the blood has a somewhat tarry or porter like appearance (Pl. X, fig. 2) compared with (fig. 1), showing the color of healthy blood. The temperature of freshly drawn blood in an advanced stage of disease in a cow slanghtered, was $91^{\circ} \mathrm{Fahr}$, with specific gravity of $59^{\circ}$; the temperature of healthy blood obtained in slaughtering being the same, its specific gravity $70^{\circ}$ less. Under the microscope, the red corpuscles are small and shrunken, their cell walls also shrink and corrugate, and many assume a stellated form. They also cohere tenaciously, the white corpuscles are greatly in excess as compared with a healthy state, are swelled out, many ruptured and their granular contents dispersed over the microscopic field. (PI. X, fig. 3, showing Rinderpest blood compared with healthy blood in fig. 4.) 
The milk when drawn from a cow in an advanced state of the disease is altogether creamy, resembling in some cases melted butter. It has a peculiar persistent taste, owing probably to a deficiency in sugar. It decomposes rapidly, and under the microscope consists of fatty cells crowded and overlaying one another (Pl. XI, fig. 1; as compared with the appearance of healthy milk in the microscopic field, fig. 2.)

IX. Tissues, \&c. The serous membranes, when the disease has no complications, are healthy and with no effusion into their sacs.

The cellular condition of the loins in some animals is highly emphysematous, a condition occurring frequently in life. But it is a dangerous complication; one of the cows under treatment died from suffocation simply from this cause.

X. Udder, Skin, \&c. The structure of this last is unimpaired; the diminished secretion of milk is to be referred to systemic causes. In one third of the cases examined by Dr. Smart, an eruption appeared very generally diffused over the skin* and most abundantly in the flanks. The eruption as seen in the udder had a vesicular character, making its appearance on the 5th to 7th day.

These eruptions were papules and not pustules, as observed by Dr. Thos. Hillier, M. D., medical officer of health (2d Rep., p. 33), though he did not trace the eruptions to their conclusion.

XI. FeEt. The lining membranef of the cleft of the hoof is very highly congested, with desquamation, \&c., similar to the other external lesions of mouth and vulva.

XII. Flesir. This possesses a mulberry or dark claret color, with the remarkable quality of irridescence or of changing color. The color of the fat is of a dark and dusky yellow, becoming more marked after exposure to light and air. Both muscles and fat exhibit an unusual degree of shrinkage. (Pl. XII, fig. 1.) The muscle, however, after a period of exposure, loses the first characteristic distinction from healthy beef (Pl. XII, fig. 3), and the mulberry hue is insensibly

* The surface of the skin over the neck and withers is often moist or greasy, from an abundant sebaceous secretion. There are no vesicles and an entire absence, as a rule, of pustules. In some cases are seen somewhat flattened nodules presenting the characters of false cow-pox. GUERsent, in his "Essai sur les Epizoötiques," speaks of this eruption in mild cases, \&c, in the form of small eminences of conical form, analogous to false vaccine. Prof. GerLacH noticed this appearance rarely in Great Britain, but more frequently in Holland, where the disease was less virulent. (Gamgee, \&c., p. 50.)

t The great capacity of this membrane for the diseased condition, naturally leads to the inference that it is highly capable of absorbing the virus from urine, dung and other exuviæ of Rinderpest subjects, with which it may be brought in contact. 
changed for a reddened tint, still with an element of brown, which imparts a peculiar duskiness to it. (Pl. XII, fig. 2.) If the animal is slaughtered early in the development of disease, there cannot be detected any alteration in the carcass. (Higgins, 1st Rep., p. 119.) Prof. Brücke, of Vienna, stated that during a recent epidemic of steppe murrain, in Bohemia, the authorities, according to their practice, had the diseased beasts slanghtered and buried; but that the populace dug the carcasses up and ate them without any injury.* Similar accounts of plenty of cases are, given in Levy's Traite Hygiene. (J. Simon.)

It is of considerable importance that we should state, that of the 98 cases tabularly reported by Dr. Smart, with the distinctive lesions which they revealed on dissection prior to the 11th of December last, thirteen were examined as distinctive cases of murrain or mouth and foot rot, and pleuropneumonia, ten of the former and three of the latter. It was deemed highly desirable to furnish a comparison of the lesions which these diseases eause, inasmuch as many of the cases of Rinderpest were found to be complicated with these and other fatal maladies; twelve with chronic pleuro-pneumonia, five with double chronic pleuro-pneumonia, five with pleurisy, acute and chronic, one with pulmonary apoplexy, \&c.

The reddened aspect of the lining membrane of the fourth stomach in murrain is limited to the upper third of the membrane, never exhibits the purple or mulberry tinge, but is found associated with dark colored spots, which are sub-mucous hæmorrhages or apoplexies; the blood thus effused ultimately induces erosion of the superjacent membrane, while the epithelium is entire and the mucous membrane otherwise sound. The dark irregular patches seen in the membrane ( $\mathrm{Pl}$. IX, fig 3), representing the hæmorrhages or apoplexies of the mucous membrane in murrain (or mouth and foot rot), are never present in Rinderpest, but have been found in all of Dr. Smart's dissections of murrain cattle. Though the mouth shows discolorations,

* It is to be hopeç that the food thus eaten was thoroughly cooked, so as to destroy the entozoa, which have almost invariably been found in animals dying of the cattle plague, and in much larger numbers than in the cases of healthy animals. For description, \&c, of the animalculæ, see Appendix to Cattle Plague, p. 819. 
or sometimes a single ulcer on the tongue, there is no reddened or abnormal affection of the vagina; while in most cases the intestines, lungs and air-tubes, and in all cases the heart, liver, spleen and kidneys, were healthy and sound. In pleuro-pneumonia, the principal abnormal signs are found in the lining membranes of the air tubes, which are congested and thickened; in the lungs, either hepatized,* consolidated at the base, adherent to the investing membranes or with effusion; in the heart, dilated and relaxed, with adherent pericardium; and in the liver, spleen and kidney being more or less congested.

\section{(II B.) GENERAL PATHOLOGY.}

As before intimated, we dissent from the opinion so generally concurred in by those whose opportunities of examination and whose veterinary skill entitle their judgments to the highest respect, that the Rinderpest is identical with the epizoötics which have visited Europe and Great Britain for ages past. But we will not express this conviction without first conceding some fair apology for those who, against reasonable grounds of doulut, have been led apparently to coincide with the general current of opinion and authority. We may then, without also yielding our judgment, venture to prove from contemporaneous evidence, which has happily been placed before us, that the murrains of the last century are wholly distinct in their pathognomical indications from the distemper we are considering.

It is natural that there should exist in the popular mind a tendency to confound this pest with all others which in past ages have destroyed, and even up to the present time are desolating flocks and herds of domesticated animals, and generally known as murrains. But scientific minds refuse to iudulge in this general confusion. We cheerfully record the

\footnotetext{
* In Rinderpest the lung is not necessarily diseased. A dull, solid-like sound is emitted on striking the ribs over a lung solidified from pleuro-pneumonia. In Rinderpest, when the lungs are emphysematous, the sound from percussion is still more resonant and hollow-like than even from healthy lungs. (T. Baldwin. Sequel, \&c., p. 43.)
} 
fact that veterinary diagnosis is now happily so far advanced that it rarely happens that the Pest is now, as it has been, identified with or mistaken for the following epizoötics which have obtained a foothold on the continent and in England, to wit: Eczema-epizoötica (month and foot rot), or pleuropneumonia-typhoica, or (by some writers styled) exudativa; (contagious pleuro-pneumonia).*

Moreover, the terror which epizoötics as well as epidemics excite in a community where their extraordinary havoc is witnessed from hour to hour, indisposes even the most heroic to those patient modes of investigation, which can alone clearly define the nature and scope of the pestilence, and secure its ultimate mastery by remedial agencies.

Hence, we have the vaguest notions of most of those epizoötics which have scourged the continent and Great Britain for many centuries. The murrains in the latter, of 1348-9, 1480 and 1665, have left behind them but little note of anything but their fatality and rude attempts at sanitary regulation. Those, however, which were developed in the eighteenth century, had the advautage of no inconsiderable skill in their investigation. And we cannot but express onr reluctance to state, that the Royal Commission have given the sanction of their high authority to the indorsement of the opinion, that the Rinderpest is identical with the murrains of 1714 and 1745. As there exists sufficiently accurate descriptions of the morbid anatomy of these distempers, and as the question of identity is of importance, not only as a matter of history but of diagnosis and therapentics, we shall offer no apology for the space devoted to the review of post-mortem and other examinations, made during their prevalence, which, as we think, clearly demonstrate a total want of identity. Perhaps, however, we ought to acknowledge two common facts in the epizoötics of 1714 and 1865. Each first made its appearance at Islington, and about the middle of July.

\footnotetext{
* We may regret that the latter disease, imported a few years since from Holland into Massachusetts, was regarded, in terms at least, as mere pleuro-pneumonia, which is enzoötic or sporadic. The pneumonia which effected no inconsiderable loss, and threatened an extended alarm throughout this country, was finally put at bay, and is now understood and recognized as typhoid in its distinctive character.
} 
Thos. Bates, Esq., F. R. S. and Surgeon to his Majesty's Household, was appointed by the Lord Justices to investigate this plague of 1714, and he has presented, in his paper* read in 1718, before the Royal Society of London, a very clear pathological view of this distemper. He alludes, in his report, to the pestilence of 1665 , resulting, as was believed, from "a want of due care in burying the cattle" who perished the year before, and insists upon burialt to the depth of nine or ten feet. He states the mortality in three counties, in 1714-15, at nearly 6,000, and the loss (prime cost) at $£ 24,500$. He limits the period of the severity of this plague to three months, though "it was not entirely suppressed until Christmas," and alludes to its $\ddagger$ raging in Holland for three years, at a loss of over 300,000 head of neat stock.

The following symptoms were furnished to Dr. Bates by the cow-keepers, who had lost from over one-half to seveneights of their stock:

"The cors first refused their food. The next day they had huskish coughs, and voided excrement like clay; their heads swelled and sometimes their bodies. In a day or two more there was a great discharge of mucous matter by the nose, and their breath smelled offensively. Lastly, they had severe purging, sometimes bloody, which terminated in death; .... some died in three days and others in five or six days, but the bulls lived eight or ten days; ... during their whole illness they refused all manner of food, and were very hot."

Bates ordered the slaughter of all cattle and disinfection of the premises. But the distemper, owing, as he thought, to the "free intercourse which both masters and servants had had with each others' cows," had "spread the contagion."

* See Philosoph. Trans., No. 538, p. 872; Vol. VI. of Abridgment, p. 375.

+Burying with lime, two bush. to a cow ten feet deep, developed a strong scent of meat, which attracted dogs, and caused them to tear up the ground with their feet-otherwise where the animals were buried at less depth and without lime. Philosoph. Trans. vol. XI of Abridgment, p. 255.

$\ddagger$ This might serve if no other proofs were presented as indicating the epizoötic on the conti. nent and Great Britain as one and the same during this epoch, and the observations of LANCIsI as well as the treatise of RAMMAZINI, we think confirm the presumption. 
He subsequently dissected sixteen cows, in "different degrees of infection," first fire, in whom the "symptoms were just become visible," then six that had "been ill about two days," and five that "were very nearly dying."

In the first set "the gall bladders were larger than usual, and filled with bile of a natural taste and smell, but of a greener color. The pancreas was shriveled; some of the glands were obstructed and tumefied; many of the glands in the mesenteries were twice or thrice their natural size. Their lungs were a little inflamed; all other parts of their viscera appeared as in a healthful state." In the second set the following differences and aggravations were found. "The livers were blacker than usual, and in two of them there were several cysts filled with a petrified substance like chalk, about the size of a pea; gall of a greener color than the first. Some of the glands were very large and hard; the mesenteries five times their natural size, and all of a blackish color. Lungs inflamed, with several cysts forming. Their intestines were full of red and bluish spots. Their flesh was very hot, though not altered in color." In the third set he noticed the following changes, to wit: "Liver now much shriveled and contracted, and in three of them there were several cysts as large as nuts or nutmegs, filled with a petrified substance like chalk; gall bladders three times their usual size, \&c.; mesenteric glands, eight or ten times their natural size, were very black, and in most of those glands in the pelvis of two cows there was a yellow petrifaction of the consistence of a sandstone. Intestines of the color of a snake, their inner coat excoriated by purging. Lungs more inflamed, with cysts containing yellow purulent matter, many as large as a nutmeg."

The dissections of these three classes of subjects were quite uniform; but Bates notices three cases as "very extraordinary" - one in which "the bile was petrified in its vessels and resembled a tree of coral, but of a dark yellow color and brittle substance." In another, "were several inflammations on the liver, some as large as a halfcrown, cracked round the edges, and appeared separating from the second part, like a pestilential carbuncle." In the third, "the liquor contained in the pericardium appeared like the subsidings of aqua calcis, and had excoriated and given as yellow a color to the whole surface of the heart and pericardium, as aqua calcis could possibly have done."

Aside from the admitted fact that this pestilence was both infectious and contagious, and that the virus was commu- 
nicated in very many cases by fomites (the clothing of attendants, \&c.); physiologists, we believe, will find little resemblance between the symptoms and dissections of this distemper of 1714 and those of the Rinderpest. Neither do we think that the Pest can be identified with the epizoötic,* which ravaged parts of the continent from 1744 to 1772 ; and England from 1745 to 1757 (again breaking out in 1765); although Professor Simonds, a very high authority, seemingly abandoning the position taken in his report made in 1857, to the National Agricultural Societies of Great Britain, on the plague which was then very fatal in Eastern Europe; has in his evidence before the Royal Commission of 1865 (1st Report, p. $2, \S 16$ ) stated that the plague of 1745 was the same as that at present existing in England.

Professor Simonds in his Report, speaking of the murrain of 1714, says:

"It appears, however, that the malady possessed many of the features of Eczema epizoötica, now common in this country, and it may possibly have been identical with this disease. The infection seems to have been communicated by the saliva, as it is said that "when this is dropped on the grass, and sound animals are immediately placed in the same pasture, they contract the disease, and in some bullocks the tongue was inflamed and covered with many red blisters."

And, again alluding to the singular exemption which Great Britain enjoyed after the subsidence of the latter epizoötic, until August, 1859, mentions the great anxiety which was created by-

"The sudden and almost simultaneous appearance of a "new affection" (although probably of the same nature as that of 1713-14), amongst the cattle in different parts of the couniry, popularly known as the mouth and foot disease."

The Professor also refers to Dr. Layard's Essayt on the

* There were destroyed in Western Europe from 1711-14, one and a half millions of cattle, and from 1745-8, three millions in Western and Central Europe. These statements are believed not to have been exaggerated by the foreign authors who furnish these statistics. giving as the loss of Denmark, from 1745-9, 2S0,000 head, and of Holland, from 1769-72, 395,000 head.

+ See Journal of Royal Agricultural Society, Vol. xviii, pp. 197 and 200.

¥ See an essay on the nature, causes and cure of the contagious distemper among the horned cattle in these kingdoms, by Daniel Peter Layard, M. D., Mem. Roy. Coll, of Physicians, and of the Royal Society, $175 \%$. 
epizoötic of 1745 , as to the opinions prevalent at that time (and quoted by Layard from Dr. Mortimer) on the origin of the disease, whether brought by imported calves from Holland, or by distempered hides from Zealand; but he seems latterly to have overlooked the pathology of the disease as described by Dr. Layard.

This learned physician inclines to the opinion that the distemper of which he so elaborately wrote was similar to that visited upon the obdurate Pharaol, 1,600 years B. C., which resulted in the destruction of all the cattle in the fields; horses, asses, camels, oxen and sheep, by a very grievous murrain, "boils breaking forth with blains upon man and beast." Adverting to the great plagne which, after destroying, in the days of Romulus, the fruits of the earth and cattle, swept off many of the Romans and Lanrentes; quoting Livy, who identifies the disease as equally affecting men and brutes; a recurrence of which took place A. U. C. 355 ; Layard passes to the authority of Columella, Gesner and Aldrovandus, who described the disease as a subcutaneous disease; makes it a plague of the same kind which destroyed "every head of cattle in Charlemagne's army, .... also throughout all his dominions ;" and rallying upon the account given by Rammazini of the distemper in Germany and Italy in 1514 and 1599, winds up with this general expression of his historical survey :

"The same countries which breed the plague and small-pox seem to have propagated this contagion. The autumnal heats in Asia or Africa, the putrid effluvia from the Nile, or from corrupted, stagnating waters, are sufficient to contaminate the blood and juices of the cattle." (Page 13.)

This presents, it is true, a theory of the identity of cattle murrains through all historic periods. As a generalization broader in its grasp than the one we are combating, we shall leave it to rest upon the evidence it brings from the records upou which it relies; or the imaginative skill with which the eloquent Doctor has grounded this universal pestilence on its effluvial origin. The pathology of that which he sat, is more to our present purpose. After describing the usual 
symptoms of sudden debility which manifest themselves in most cattle affected with blood-poison or ferment of any kind, he notices:

"A constant diarrhœa of fetid green freces, a stinking breath, nauseous steams from the skin, blood very florid, hot and frothy urine, or stale, high colored; roofs of the mouths and barbs ulcerated, tumors or boils felt under the panniculus camosus or fleshy membrane of the skin (note reference to Rammazini and Lancisi), eruptions all along their limbs and about their bags (note reference to Aldrovandus, I, 110, De malide Subtercutanea), visible irritation during some time in ano, much groaning, symptoms aggravated in the evening, animals mostly lying down." "The symptoms continue increasing till the seventh day from the invasion, on which generally, though sometimes protracted till the ninth, the crisis takes place."

Now, we will admit that some of these symptoms might present a difficulty in distinguishing between themselves and those occurring in Rinderpest; but the Doctor, in his chapter on prognosis, clears up every doubt or mystery.

"If, therefore, the following symptoms be observed on the seventh day from the seizure, namely, either eruptions all over the skin or boils as big as pigeon's eggs on different parts of the body, but especially from the head to the tail, all along each side of the spine or back-bone and tail, so ripe as to discharge putrid and stinking matter; large abscesses formed in the horns or in some parts of the body, \&c.; $\& c$, the nose be sore and scabbed, \&c., \&c., the beast is out of danger. But, on the contrary, if on the seventh day from the invasion the eruptions, boils or abscesses are decreased in bulk, or totally disappeared without having broke or discharged outwardly, \&c., \&c., the running from the nose and eyes lessened; the eyes dim and sunk into the head, a perfect stupidity, the beast inevitably will soon die.".... "Within some hours of its death, there frequently arises on the back, upon the sinking of the small swellings, a large tumor, or bag filled, as it were, with air, pressing upon which the contents will move to and fro from the head to the tail. This is not only mentioned by Rammazini, but also by authors who deemed the disease to be only an inflammatory fever; it is called an emphysema, \&c."

The term " emphysema" was eridently intended by Layard (if not as synonymous with that, immediately preceding, " inflammatory fever"), to serve as an expressive designation of the "large tumor, .... filled with air," which supervened 
in a fatal resolution of the malady he observed. Gamgee, however, who is a zealous advocate of the theory from which we dissent, quoting at length the passage from Layard, which precedes his prognosis, and omitting the latter; in a note-comment on the "tumors or boils felt under the panniculus carnosus," \&c., declares these to be "evidently the emphysematous swellings" described by him as apt to form within the first three days after the external symptoms are manifest, and about the stage of the disease when severe diarrhœa sets in and thirst supervenes. It is clear, however, that the term "boils" was used in the unsophisticated sense of that term.*

But what says Dr. Layard of the morbid appearances which were presented on dissection. We will note most of those characteristic of the malady of 1745 .

"The membrane of the nose (note Rammazini, p. 458), the glands (note Lancisi, III, 11), the whole extent of the frontal sinus, the pith of the horns highly inflamed, ulcerated and full of small abscesses; the same appearance in the mouth and about the glands of the throat. The lungs inflamed with livid sphacelated spots and here and there loaded with hydatids. The heart large, flabby and dark colored, containing in its ventricles clots of black blood, of a very loose texture without serum, the fat about it of a bright yellow. The liver large, its blood and biliary vessels fully extended with dark fluid blood and very deep colored bile; the substance of the liver so rotten as to separate on the least touch; the gall bladder stretched to a great size and full of greenish bile; the esophagus ulcerated in some. Several marks of inflammation and gangrene appeared on all the stomachs - all the intestines empty, and beset with red and black spots. The kidneys and bladder large, without urine; the kidneys of a loose texture, easily torn. The flesh in some was livid, in others of a lively red, but soon turned green. The fat that remained was of a bright yellow all over the body. In such cows as were with calf the uterus was gangrened in several places, and the waters which surrounded the fotus or calf stunk intolerably. In short every carcass gave sufficient evidence of a general putrefaction," \&c.

It should be noted that the italics are those applied by the learned Doctor mostly to his Latin terms. We have refrained

* Cattle Plague, pp. 48, 52. 
from underscoring the symptoms and morbid anatomy of this species of anthracoid plague which, unless we are greatly in error, places it "toto coelo" in the constellation of epizoötics from the Rinderpest.*

If, however, it should seem that Layard's account is not as explicit in establishing the diversity between the distemper of 1745 and the Pest, as that of Bates, with reference to the murrain of 1714 : it will not be a difficult task to supplement the evidence by a concise review of three papers on this subject, read before the Royal Society, + by Cromwell Mortimer, M. D.; premising, however, that his first might, in some respects, have misled Layard, as it seems to have led astray some of his readers in later times. The description which is given in his earliest account of animals, observed to be ill-

That on " the very first day they have a huskiness, breathe short and wheeze, but have no great cough...... Some lay down their heads and run much at the nose...... The second or third day most of them fall into a purging; groan much and seem to be in great pain. The stools seem to be bilious; have cakes of jelly come away with them, and some were streaked with blood. They soon died after these stools came on. Those that are kept out in the cold air seldom lived beyond the third day; those that are kept in warm houses and clothed; live five, six and seven days. Many of the cows have a wild stare with their eyes; the whites of the eye and the skin of the eyelids looked yellowish; their tongues looked white; they had no extraordinary heat in their mouths, or at the roots of their horns (a place where they usually feel to judge of the heat of cattle), or in the axilla or arm-pit. The mucus running from their nose is very thick and ropy; their milk is thick and yellow."

might have deceived those who did not carefully study the post mortem given; notice the fact, that the description of symptoms while suffering under the malady, and of the appear-

\footnotetext{
* We note that GAMGEE, in objecting to the title given to the Pest by Dr. BuDD, "The Siberian Cattle Plague," says: "It is apt to lead to confusion with the Siberian Boil Plague, an enzoötic rather than an epizoötic disease, a form of anthrax which never spreads beyond the Russian dominions, and which is unknown in healthy districts, even in Siberia itself. The Siberian Boil Plague attacks cattle, but principally men and horses; and although there are at times wide-spread outbreaks, these occur under the influence of excessive heat during the hottest months of the year," \&c. (Cattle Plague, p. 23.)
}

† See Transactions for 1745 , No. 477, p. 532 and 549 ; No. 478, p. 4; Vol. IX of Abridgment, p. p. $171,177,184$. 
ances found in dissection, was taken at second-hand by Mortimer, from one who had flayed and opened the two cows particularly described in this paper (although the unprofessional demonstrator stated that "these were the general appearances in most he had flayed; only that in some he found water in the cells of the horns"), or stop to meditate upon Mortimer's pathological summary;

That this distemper began by an inflammation of the lungs, attended with a catarrh or flux of humours from the nose; that in the progress of it there came on an inflammation of the guts, and a purging, caused by an acrimony and overflowing of the gall, which ended in stools tinged with blood-exciting great pain in the bowels-and brought on death.

The more careful reader of his second paper would have reasonably inclined to place due emphasis upon Mortimer's descriptions of those post mortems conducted under his own experienced eye. He was present when three cows were examined; the lungs in all were inflamed and blistered, \&c. But not content with these dissections, he procured the services of an ingenious apothecary ...... to help him in examining everything very carefully.

But let us give the Doctor's luminous account of what was displayed, and as fully at length as it is given in the abridged edition of the Transactions of the Society :

"When the skin was taken off, she appeared very fat; the muscles looked of a darker color than usual. On opening the abdomen, the caul appeared very fat; the paunch was greatly distended; on making a puncture much air gushed out; it had in it a great deal of food; the inside looked well and did not peel; the $2 d$ and $3 d$ stomach, or the omasum, as also the 4th stomach, or abomasum, were almost empty, but looked well; the liver was firm, well colored and sound, except a few scirrhous knobs about the size of nutmegs; the gall bladder was exceedingly large, and full of very fluid gall; the guts were inflamed in many places; the colon and coecum livid; he had the curiosity to have them measured; from the anus to the insertion of the cæcum there were 12 yards (the cæcum was an ell long), and from the cæcum to the pylorus there were 52 yards. The midriff was much swelled and inflamed; the lungs were swelled, inflamed, adhered in some places to the pleura, and almost wholly covered with 
bladders of water; there was no appearance of any inflammation in the pleura, or in either the internal or external intercostal muscles: the windpipe was inflamed greatly throughout its whole course, especially its inside, but the gullet, which lay so near it, was not in the least inflamed; the heart was of its natural size; the pericardium full of very fluid blood, probably from the bursting of some branch of the coronary artery, caused by the extraordinary accumulation of blood in the right ventricle, for the vena cava and right ventricle of the heart were turgid and full of black coagulated blood, though this cow had been dead but 12 or 14 hours; the iungs were likewise turgid with blood, but little or none was found in the left ventricle or aorta; the obstruction seemed to have been so great in the lungs that very little blood could pass through them from the right to the left ventricle of the heart, and therefore evidently evinces the existence of a confirmed peripneumony. All the membranes lining the nostrils, and the spongy bones there, were quite turgid with blood and in the highest state of inflammation." He had not seen in any cows he had examined any cutaneous sores or exulcerations, nothing like the boils, carbuncles, \&ic., described by authors as the constant concomitants of the plague in men; nor does there seem to be any attempt of nature to fling off the distemper by any internal imposthumation or discharge, unless by the running at the nose and by the bilious stools or bilious urine."

After noticing a few cases of recovery through occasional bleeding, warm mashes of malt and bran, and warm drenches of herbs, such as rosemary, wormwood and ground-ivy, with honey or treacle; and regretting that his instructions as to treatment, \&c., had been so poorly followed by the cowkeepers; he proceeds with his method of treatment, after reiterating his previously assured opinion.:

"..... The state of the disease seems so evidently to be a peripneumony or inflammation of the lungs, windpipe and nostrits, attended with a redundance of gall ......"

He next gives the symptoms of a favorable resolution of the distemper, on which so much reliance has been placed; because of the parallel citation made by Layard in a note to page 54 of his Treatise, from Rammazini (p. 462); "that not one of the cattle recovered but such as had pustules broke out upon the skin:" also quoted by Dr. Murchison 
to establish his theory of the identity of the Pest with human variola.

"They are observed to have scabby eruptions come ont in their groins and axillie that itch much; for a cow will stand still, hold out her leg, and show great sigus of pleasure when a man scratches these pustules or scabs for her."

After seeking in vain to satisfy his mind as to the distemper being propagated through certain kinds of food, green or dry; being in doubt whether its cause was in the air, or attributable to the changes of the seasons, as to moisture and cold, he affirms his clear conviction on one point:

"This was certain, the viscer $a$ concerned in respiration are the parts chiefly affected:"

In his third account he gives "an instance of the most surprisingly quick progress of this distemper ...... not come to the state of purging," the case of a cow, in which the inflammation in general was greater than in any he had before seen; which had, under the specific treatment then mostly relied upon, not only as a curative but prophylactic, been bled about three weeks before she was taken, and once as soon as taken. The autopsy was as follows:

"The caul was greatly inflamed, the paunch inflamed, and the inner coat peeled off, especially that of the (abomasum) faidle; the guts were all inflamed; the liver was much inflamed in some parts, in others was turned livid; the gall bladder was very large, and the gall very liquid; the lungs adhered in many places to the plenra, were greatly inflamed and turgid with blood, and were in many places quite black; he did not find any of the watery bladders on the surface of these as he did on all the others he had seen opened."

If the examination we have given to Bates' autopsies, Layard's Treatise, and Mortimer's papers, may seem to have been unduly extended, we must seek our apology in the conclusive evidence thus furnished, negativing the dictum of the Royal Commission, that the Rinderpest had appeared in England prior to its introduction in $\mathbf{1 8 6 5}$.

Making due allowance for any attributable imperfection in the accounts given by those who may not have possessed the same accuracy of descriptive power attained by modern 
pathologists, it is beyond reasonable conjecture, that those who saw only epithelial denudation of the fances, should have described ulcerations and abscesses involving even the glands of the throat, sometimes the asophargus, extending to the lungs, and inducing in the liver a general rottenness; and all this while the same tendency to the development of purulent abscesses being exhibited in all the external tissues.

There seems, in the descriptions of Layard, of the distemper of 1745 ,* hardly a symptom or post-mortem appearance to be viewed as in common with those of the Pest, except those which necessarily attend all inflammatory action. Even the fat in all parts of the system remained of a bright yellow, and the flesh soon turned green. Should the plea be interposed that, in the cases described by Dr. Mortimer, the pneumonic symptoms overshadowed the current epizoötic, the reply is fairly to be made, that Mortimer, who was as learned an expert as the medical profession of his day could produce, does not, if his statements are fairly canvassed or credited, admit or support the possibility of the existence of any other primary affection than that embraced in and bounded by the pneumonic congestion. And if this had a marked tendency towards a typhous form, it is not so difficult to account for the exacerbated manifestations on the intestinal canal in some cases he has described, as the result of the depletory and purgative treatment pursued.

If, however, the most subtle analysis of the opinions of Mortimer and Layard should reveal discrepancies, these we think will be mainly on minor particulars; and cannot disguise the dilemma in which their successors in veterinary pathology are placed, who have by hasty deductions formed

* The distempers of 1711 and 1745, as malignant and contagious epizoötics, may find their type in the enzoötic disease commonly called quarter-ill or murrain, in which, from bad food, impure water, or other causes, the hepatic or cystic ducts, either separately or conjointly, and in combination with the ductus communis choledochus, are obstructed : producing an enlargement of the gall bladder, and, in connection with a congested affection of the liver, forcing an absorption (by the method of osmose; of vitiated biliary secretions into the blood; thus inducing the primary symptoms as well as final results of such too copious an infusion of purulent matter. We do not allude to concomitant symptoms, such as the destruction of unuscular substance in the glutœi, \&c., and the formation of large cells of vitiated blood corpuscles in their places; neither do we design in presenting in the enzoötic form a countertype to the epizoütic, to assign a common or any original canse for their separate developments. All such theoretic views must be referred to future scientific investigation. 
on garbled statements of the views of these writers, sought to sustain the theory of the recurrence of the English murrains of the last century, and their reappearance in this.

But we are disposed to move to a further standpoint, and. to add that if English writers could confuse or mistake observations on malignant distempers occurring in their own country, within the period of a century and a half; it is a fair inference that continental and classic writers may have labored under similar misapprehensions in regard to the identity of the various pests which have devastated flocks and herds in different ages.

On mere grounds of probability, we might impeach the calculation that during the last century alone, twenty-eight million head of cattle in Germany; and in the whole of Europe, including Russia, but excluding Siberia and Tartary, two hundred millions had fallen victims to the Rinderpest, (as these statements are presented in a report to Her Majesty's government, by Mr. Blackwell, British vice-consul at Lubec); when we consider that Europe has been afflicted with epizoötic hydrothorax, dysentery and catarrhal fever, in addition to the other distempers we have before enumerated, and one prevalent in Hungary, called blood plague (2 Rep., 29); and that her cattle, as well as human population, in many localities, have suffered great mortality in bad seasons for maturing and harvesting crops; from damaged, sprouted or ergotized* grain.

Now while we are in hand, let us push this investigation to remoter regions and times, and enquire what reasons exist for imagining that the distempers which scourged the continent for a hundred years, commencing at the latter part of the seventeenth century, were in any important particulars, physiologically akin to the Pest.

Rammazini, so often quoted in affirmation of this view, has left in his dissertation on the distemper which broke out in the Venitian territory, especially in the neighborhood of Padua, but a meagre substratum on which to found any such

\footnotetext{
* By this phrase "ergotized," we mean to denote the parasitical growth of all the fungi which infest ccreals, \&c.
} 
hypothesis. Nay, those who labor to pervert his views to any such end, must deny to him the right or ability to present or maintain the conclusions he favored. His tractate, far from being as voluminous as that of Lancisi, is clear, though terse in its pathological summary, and bears the marks of a scholarly and independent thinker. Refusing to be guided by the astrological lore, in which he had been instructed in his youth; discarding all reference of that cycle of malignant disease of which he wrote to any ill-starred conjunction of Saturn and Mars; he avowed himself as the advocate of a rational system in medicine, and evidently seeks to conform his style of reasoning to that of the inductive school. True, he was misled by that which he gives as the most definite pathognomonic mark; so often cited of late to prove the theory of the variolous character or of continuous outbreaks of the Pest, and its recrudescense at the present time: "pustula quinta vel sexta die per totum corpus erumpentes, ac tubercula variolarum speciem referentia." He viewed the distemper as mainly eruptive and pustular, and styled it "The Cow-pox Plague." And it is to be urged on grounds of just reasoning, that he was borne out by what he observed in viewing it as an inflammatory and phlegmonous disease, if not in the parallel he sought to draw with variola; and that with his clear perceptions and sturdy diagnosis he could not have confounded it with any distemper such as the Pest. His general description is " that it was a malignant, pestilential fever, accompanied by rigors, followed by a burning heat, quick pulse, difficulty of breathing, \&c." *But what light is thrown upon the pestilence by his examinations of the carcasses of those who fell victims to it?

"It was particularly observed that in the omasus or paunch, there was found a hard, compact body, firmly adhering to the coats of the ventricle, of a large bulk, and an intolerable smell; in other parts, as in the brain, lungs, dec., were several hydatides, and large bladders, filled only with wind, which being opened gave a deadly stench; there were also ulcers at the root of the tongue and bladders filled

* Rammazini Ed., 1716; Geneva, p. 787. 
with a serum on its sides. This hard and compact body, like chalk, in the omasus, is the first product of the contagious miasms."

This description corresponds tolerably well, both in the sketch of living symptoms and the autopsy of the dead, with two other accounts: one by Michelotti, of the same murrain described by Rammazini, and one by Wincler, of the plague which preceded it.

In the year 1682, on the border of Italy, there arose a distemper among cattle, which spread into Switzerland, Wirtemburg and other provinces of the Empire, extending at the observed rate of nearly two German miles in twenty-four hours until it reached Poland. Its march was without intermission; no neighboring parish escaped. It was a complete desolation.

It seemed to propagate itself in the form of a blue mist, which fell upon those pastures where the cattle grazed, insomuch that whole herds returned home sick, being very dull; forbearing their food, and most of them would die in twenty-four hours. Upon dissection there were discovered large and corrupted spleen, sphacelous and corroded tongues, and some had angina maligna. The persons who carelessly managed their cattle, without a due regard to their own health, were themselves infected, and died like their beasts. The method of cure was this: "The tongue was carefully examined, and if they found any aphthce or blisters, whether white, yellow, or black, they were obliged to rub, scratch and tear the tongue with a silver instrument until it bled; they then wiped away the blood and corruption with new unwashed linen. This done, a lotion for the tongue was used, made of salt and good vinegar."

The antidote and remedial prescription were the same.

"Take of soot, gunpowder, brimstone, salt, $\uparrow$ equal parts (a large spoonful for a dose), and as much water as is necessary to wash it down."

Michelotti, was eye witness of the greater part of what he described, having been in the Venitian territories about

\footnotetext{
* Philosoph. Trans. No. 338, p. 46; Vol, VI of Abridgment, p. 79.

tDoubtless, Mr. NeEDHAM, taking the popular side of the theory of identity of murrains in modern times, and ascertaining from continental veterinaries, that salt was the sovereign remedy, was induced in his elegant essay, read at Brussels in 1776 , to recommend this agent as the specific remedy for the murrain of 1745 , a view which LAYARD proceeds to refute in his letter to Joseph Banks. Philosoph. Trans, ubi sup., and Cattle Plague, p. 305.
} 
October, 1711, and received the rest on the spot from persons of integrity and credit. His account bears the stamp of his extensive skill and repute as a doctor of medicine. We shall give it quite at length :

"Almost all the sick cattle refused every kind of food and drink; they hung their heads, had shiverings in their skin and limbs, they breathed with diffeculty, and their expiration in particular was attended with a sort of rattling noise; they were so feeble that they could scarcely go or stand upon their legs. Some few of them eat a little and drank very much, others had fluxes of excrements variously colored, of an offensive smell, and frequently tinged with blood; many of them had their heads and their bellies swelled in such a manner, that in clapping them with the hand on the paunches, or along the vertebræ of the loins, they sounded like a dry bladder when full blown. In some the urine was very turbid, in others of a bright flame color. In comparing the pulses of the sound cattle with those of the diseased, he found the latter to be quicker and weaker. There was but little heat perceivable by the touch in any of them; their tongues were soft and moist, but their breath was exceedingly offensive. Besides these particulars, he was informed by those who attended the sick cattle, and by other persons worthy of credit, that in some of the beasts they had observed crude tumours in several parts of the body, as also watery pustules, and disorderly motions of the head, with $d r y$, black and fissured tongues; that in others there were tumours which came to maturation, with putrid matter issuing from the mouth and nostrils, worms in the frees and in the eyes, bloody sweats and shedding of hair."

\section{The pathological description follows :}

"In comparing the flesh of the cattle dead of the distemper with that of others killed for the market, he found the muscles in the former, lying immediately under the skin, to be something livid. Having opened the three cavities of the body, he applied himself with the utmost diligence to examine the brain, with its membranes; the trachea, œsophagus, lungs; heart, with its auricles, the vena cava, aorta, and diaphragm; the liver, spleen, and other parts of the lower belly; in all which there was no discernible difference, either as to figure, size, contents, situation or connection with the neighboring parts, from what was observed in sound cattle, killed by the butcher, except the particulars hereinafter mentioned. The blood found in the ventricles of the heart, in the pulmonary vessels, in the aorta and cava, 
thongh still warm, was considerably blackish, and almost coagulated. In opening the upper and middle cavity, the scent was offensive, but tolerable enough; whereas that proceeding from the lower belly was quite intolerable. In some few carcasses the viscerca differed from their natural state, with regard to their size, their consistence, their contents, color and smell. In several the paunch was found very much contracted and dried, and contained a hard substance. In others the lungs were swelled and livid, the liver tumefied, and the brain watery and putrid. Having ordered several of the cattle to be blooded, he found the blood not to issue out of the vessels in a continuous stream, but with a broken and interrupted flux, one part of it not immediately succeeding another ...... He found it entirely coagulated without any separation of the serum, and attached to the sides of the vessels with a reticular pellicle in the surface exposed to the air. Of the eighteen who were bled, all died within a few days, except one which underwent the operation on its first being taken ill." "*

The symptoms and post-mortem appearances, as given by Michelotti, tally so well with those described by Lancisi, that here forbearing to reserve space for them, though somerwat tempted; we will give them in an appendix to our classical and curious readers in their original text; with some quotations also from Rammazini, not merely to show the exact relation which certain sentences generally quoted bear to the whole description, but to leave the critical in such matters to measure the unfairness, the reckless readiness, or the o'erweening zeal with which such citations have been used.

Had it not been necessary to summon the principal witnesses (men of erudition and renown in their age) with their entire declarative testimony, withont perversion or gloss from hasty criticism; that this investigation might be a thorough and impartial review of the distempers they observed: we might have been contented with a summary of the English distempers given by an admirer of Layard, who has preserved its ancient but quite forgotten synonym, Hyanstricking, a corruption doubtless of an Anglo-Saxon term, compounded of Hyan (cattle disease) and stric (plague) or strica (a stroke), indicating in the compound, either cattle plague or disease by which cattle are suddenly strickien; from which we may infer

* Philosoph. Trans. 1720, No. 365, p. 83. Vol. VI of Abridgment, p. 481. 
that our Anglo-Saxon ancestry were not free in remote periods from an outbreak of pestilence among their stock.

In an appendix to a posthumous work on diseases of cattle and their cure, by J. Rowlin, a veterinary surgeon of considerable eminence, a century ago; an account is given of this distemper, in which the one of 1745 is distinguished from the one of 1765 : the common external sign of the former being "Wlotches arising all over the body," and of the latter the symptoms "in the roots of the tongue or glandular parts of the throat." The one is also described as an emphysema, or a flatulent crackling swelling, attended with a mortifying blackness. In the other the primary symptoms are said to be erident " by the mouth being generally open, and a matter falling therefiom; by opening the mouth you will find on one or both sides of the tongue a large blackish colored substance, which wili easily yield to the pressure of your finger."

In fine, if, we undertake to separate from any authentic list of the symptoms and morbid appearances of the murrains which scourged the continent as well as England in the seventeenth and eighteenth centuries; in the first instance, those which are peculiar to and accompany all deadly distempers of cattle; and next those which indicate primary and idiopathic affections of the lungs, or constitute the invariable signs of catarrhal fever; what is there left on which to base any diagnosis of a malady which, in its uncomplicated form, does not touch a single serous surface, does not of necessity involve the thoracic organs, but leaves its stamp solely on the mucous vestment? Where, at any rate, to take the most apparent indications, as tests even for untutored minds, where is the simple epithelial denudation of the mouth? where the characteristic redness and aphthæ of the vulva?

We insist, in the behalf of science, which sooner or later has morlified, if not curbed, the fatal march of pestilence, that indistinct viers and crude generalizations on this pest, or its theoretical pathology, should be banished at once from the field of observation; and that facts, indisputable in themselves and arranged according to the methods of scientific induction, should alone guide all future investigation as to 
the nature or treatment of this distemper. We should as soon now deem it wise, from the vague descriptions given by Homer or Plutarch of the cattle pestilence which prevailed in their days, or from the lines of Virgil in his Georgics,

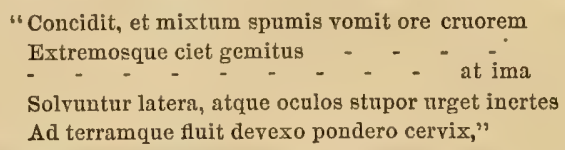

or from any such meager materials, to theorize upon the pathology of the murrains which afflicted those ages, or their resemblance to or identity with those which have appeared in modern times; as from the occasional pustules, inflamed follicles, or the congested epithelinm observed in Rinderpest, to ally it with variola, typhoid fever, or scarlatina in the human subject.

But to proceed with the more positive share of our task. We have seen that the eruptions noticed on the flank and udder are papular (p. 39), not pustular, and that in a majority of cases they appear as indications of convalescence or resolution effected through the functions of the skin; so that it is quite impossible to trace any parallel between the Pest and small pox, unless it be urged for the most fatal cases, where coma and death follow closely upon the first intimations of ailment, and the type of the former be sought in that most malignant form of the latter, known as Tariola sine eruptione. All methods then, designed to ward off or mitigate an attack of the Pest by inoculation with variolous matter from the human subject, would, on grounds of similarity as to type between these diseases, and viewed theoretically, be condemned as empirical; a conclusion amply confirmed by many abortive trials to prove it otherwise. So too, we must treat as fanciful the opinion lately advanced, that this epizoötic should be regarded as an acute internal scarlatina; the reddened appearance of the mucous surfaces, unaccompanied by the rash, as in the human subject, presenting the only common symptom. Yet we are happy to record the fact, that no attempt has been made, either for prophylactic or curative 
ends, to transfer the poison of Scarlatina, into the veins of a Rinderpest subject.

Except in a few cases where vaccination may have introduced, in addition to the specific virus of the Pest, some typhoid germs, the inner surfaces of the viscera do not exhibit evidences of the degeneration peculiar to typhoid fevers, or observable in the muco-enteritis of cattle; nor do the respiratory organs reveal serous effusion, as in typhoid pleuro-pneumonia. Dr. Tucker in his report to the Lord Lieutenant of Ireland, while repudiating any theory of identity, says: "The purple gum, the black, saltless blood, and some other symptoms of the African typhus, may be recognized in the Rinderpest." Why might not a parallel be drawn also with cholera, and influenza? The answer to this and the refutation of all the fanciful conceptions to which we have alluded, is given by science, which has very recently exploded the old classification of diseases, and has grouped those which we have mentioned, with many others,* in one leading class of zymotic diseases (order, miasmatic).

The word Zymotic is derived from the Greek of ferment, and was first suggested by Dr. Wm. Farr to indicate that diseases, so named, manifest in their course a destructive influence on the circulating medium, approaching as near as may be to fermentation, and due to the action of specific poisons of organic origin. These, like inorganic poisons introduced into the system, are found to obey certain general laws; first, that each has a specific action, and secondly, lies latent in the system a certain though varying period of time, before its specific action is evinced; and thirdly, that the phenomena resulting from such action vary with the amount of poisonous matter taken into the system, and the receptivity of the patient.

The miasmatic order of this class, as applied to the diseases of cattle, may be understood to embrace all diseases which are commonly ascribed to paludal or animal malaria, all due

* Such as chicken-pox, measles, quinsy and diphtheria, croup and hooping cough, ague, remittent, continued and yellow fevers, ophthalmia, erysipelas, hospital gangrene and childbed fever, plague and carbuncle, dysentery and diarrhœa, \&c. 
to specific disease poisons, capable of propagation from one animal to another, and communicable either by direct contact or indirectly through various channels of intercourse.*

It is frankly admitted that this or any classification would be valueless in the investigation of the Rinderpest, unless it be conceded that this epizoötic is wholly distinct from others, not only in its leading characteristics, but in its source or origin as a blood-poison. And it is principally in this latter sense, that we can pronounce it a disease "sui generis," developed through the agency of a poisonous germ, which breeds after its own type, and multiplies "after its own kind," and by a process as regular and uniform as that (to use the emphatic though homely language of John Simon, medical officer of the Privy Council in his sixth report) "by which dog breeds dog, and cat breeds cat, and as exclusive as that by which dog never breeds cat, nor cat dog."

The seminal principle or germ of the Pest being considered then as one and distinct from that of other epizoötics, its varying manifestations remain to be accounted for. Its derelopment as to time and potency is dependent upon certain spheric conditions, and the different susceptibility of races and individuals. Prof. Röll states that for many years the cattle plague hung upon the Polish frontier without entering Austria, until certain other diseases appeared among cattle and men, and then it became a general pestilence. As far as the historical records of other desolations among the lower orders of creation bear reliable testimony, this view is corroborated. It is also confirmed by the cyclical periods which, as is claimed, mark the devastation of this plague in its native steppes.

Again, it has been too frequently observed to admit of denial, that its fatality has been less marked with those cattle, of whom it may be said that the Pest is to their manor born, than among other races. Devons taken to Russia, after thriving admirably for a time, when brought within range of this distemper, yielded under its most frightful manifestations, and in droves.

* See Aitken's Science of Medicine, Vol. 1, p. 200. 
So among the cattle first seen by Prof. Simonds in quarantine at Kamienica, a neighborhood which had then been free from the plague for eleven years, were four steppe oxen, three of which recovered, one having never sickened; while of the native cattle, with whom these and six other steppe oxen were housed at this and an adjoining village, in sheds belonging to the same proprietor; thirty-one, being the whole herd in one place, died within nineteen days after the steppe oxen arrived: and of the other lot, which included the four first mentioned, twenty-eight in all; thirteen died and eleven were slaughtered.*

The power of contagion being limited or increased by the operation of certain conditions in nature which it may be difficult to define, or by varying developments of constitutional vigor (which may be equally vague in statement, though undeniable in fact) we are prepared to understand why in different climates and with different races of cattle, the symptoms and the morbid anatomy may seem doubtful or conflicting in particulars, and yet center in a common type, to mark the specific action of a specific virus.

Thus, where from any predisposing or dominant cause the force of the disease in its early incubation is expended on the membranes investing the brain (cerebellum, principally) or the spinal cord, we should expect the twitchings, nervous rigors and fury, and the consequent effusions in those regions observed in Hungary and Galicia by Egan and Simonds.

Where, again, as in the few cases referred to by Prof. Gamgee, the concentrated action of the poison is seen in the trachea and its bronchial branches, we could hardly imagine relief from this obstruction of the respiratory functions in time for any reaction on the intestinal canal. And where, lastly, the grand onslaught of the distemper was in the latter direction, we might reasonably look for lesions so much more distinctly pronounced, that what seemed only aphthous appearances in other cases might in these be imagined to be

\footnotetext{
* Perhaps a more marked case is given by Dr. WEBER, as occurring at Kamionka Woloska (Galicia), where 101 oxen, which were brought from Bessarabia, developed the contagion in the farmsteads in the village, so that 158 animals were attacked, of which 93 died; only one of the imported oxen euffered.
} 
ulcerations; and glands which, in a vast majority of cases, seemed untouched, might give sigus of purulent destruction. Making every reasonable allowance for different manifestations in cases such as those we have given from Jessen, where the disease was induced by inoculation; or for a predisposing tendency to the typhoid state, muco-enteritis, pleuropneumonia and the like; we are still able to group together all the seemingly conflicting indications, and define the general scope of this disease by its congestion of the mucous tissues, more or less diffused, and that congestion as mainly destructive of the epithelial covering of these tissues.

In the incubative stage, marked changes manifest themselves in the condition of the blood, and the commencement of feverish action. We have seen (p.22), that when the virus has once been absorbed, it permeates within a few hours every portion of the blood, rendering each drop a fresh medium for inoculating the healthy animal with the Pest. It would almost seem credible, that the poison is a vital germ, feeding upon the germ cells of the blood, appropriating its serous and driving off its saline constituents; and propagating its kind until the red corpuscles become amorphous and shrivelled (see PI. x, fig. 3). Gamgee, however, did not in his microscopic investigations, observe the serrated condition of the corpuscles noticed by Dr. Smart. In some cases he found "a great excess of white corpuscles, and in others delicate needle-shaped crystals, which are probably hæmato-crystalline,* form in the blood after this fluid has been drawn from the body." $\dagger$ (Pl. x, figs. 4, 5 and 6).

The moment that the normal balance in the blood constituents is disturbed, feverish action, which escapes notice by ordinary means of observation, is truly established. Gam-

* These crystals may be regarded as evidence mostly of the decomposition which the blood undergoes, and of abnormal chemical combinations of its saline constituunts. They resemble closely in form and appearance those recently obtained by WormLEY in the methods proposed by him for the discovery of poisons when found in human tissues in minute quantities. For these correspondences, see his "Micro-chemistry of Poisons, Pl. J, figs. 1, 2 and 3, where the forms

of crystalline products are given, as revealed by the microscope magnifying, from 80 to 225 diameters; the 1-250 gr. of chloride of potash having been tested by a minute trace of tart. soda; $1-100$ gr. potash as nitrate, treated with bichloride of platinum in one case, and tartaric acid in the other, and in Pl. IV, fig, 4. where the crystals of tart-emet. from a hot super-saturated solution without any re-agent, are magnified 80 times; and in other plates for the needle-pointed crystals.

+ See Cattle Plague, p. 64. 
gee, reviving the use of the thermometer, * first proposed in 1754 by De Haen, a celebrated Clinical teacher in the Hospital of Vienna, as the best aid in the diagnosis of pyrexia; instituted a series of remarkable experiments in the use of one of Casella's registering thermometers. He discovered an elevation of temperature in the earliest stage of the disease, varying from one to four degrees, Fahr., "preceding the acceleration of the pulse and every other symptom."

He inserted the bulb and about two inches of the stem of the thermometer within the vagina or rectum, and kept it in place a couple of minutes. To prevent error in the use of the instrument, he adopted the precaution, between each observation, of dipping it in water $\left(90^{\circ}\right.$ Fahr.) and used a few drops of Candy's disinfecting fluid for cleansing purposes. He found the temperature of these parts, when the animals were in a healthy condition, and the females not in the period of cestrum or sexual excitement, varying from $100^{\circ}$ to $101^{\circ}$, rising occasionally to $102^{\circ}$, and perchance, in a hot day or when driven from their pastures, "one or twotenths more" than usual. He visited, on the 17th of November, a stock of Ayrshires, at Corehouse, near Lanark, where a cow seized on the 9th had died on the 14th, a second case occurred on the 15th, a third on the 16th; and where, on cursory examination, he found six more ill. On the 18th he examined forty-two cows with a thermometer dipped in water $100^{\circ}$ Fahr., before each observation, inserting the instrument in the rectum up to that portion of the stem marked $80^{\circ}$. Of this entire lot, one or two had slight discharge from the eyes; one gave more marked indications in rapid respiration, one in urine of dark brown color, and a half dozen in scanty supply of milk. The rest were eating and ruminating, giving full quantity of milk, \&c.; none had diarrhœa. "The temperature was recorded at $102^{\circ}$ in one case ; at $104^{\circ}, 1$ - in another; at $104^{\circ}, 8-$ in two ; from $105^{\circ}$ to $106^{\circ}$ in ten; from $106^{\circ}$ to $107^{\circ}$ in seventeen; in the rest from $107^{\circ}$ to $107^{\circ}, 8-$. Twenty-five succumbed by the $22 \mathrm{~d}$ inst., and only five were living on the 25th, "in spite of careful nursing and the best 
medical treatment." Gamgee observed variations in the frequency of the pulse and temperature during the course of the disease, as Jessen did between the pulse and respirations; also a sudden lowering of temperature with increased frequency of pulse from 120 uprvards, a few hours before death. A gradual decrease of temperature until it reaches the normal standard prognosticates recovery.*

It seems a matter of regret that Dr. Gamgee, who has evinced in all his researches, skill and learning of the highest order, should have felt such utter hopelessness of the efficacy of remedial treatment in posse if not in esse. Otherwise we think he might have gained another laurel to his veterinary prowess. Nothing seems to be clearer than this proposition, that if the pest is to be properly regarded as a zymotic disease whether developing its fatal germs in the blood, on and in which they feed and multiply; or by an action analogous to ferment, or that chemico-physiological action which Liebig has denominated catalysis, producing abnormal changes in the circulating medium; before the disintegration of structures (the principal test of infection in disease) is manifested: or to take a more palpable illustration, to be viewed as poison from a venomous bite, which must be instantly neutralized, or whose absorption and propagation must be arrested without loss of time that life may be saved; the treatment must be antidotal or destructive of the foreign germ-life, and attempted before the processes of decomposition in the blood have gained much headray. And to this end the use of the thermometer as afresh proposed by Gamgee is indispensible. But it is unnecessary further to foreshadow the use to which we propose to put this method in the treatment we may recommend.

The microscopic researches of Dr. Brauell, of Dorpat, made in Sonthern Russia in 1861, extend, in some respects, the pathological views to be derived from the investigation of lesions heretofore given on the authority of Smart and others. He observed in the glands of the mouth and pharynx, new formations of cells simultaneously with (probably 
before) the detachment of the epithelium, and a more exuberant mass of such cells in the glands of the fourth stomach, and small intestines, followed by the hæmorrhagic erosions, or so-called superficial ulcers. In the solitary glands of the small intestines, in a less marked form than in the Peyer glands, the cell development goes on, attended by the "socalled plastic exudations and croupous deposits from the follicles, the vesicular eruptions and the nlcers" of the glands described by authors; all owing their origin to the nature of the cell changes. In the mucous glands of the membrane lining the respiratory passages, there is cell multiplication, associated with the extraordinary development of the elements of connective tissue, whereby the detached masses are accounted for. The separation of these is the end of the process.

Brauell affirms that there are never and nowhere exudations of lymph. He also notices differential manifestations as between the natural Rinderpest and that from inoculation.

"The nodules which appear on the skin owe their origin to the modified development of the epidermic cells on small localized spots, from which the deeper sooner or later become detached and result in the dispersion of the nodules. The most superficial layer of the skin, wherever it is covered by each nodule, sometimes suffers molecular change."

Perhaps the most important observation made by him in inoculated cases, is that, in the lateral ventricles of the brain, and particularly under the arachnoid over the cerebrum, exudation is met with.*

It may not be easy of comprehension how the imbibition of the virus through the organs of the skin, should produce such marked cerebral disturbances, not consequent upon its inhalation by the lungs, or its absorption by the mucous surfaces of the mouth, nose, \&c. When this statement of Dr. Brauell is connected with the general testimony of all observers, that in a multitude of cases where the pest has been induced by the seton or puncture, the lesions are more extensive and serious ; it may lead us, as a teaching of practical 
sagacity, not only to avoid inoculation as a method of cure, and to guard the entire dermic structure of subjects exposed to contagion by cleansing and care; but in some measure, at least, to adapt their treatment, when ill, to the consideration, however conjectural it may seem, that the secernent function of the skin is the most important instrumentality by which the poison may be counteracted or eliminated.

Lest we may seem to speak slightly of the inoculative method, which we cannot recommend as a therapeutic or preventive agent, we will add a brief sketch of the efforts made to test it as an agency of cure. The seeming success which resulted from inoculation for small-pox in the human subject, led to great hopes of the efficiency of a similar use of the poison of the distempers of the last century. England, which was prompt through Dobson, in 1754, and Dr. Flemynge, in 1755, publicly to approve the method, exhibited the same decision in proclaiming it a failure. The first tabulated series of experiments, were made under the direction of the famous Camper, on a small island on the southrest of Zeeland, of which accounts are preserved for three years prior to 1773 . In 1770 , sixty-one animals were inoculated, by threads charged with the virus and passed beneath the skin, of which eighteen recovered and forty-two died; one not having sickened. Of those treated in the next two years, a fraction of over onethird did not catch the contagion, and the number of deaths reported was three.

Gamgee, in his review of this subject, deems the experiments of 1770 most reliable, as he found in the accounts for the tryo succeeding years, records* " of long periods of incubation, and constant recovery, quite incompatible with our existing knowledge of the disease."

The success of Dr. Barrasch, who inoculated twenty-five hundred cattle in Hungary, of which only seventy-five died, and the serious losses of Pussia, amounting, as was estimated, to ten millions of roubles annually, led to the appointment of a commission with the view of extirpating the pest

* These may be regarded as additional evidence that the distemper of that period was not the Rinderpest. 
among the steppe oxen and on their native pastures. Jessen and Unterberger conducted the experiments, which were first tried with the virus taken from a subject who had taken the pest naturally; then from one so inoculated, making the first remove, and so on until they obtained and used the virus in the tenth remove. With great alternations of large percentages of recoveries and failures; with instances of immunity in the midst of surrounding pestilence, which inoculation, wherever tried, had not stayed or much ameliorated; with a tabulated record, though on a small scale of 50 per cent loss with matter in the first and ninth remove, $66_{3}^{2}$ per cent with that in the third remove, and no loss whatever with that of the second, fourth, fifth, sixth, seventh, eighth and tenth: it is difficult to discover any method for the arrangement of such statistics and the evolvement of any scientific formula.

The impression that steppe cattle might be advantageously fortified in this way, was modified by the observation that inoculation must be accompanied by mild and uniform weather, and followed up by careful nursing.

The recent trial on steppe animals at Karlowka, in 1864, in which of three hundred and forty-nine inoculated animals, the sickness consequent upon the operation was so remarkably intense, that only ten were declared to be "not severely affected," accompanied by the fact that there are in the steppe regions of Southern Russia herds among which the pest has not prevailed in ten, twenty, and in one case forty years, give great force to the practical question put by Prof. Unterberger, whether such experiences do not prove how disadvantageous under certain circumstances protective inoculation may be even in the steppe regions.

Jessen, whose loss in the treatment by inoculation of the stock of the Grand Duchess Helena Paulowna, has been reported at ninety per cent, does not pronounce so decidedly against the method as his colleague, although he admits great losses by inoculation with fresh matter. He sums up his report with the following conclusions: 
1. Animals having had the Rinderpest three to four years previously, cannot be infected again.

2-3. Vaccination in the first generation (taken from diseased animals), on sound cattle, after they have passed through the disease, frees them from further infection.

4. The loss by first generation is too large to recommend itself.

5. The vaccine can be mitigated by second generation, producing only a slight affection.

6. This slight affection is also a preservative against new infection.

7. Vaccination in older animals often fails, probably because they have had it.

8. Vaccination sometimes does not take, and yet they take the plague naturally afterwards.

9. Some cattle show no symptoms of disease after vaccination, and yet they seem to be proof against infection.

10. Well preserved vaccine keeps good for a few days, even in hot summer.

11. It is yet to be discovered on which day of the disease to take the virus, to get its full power.

12. The tears, even diluted with distilled water, remain infectious (these and the nasal mucus having been used for vaccination).

To these may be added other conclusions arrived at by Gamgee, who obtained 40 per cent of recoveries in experiments by inoculation in seventy-five cases, and who, besides refusing to recommend this method as a preventive; noticing the aggravations resulting from cold, wet and exposure; declaring the means adopted for cultivating or modifying the virus unsatisfactory and unreliable; and any liquid from the body of a sick animal capable of becoming a medium for inoculation, adds :

1. The cutaneous eruption not constant in natural Rinderpest is usually seen in inoculated animals.

2. Sheep can be inoculated from cattle, and again cattle from sheep, without modifying the virulence of the virus.

3. Glycerine modifies and then destroys the virus, as in the case of pleuro-pneumonia (typhoid?)

4. Animals escaping after inoculation, without indicating the characteristic symptoms, are not protected from future attacks.

5. The produce from progeny of animals which have had the Rinderpest, is as susceptible to an attack as any other.* 
The science of Pathology which has made such mighty strides during the last half century, has yet to search out the nature and perchance figure the form of those poisonous germs which develop zymotic disease; to give them distinctiveness by due classification, and to separate or identify their action on and porver over the animal economy, with those of the well known poisons of the mineral or vegetable world, especially, perhaps, of the sporules of the various tribes of fungi. The work though vast, is not beyond present hope. It has now all the preparation needed to justify the loftiest claim, and maintain the highest attitude of expectancy. The microscope which haś depictured and classified the various forms of spermatozoids constituting the generative power of the divers species of the animal kingdom; which has counted the number of the dust sporules* which feed upon vegetable products useful to man and beast, and which, as we have seen, reveals to the eye the various shapes of blood corpuscles when invaded by various parasites of variant diseases, may yet so group its subtle lenses and direct their ken into such unexplored hiding places, and triumphantly parade the tiniest instruments of torture which the common enemy of all things living employs.t While we await with becoming patience, such wondrous revelations, we are not without the analogies of nature in disease to assist and advance our investigations.

Dr. Salisbury, of Ohio, in the presence of an alarming epidemic of scarlatina, inoculated himself and family with the smut of the Indian corn, produced an eruption and ferer similar to that of the prevailing distemper, and effectually warded off the contagion. Had he gone a step further, and ingrafted the poisonous fluid developed by this coniomycete upon a healthy structure, he would have identified or shown

\footnotetext{
* The sporule of the Uredo segetum, one of the most minute of the coniomycetous fungi which attack gramineous plants, has been decyphered as equal in size to $1-7,860,000$ th part of an $i n c h$ square.

+ The most serious difficulty in the present extension of microscopic vision, which has revealed the multiplication of bacteria and low animal and vegetable organisms by powers estimated at 3,000 diameters, does not seem to lie in a further extension of micrometric power, but in the transparency of these infinitesimal germs; a difficulty which may soon be remedied by the ingenious adaptations of enthusiastic observers.
} 
the disparate action of the inoculate and natural forms of the scarlet infection. We know that a pregnant heifer may, by ergotized grain, or grasses infested with fungoid growth, suddenly abort, and unless removed from her associates of the byre, the poisonous exudations from the vulva will produce like disaster upon the entire pregnant stable; leaving in the future for all such aborting from the contagious matter, less chance of carrying their next foetal burdens to full development, than in the case of the one which miscarried under the action of the vegetable poison. So that there may be in nature a general law by which certain poisons, vegetable as well as mineral, may become potentized in their victims, and taking to themselves a more deadly virus, spread the most virulent infection. Strange as the announcement of such a doctrine, mysterious as the conversion or coöperation of such agencies may be; they do not afford so great a puzzle to the understanding, as that by which we are called upon to account for the first developed case of any contagion, whether of small pox or cholera in the human race, or of any of the deadly murrains in the bovine.

We state the difficulty which is experienced in the scientific world, without insisting upon any theory, conjectural or imaginary. It is enough to dispel existing delusions which trace the sources of contagion solely to malarious vapors or atmospherical degenerations, or again, to active animal or vegetable parasites, or to any other source than that of poisonous vitalized germs.

It is impossible to deny the vitality of pus corpuscles in ophthalmia, in the public nurseries or hospitals provided for children; or of their minute offsets (revealed with wondrous power of subdivision under the microscope), as they are transported through the air, remain dormant on clothes, communicated by towels, until they reach the conjunctiva, prepared, in under-tone or by morbid process, for the supply of nutrient matter for these putrid germs. The statistics of surgical cases in our armies during the late war confirm the observations made elsewhere, that pus globules invade the 
system of one recovering from the primary effects of wounds or amputation, and carry him off with pyæmia.

Like observations as to syphilitic or gonorrhœeal pus, the poisonous matter of puerperal fever, or the more familiar illustration of vaccine lymph, give confirmation suited to the general mind of the theoretic views we have advanced, and which are so thoroughly supported by the researches of Prof. Boeck.

But the nature of this exotic germ-life which, when introduced into the vital economy, is the harbinger of pestilence, is not to be explained by (as the morbid germs themselves are not to be confounded with) the animalculæ observed in the dying organism. The bacteria which have been revealed by the microscope, prove only the previous destruction of tissue and its advanced state of decomposition; such relation being reversed, however, in the case of parasitical growths.

Should we pass over, although not precisely relevant in this connection, another condition, under which this morbid germ-life may be sustained, we should be guilty of a neglect which might result in great practical injury.

It may not be easy to prove that the germ cells of the Pest or other infectious disease can multiply in excrementitious matter as in the living body. But it would be unsafe to consider the exuviæ when kept moist and of a moderate degree of heat,* as incapable of furnishing the media for such propagation, unless we had reason to conclude that the matters thrown off by the bowels or otherwise, contained none of the nutrient matter, on which these germs of pestilence might feed, or the enveloping substances in which they might lie dormant and be preserved. For all practical purposes, and as the first law of hygiene applicable to such cases, all matters thrown off from the organism that is contending. with the Pest, should be regarded as a fresh nidus of infection; unless thoroughly disinfected by chlorine, carbolic or sulphurous acids or the like.

\footnotetext{
* Prof. HeRTwig stated at the First International Veterinary Congress, a case where dung of diseased animals, even after it had lain in a frozen state for four weeks, was known to have transmitted infection. (Gamgee's Cattle Plague, p. 479.) Even the water in which Rinderpest flesh (whether previously salted or not) has been washed, if drank by cattle otherwise untainted, will produce an outbreak; as will the hawking about of the flesh. (Ib., p. 36.)
} 
Here it may be desirable to insist upon the necessity of a very careful diagnosis. This should be made at the earliest possible opportunity of observation, and then with all the precision which scientific research demands. We have already observed the great importance of thermometric observations as testing the commencement of feverish action at a time anterior to its sensible perception by ordinary methods. Where the means of applying this test are not afforded, it will be proper to observe the condition of the papillæ of the buccal cavity (and where easily done of the Schneiderian membrane) before epithelial desquamation has taken place. These will show to the eye (more thoroughly if aided with an ordinary lens), enlargement if not engorgement, in the uprising of small round nodules (seldom according to Jessen larger than a millet seed), with marked redness beginning at the apex. The papillæ are still covered with epithelium, beneath which, after a little while, a yellowish or yellowish gray fluid can be seen. Within twenty-four hours, the investing membrane breaks away, and if the neighboring papillæ are not then affected, the minute orifice may soon be hidden and heal; but if they are, their cicatrices become confluent, the epithelium is rolled off in masses, the scarlet redness of the subjacent mucous membrane is quite apparent, with irregular marginal outline. As others in a widening circle become affected, redden, and desquamate towards the outer rim, the central portion thus run over, loses its ruby tinge, and gradually assumes an aphthous or gray appearance, mistaken by the ignorant for an ulcer.

The philosophy of this action in these minute nodules can only be fully revealed through microscopic teachings, which show that each papilla and the villi (fringe-like hairs which emanate from it and give to all mucous membranes, more especially in the smaller bowels, a velvety appearance), are furnished with a complete vascular plexus (arterial mainly in the villi*); and that through such exceedingly delicate network the diseased blood corpuscles are borne, and are thus enabled to expend their peculiarly destructive action upon 
the speck-like expanse of epithelium which invests the external surface of this miniature circulation.

Whether these processes of congestion and desquamation in the Pest are precisely the same in epizoötic aphtha or eczema, is not probable, if analogy be sought with the observed action of the latter disease in the fourth stomach, (see p. 40,) where hæmorrhagic or apoplectic effusion and erosion; sometimes attended or followed by melanotic deposits, seem to take the place of the simpler lesions which result from pure capillary congestion in the former malady. No careful inquisition has, as far as we can learn, been as yet instituted to demonstrate or disprove in the membranes lining the mouth and pharynx, the difference of action just indicated.

The appearance to the eye of these lesions in the mouth and the common phenomena of smacking the lips, of aphthous eruption and salivary discharge, are said to be the same in both affections; and to distinguish between the two, resort is had in order to identify the eczema, to the morbid condition of the cleft of the lame foot, the papulæ on the teats and the symptoms of congestion and inflammation of the udder.*

The unwary might also easily be deceived by the redness of the vagina which exists in the case of those that have recently calved, or aborted after long gestation, or who arrive at the period of sexual excitement; if looking only at the arterial color of the parts to which the unusual flow of blood is directed in these processes of nature, they should imagine a general papillary congestion to have taken place, not to be resolved and fade away without epithelial disorganization.

Nay, it is further said, that in those who are ruminating in pastures and daily yielding a full flow of milk, a like rubescent demonstration not unfrequently takes place, so that the mere indications of color may be fallacious. Unless then, the sanguineous tinge of the vulva be seen on the near approach or in immediate presence of the Epizoötic Pest, it would be 
no sure sign. If the eye, unaided, could not detect engorged or discharging papillæ, a lens should be brought into requisition, before the true pathological sign shonld be anticipated, the destruction and peeling off of the epithelium.

We will briefly notice other sources of illusion. The discharge from the eyes and nose occurs in many affections, fatal or transient; but in the Pest, it soon becomes glairy and changes to what is termed a turbid secretion. Yet it would be absurd, in view of the pathology of the murrains of the last century we have so fully detailed; to confound this discharge with the purulent one, resulting from a phlegmonic or ulcerous condition of the system ; neither should the prediction be too easily made, that the initial watery flow, however copious, would readily be changed to one of more significant consistence or color. Gamgee gives an aptillustration* of this, from cases occurring at his establishment in Edinburgh, during a series of inoculation experiments, conducted by a commission of the French government. Great care was exercised in the purchase of animals free from the distemper, in order that such experiments might be wholly reliable.

Three animals were purchased one day, receiving the guaranty of the seller as being free from any contamination with the prevailing epidemic. They had each, however, the glairy discharge from eyes and nose, but did not develop any further evidences of ailment. It appeared, on inquiry, that they had been exposed to easterly winds in an ill-sheltered field, and the discharge was only diagnostic of a slight catarrh.

Greater complication arises mainly from discrepant authorities, perchance from inherent causes, as to the proper diagnostic position of the lung and skin symptoms.

Smart affirms that "there is no cough or lung symptoms in the pure and uncomplicated examples of the disease," but limits the respiratory changes to a prolonged outbreath (p. 23). Egan, Gooch and Gamgee notice a short, dry or husky cough, with difficulty in breathing (Gooch), attended by more noise in expiration than in pleuro-pneumonia (p. 24). These may, at the commencement of the attack, be regarded as merely 
nervous demonstrations, pointing to cerebellar or spinal irritation. But if they do not shortly subside, if with the cough the head is kept depressed and protruded, and a spasmodic action of the nostrils and flanks sets in, serious pulmonary paralytic action, if not lesion, must be apprehended. Gamgee, combatting the observations and authority of Smart, insists that emplyysema occurred in many cases under his eye, usually beginning in the anterior lobes; the modus operandi of the peculiar respiration induced, being explained by Dr. Weber, who says that the anterior intercostal spaces become somerhat fixed, while the posterior true ribs are raised with an effort and sink rapidly.* The signs which attend this forceful outbreath on percussion have been given (p. 41 and note). Auscultation reveals râles of various pitches, either accompanying the vesicular murmur or superseding it. The sounds of the heart are inaudible and impulse imperceptible on the left side.* But these furnish indications of a fatal resolution, and are not to be regarded as among the earlier symptoms.

The cutaneous eruption which frequently occurs on the neck, back and teats, justifies a favorable prognosis, if occurring in the earlier stages; but if, instead of drying up and scaling off, the papules remain or multiply, and the color of the skin becomes a dirty yellow, desquamation of the epidermis becoming general, and the surface of the neck and of the integuments extending over the crops becomes greasy from a sebaceous secretion (see p. 39 and note, \&c.), then coma and death may be speedily anticipated. In the first issue the relief that is afforded to the perspiratory energies, without serious impairment of the subcuticular structures, is communicated to the nervous centres, and a rallying of the sustaining power is soon manifest. But if, as in the second issue, the destruction of the epithelial cells of the skin proceeds far enough to involve to any great extent the nervous periphery; the ganglia, cord and brain labor with the barest possibility of recuperation of energy.

* Gamgee's Cattle Plague, p. 49. 
It is in view of the preservation of this balance of nervous power in struggling nature, or, if more precisely phrased, of the salient energies of the filamentous nervous expanse reticulating about every gland and perspiratory orifice of the skin; that we may find a clue to the mystery in which we were content for the time being to remain, when we did not essay in a previous connectiou (see p. 66) to explain the cerebral disturbances, produced by the burrowing of the inoculative virus throughout the epidermic cells and their mucous substrata. Nor can wo find timo to dwoll upon this problem in physiology, or deduce any corollary, except as presage of the pratctical use to which wo may apply it in the treatment recommended.

The nature of these eruptions on the skin we have seen not to be resicular. Wherever they have appeared to be partly umbilical, the Pest is complicated with ordinary cow pox; Gamgee giving the assurance that he had never seen an eruption of this description where the previous existence of the vaccine pustule could be doubted. MLoreover, this eruption is not to be mistaken for the macula or petechix which are met with in typhus of the human subject; the former of which aro slightly elevated spots of a dusky pinkish red color, somewhat like the stains of mulberry juice, fading under pressure, but changing sometimes to the nature of the latter, which are of a dusky crimson or purple color, numerous and closely compacted, unaffected by pressure. Neither these eruptions, the appearance of the tongue, the pyrexic period, the general absence of capillary congestion in the bowels, the red serosity found in almost every serous cavity, the deep dusky red hue of every structure in contact with the blood, in which the salts are increased instead of being diminished; the absence of bilo acids and the presence of tyrosine and leucine (p. 3s); nor the absence of exhausting diarrhoa; the deep inspiration followed by short respirations in rapid succession; the wasting of the involuntary muscles; the softening of the heart and the atrophy of the brain which occur in typhus, furnish any common basis from which we may view the Pest as its counterpart; nor for the justifica- 
tion of the synonym given to it on the Continent, "Typhus boum contagiosus," or "Le typhus contagieux des bêtes bovines" of the French school.

Time will not permit us to notice all those marked symptoms and lesions of typhoid fever (in themselves very numerous and variable) which are not to be found in the vast majority of cases in the Pest. We may briefly specify the greater redness oluserved on the surface of the mucous membrane in the latter disease (compare the capillary congestion of the small bowels, P. IV. fig. I) or the engorged spaces between the rugre of the creum (Pl. VIII fig. I), with Pls. CXII, CXIII, CXIV, of Lebert,* where the mucous surfaces of the smaller bowels do not show congestion beyond erythema; this faint rosy or pinkish redness being a characteristic of typhoid exanthemata in the smaller bowels, as confirmed by the previous exposition of Cruveilhier (Liv. 7 Pls.1-3). This congestion quite limited to the ileum; the deepening erythema investing the solitary glands, leaving the adjacent tissue almost anxmic; the ulceration of these glands, as also of those clustered in groups, (Peyer's patches or plates) starting from within the mucous bed and inducing frequently gangrene, not only opening out upon the inner surface, but perforating sometimes the peritoneal coat; the invariable enlargement of the mesenteric glands and of the spleen; together with infiltration and consequent solidification of the lungs, previously adverted to, (p. 4l) make a more marked departure from the type of the Pest in typhoid than in typhus fever. Yet, however, it must be constantly borne in mind that vital depression, which is the leading characteristic of what is commonly called the typhoid state in disease, is manifest in the Pest from the first stages until convalescence is established.

The exanthematous process which shows itself, as we have seen in the agminated and solitary glands, producing slight rubescence, then injection, tumidity and enlargement, ordinates the general progress of what is commonly described as follicular growth. When the enlargement has reached its 
acme two variations occur; in diminished or suppressed secretions from the glauds or follicles, or in its becoming more abundant; in which last case are manifested alternative methods of disposing of the fluid secreted; in its either being poured out in the membrane very freely, or in being retained in the cavity of the follicle, becoming inspissated and undergoing various other secondary changes.* The progressive stages of exanthematous action thus defined, give euabling facility to explain the seemingly discrepant statements given by different observer's as to the manifestations of the Pest on the intestinal canal ; in the apparently opposite show of diarrhoic discharges, unmixed with muens, as in the majority of cases (see p. 26, \&c.,) observed by Smart and others; in more acute cases tinged with blood, becoming dysenteric in appearance, \&c.; in others partaking of the character of rice water stools, and, as in the vaccinated cases, leaving traces of purulent destruction. Yet we are not, by reason of such occasional manifestations, to misapprehend the general nature of this Pest for muco-enteritis or dysentery, as the principal seat of such lesions is in the tubular glands (follicles of Lieberkiihn) of the large intestines.

The occasional occurrence of rice-water stools intimates that in the acutest form of the catarrhal inflammation of the mucous coat of the intestinal canal, we have some approach to the rapid and fatal exhanstion of cholera; this leads us to dwell briefly upon the lesions of the latter disease, which bear not only to the ordinary observer, but to the skillful eye of the pathological anatomist, some very singular resemblances. During the period of transudation, we find the same separation of the water and salts of the intercellular fluid of the blood through the mucous membrane of the intestinal canal, resulting in the same colliquative discharges per anum, and the inspissation of the blood itself, which becomes dark and tarry (p. 3s). The hypertrophied muscles, after death, show on section the same dark purple red color, with a shade of blue or violet (p. 39), although, according to Rókitansky, this peculiar iridescence is shown in other affections.t

* Rókitansky's Patholog. Anat., Vol. III, p. 56.

† Typhus, acute convulsions, scurvy, cyanosis, and in persons suffocated. Vol. III, p. 304. 
We notice in the pest less marked absence of external heat, comparatively little tendency to the suspension of the decarbonizing function of the lung-cells; and while in the intestinal canal the follicular structure is equally involved in both maladies, though in a different manner, and except in the rare cases seen in Pest, with discharges of a totally different character; the congestive process in its earlier stages suggests its rationale as well as that of these variations.

We need not reiterate that we do not seek to build up any theory of identity or amalogy except that which is necessitated by the common zymotic character which pervades all pestilences. Having given the few points in which their orbital paths fiud conjunction, we still desire as far as practicable within the narrow compass of a General Report to project the direction of their courses in departure. We shall collate two descriptions of such variations from Perigoff, whose recondite observations on cholera accompanied by remarkable illustrations of lesions (also of microscopic researches) are to be found in his Anatomie Pathologique, \&c. Premising that in the congestive stages of this disease, we are met with deeper blood-tinting than in any of the affections of the human frame, we have before referred to ; we find it necessary to show other manifestations in these stages in the two diseases, between which it is now proposed to mark tho difference. Perigoff gives in Pl. II, fig. 3, (in a case of death in typhoid stage), the sanguineous coloring of membrane less deeply tinged than others given by him, which on cursory examination would seem to be identical with that described by Smart (p. 32 and Pl. III). Sangtineous effusion upon the mucous membrane in dots occurs also in simple cholera; and when multiplied in an aggravated case presents an appearance of dark ecchymosis, bordering upon what is elsewhere described by Perigoff, as the incipient stage of mortification. His Pl. V, A, fig. 3, gives a view of the sigmoid flexure of the colon in the transition from the algid to the typhoid stage which bears a closer resemblance to the inoculated cases in Pls. VI and VII (pp. 28 and 30). You can easily see in all of Smart's drawings 
that the scarlet tinge we are noticing is the result only of the congestion of the minute and intricate network of the capillaries, the attendant sign of this vascularity being always present; while in these plates of Perigoff, this gorging of the arterial plexus is not apparent, the blood seems rather to be effused, its particles impaired and aggregating by some molecular attraction (not of course as in the normal adhesion of the rouleaux); in short, in the first plate referred to, a bright red, in the second the deep crimson tinge quite approximating to a dark red ecchymosis. The mucous membrane in both plagues is peeled off or abraded; but in the choleraic cases, by a different process, and by a movement starting at a deeper point in the mucous tissue than in most cases of the Pest, being covered with mucosity as well as with detached epithelium; and when these are removed, presenting not simply the spots of membrane run over by vascular engorgement aud left seemingly aphthous; but depressed eschars in the surrounding membrane which is puffed up and anæmic.*

When we follow Perigoff to his Microscopic Researches in cholera, we find his tracings of engorgement of the solitary glands and Peyer's plates, and their transformations ; of capillary congestion of the villi (villosities of the continental schools), as well as the deeper burrowings in the mucous coat; confirming to a large extent the observations previously made, and giring the starting point, of congestion, infiltration and exudation in most if not all zymotics. We must

\footnotetext{
For confirmation of these and more singular indications and processes of abnormal action and illustrations of its rationale, see pl. V. A., fig. 1, where Brunner's glands decply inflamed, surrounded by injection are ready to ulcerate, summits yellow and containing pus; the membrane (duodenum) swollen and presenting traces of dysenteric exudation; also fig. 2 in same plate, where the mucous membrane completely hyperæmical, is covered by thick adhereut greenish yellow effusion, composed of the debris of plastic globules, epithelial cells, \&c. Pl.VIII. gives section of the colon of one who had suffered from chronic diarrhœa when cholera supervened, and shows the aphthous appearance resulting from the former affection, with hyperemia and sanguineous effusion in the intervening spaces from the latter. Ulcerations of Peyer's plates were seen but three times and then in the cholero-typhoide period. Comp. pl. IX, fig. 5 \& 6 . Pl. XII. gives section of stomach in diptheritic cholera, the mucous membrane being hyperæmic, and covered in places by patches of adherent gray exudation, these surrounded by a grey areola; when the patches are scraped off, the subjacent membrane very hyperæmical. (Comp. pl, VI., fig. 2.) In the case where the stomach was covered more or less with mushrooms (eaten in Lent by a Russian), the membrane showed a swollen appearancee, being described as in "un état catarrhal aigu"hyperæmic with punctated injection.
} 
refer the curious in such details to the subjoined translation* of the text expository of these minute portraitures. The deficiency of its proper salts in Rinderpest blood has been previously noticed (p. 35). In the inquiries prosecuted by Dr. A. Gamgee to ascertain the changes which this and other fluids underwent in the earlier and progressive stages of the disease; no attempt was made to ascertain the percentage

* Pathological alterations of the mucous membrane of intestines, enlarged 50 to 400 times, as given by Perigoff in explanation of his Plate XVI.

Fig. 1. Peyer's plates (glands) of ileum, tumefied by simple choleraic processes, enlarged eight times; mucous membrane detached, muscular covering naked. Plate of Peyer looked like a bunch of grapes, composed of semi-transparent vesicles reposing upon the mucous membrane, and covered by villosities. When magnified, the epithelial cells, their nuclei and globules, resemble somewhat the microscopic elements of recent plastic exudations.

Figs. 6-9. Isolated follicles of mucous membrane represented under aspect of vesicles, a little swelled, as in chronic maladies of mucous membrane, and surrounded by a bloody areola.

Fig. 7. Shows enlarged by microscope nearly 30 times, little fly-spots (mouchetures), round and blackened; met on mucous membraue, near the isolated crypts in the typhoid stage of cholera and chronic diarrhoa, shown under the form of an areola, composed of the vessels of the sub-mucous coat; at circumference and center of areola, sometimes numerous blackened points or fly spots, being the ruins of bloody globules escaped from the vessels and dispersed in the mucous tissue. Sulphate of iron enters into their composition, as is proved by its solubility in Hydro-chloric acid. The contents of these crypts resemble epithelial cells, and their nuclei; more than pyoid and plastic globules.

Fig. 8. Isolated follicles, tumefled, enlarged 10 times and covered with villosities, which are swelled and engorged with blood.

Figs. 10-11. Superficial layer of eschars in large intestines; brown appearance depends upon agglomeration by matters of decomposed bloody globules, under aspect of brown spots, (containing sulph. iron) sometimes deep purple. Numerous crystals on surface of scars are the double salts of ammoniated phosphate of magnesium. Same microscopic elements seen in dysenteric exudations accompanying cholera.

Figs. 13-21. Villosities of mucous membrane, covered with cylindrical epithelium, seen sometimes in the algid (cold) period, dissolved in choleraic liquid, macerated and swollen; and epithelial envelope detached and exfoliated. A light touch detaches it completely; under the microscope looks like the down of the dandelion. The denuded villosities show sometimes a strong hyperæmic state, the vascular net-work is completely injected; or, in places, sometimes an anxemic state; the empty vessels showing across the pulp of the villosities, covered again in some places by nuclei of detached epithelium-the black fly spot and globules of blood decomposed and coming out of the vessels on the pulp of the villosities; and the principal coloring that of bile. Sometimes, in fine, the tissue of the villosities despoiled of the epithelinm, is softened, macerated; their extremities are ragged, flocculent, ulcerated and mortified. The puffing up of the villosities, the hypersemia, and tendency of the epithelium to detach itself after the maceration in the choleraic emulsion are principally observed in the algid period. It seems that the cellules of the epithelium were themselves altered. They appeared more swollen, more gorged with liquid, and fuller of fatty globules, than in the normal state.

At the same time the mucous coat of the intestines is pale and anæmic, the sub-serous vascular net-work is incompletely injected, and even when the vascular net-work of the villosities shows itself to the microscope, empty in whole or in part, the contour of these vessels remains incomparably more distinct than in the normal state. One sees that the net-work was but lately filled with blood, and that it had been in a hyperæmic state.

I have often observed with the microscope, bloody globules in the vascular net-work of the villosities agglomerated, adhering strongly to the coats, having an angular form, stellated, color deep purple, yellow-brown or black-brown. As to the villosities deprived of epithelium, covered 
which the salts bore to either, except in the case of the milk.* The analysis of the urinet in some cases showed the chlorides to be abundant; in others, where inflammation (pneumonic especially) was extensive, deficient; but these were never quantitatively determined. It is to be regretted that the same elaborate examination has not been essayed to ascertain the loss of the several saline constituents of the blood, and the order in which they take their departure from the serum as well as from the blood corpuscles in cases of the Pest, as has been in those of cholera. We would theu

with little points of a yellowish or dark brown, softened and ulcerated, they have been observed principally during the typhoid period, and in the mixed kind of choleraic processes.

Finally, in typhoid and choleraic dysenteric forms, I have often seen the mucous membrane, especially in the ileum, stripped of its villosities for a considerable extent.

The exfoliation of the cylindrical epithelium, and the denndation of the villosities, are not to be considered as pathological indications essential and characteristic of cholera. 1st. Because found in chronic diarrhcea, in typhus and dysentery, and other affections of the digestive canal. 2d. Not always found, in the algid period, at least, in such degree as to be regarded as the principal alteration of the mucous membrane of the intestines; and, $3 \mathrm{~d}$. When the exfoliation of the epithelium by the choleraic process has taken place, even to a considerable extent, this alteration is probably not primitive, but more a consecutive state, depending upon the dissolving and maceration of the villosities in the choleraic liquid.

Fig. 22. The fatty globules on the liver are agglomerated, are of different sizes, and spread here and there in little clusters among the cellules of the liver, which also contain a greater number of the fatty globules than in the normal state.

\begin{tabular}{|c|c|c|c|c|c|c|}
\hline No. of sample, ................ & No. 1. & No. 2. & No. 3. & No. 4. & No. 5. & \multirow{3}{*}{$\begin{array}{l}\text { Average } \\
\text { Cow's } \\
\text { mill. }\end{array}$} \\
\hline Total quantity of milk obtained, & $9 \mathrm{oz}$ & $9 \frac{1}{2}$ oz. & $51 / 20 z$ & $21 / 20 z$ & $2 / 2$ oz. & \\
\hline Density........................ & 1027.8 & 1024.4 & 1030.05 & 1021.8 & 1026.6 & \\
\hline Water in 1000 parts,... & 903.100 & 866.166 & 857.282 & 813.60 & 875.311 & 870.20 \\
\hline Solid matters " $\quad$........... & 96.900 & 138.834 & 142.718 & 186.40 & 121.69 & 139.80 \\
\hline Casein, " & 52.0870 & 51.030 & 54.295 & 34.921 & 54.880 & 44.80 \\
\hline Butter, " "6 & 27.7180 & 70.279 & 63.689 & 129.314 & 48.401 & 31.30 \\
\hline Sugar of milk, "6 & 7.7210 & 8.463 & 14.740 & 12.820 & 12.345 & 47.70 \\
\hline Soluble salts, "s & 5.9755 & 3.798 & 4.166 & 4.795 & 4.873 & \} \\
\hline Insoluble salts, "6 & 3.3985 & 5.264 & 5.834 & 4.550 & 4.191 & 6.00 \\
\hline $\begin{array}{l}\text { Day when animal became af- } \\
\text { fected,...................... }\end{array}$ & Nov. 17 & Nov. 16 & Nov. 15 & Nov. 16 & Nov. 16 & \\
\hline
\end{tabular}

t The specific gravity of the urine rose with the charge of albumen and excess of urea, from 1021 (urea 1.71 per cent) to 1034 (urea 5.47 per cent), in which last case, that of a cow slaughtered on third or fourth day of disease, which had suffered great dyspnoea during life and showed most marked pnlmonary emphysema after death, on the addition of nitric acid to the urine, and without concentrating, a large amount of nitrate of urea separated out. (Cattle Plague, p. 78.) 
have the confirmation of what must remain for the present as a probability, that in all zymoties such an order exists; and that leaving out of view those where the process of the decarbonization of blood in the lungs is arrested at the outset, or in the earliest stages of attack, this order is in most of the pestilential classes of disease much the same; making a fair allowance for incidental changes in the terms of the series by way of permutation. This order in cholera, as determined by the ingenious researches of Dr. Schmidt of Dorpat, marks the steps by which the constituents of the serum transude into the alimentary canal, and after such action has been established for a little, those of the blood corpuscles move into the serum. This order is as follows: First the water of the serum (and of the blood-corpuscles in turn) passes before the solids, then the inorganic. before the organic solids; next the chlorides before the phosphates; and last, the salts of soda before those of potash. And in giving this summary, it is interesting to observe that the order, as Dr. Aitken says, "is very much the same as takes place during the action of some purgative medicine, such as elaterium." **

Now although it would be appropriate for those versed in Pathological lore, and standing in the foremost ranks of science, or those capable of such intricate research, to compare the gradual withdrawal from the vital circulation of these essential constituents, with the symptoms which such successive drains upon the fountain of life produce; we may be pardoned in the attempt to draw attention to such considerations as next demanding elucidation in the advancing progress of Pathological inquiries, if we interpose an inference. Dr. A. Gamgee has intimated that the disappearance of chlorides from the urine, indicates the existence of pulmonary trouble, not hypostasis, carnification, or serous effusion, but what is popularly, as we have noticed in our earlier pages, termed difficulty of breathing, \&c., in short, a state bordering upon asphyxia. Now, as it is fair to presume (at least until science by exact methods has determined otherwise) that the 
chlorides leave the serum at a stage in the Pest corresponding to that when they move in cholera; but whether at this time or at this stage in the process the bases of soda and potash go also or remain a little longer in the circulation, so that a disengagement of chlorine takes place in the blood, and is carried to the lungs in greater or less quantities, producing the partial asphyxia in the Pest commonly as before (p. 67) ascribed to nervous irritation, or that more general suspension of the aerating action of the lungs occurring in the algid state of cholera; it may not be wholly pertinent or appropriate in us to inquire. We may venture at least upon such themes when we come to the therapeutical part of onr labol.

Stopping only to draw the attention of the scientific reader to the similarity in form, of the crystals produced by the. changes in the saline constituents of the blood, effecting in their singular escapade from the vascular system, new combinations on the surface of the tissues; we ask the expert in such microscopic crystallography, to say whether the cubical crystals Gamgee observed* are the same as those seen $\dagger$ by Perigoff; and then we would invite the attention of the Chemico-Physiologist to their true substance and composition: and if truly ammoniated phosphate of magnesium, to explain by what process, and in which of the series of saline degeneration as just stated, they are formed.

But let us bring this extended pathological summary to a close; and claim, withont any further attempt to substantiate the thesis; that it is necessary, in order to embrace the various cases set forth in our earlier tracings of symptoms and morbid anatomy, and to bring unity out of their apparent diversity, to propound the following classification for the main varieties or stages of the Pest.

1. The Congestive or Catarrhal Stage, presenting the disease in its simple and uncomplicated forms, where the lesions do not extend deeper than the epithelial coat of the mucous membrane wherever affected. 
2. The Emulsive or Hyperamic Stage in which the mucous membrane is softened (more so in all probability by its own ejections lying in the concave folds of the intestine, \&c.); pours forth mucin in thin form, and is sometimes in parts completely degenerated, losing its hold on the muscular coat. (See p. 34, \&c.)

3. The Exudative Stage, where the separation of Iymph proceeds, and croupous casts or diphtheritic deposits are formed or poured out (like polypus). (See pp. 30, 31, 37, \&c., and plates VI, figs. 1 and 2, VIII, figs. 3 and 4.)

4. The Suppurative Stage, when the follicular growth takes on a pyoid form, and granulations are attended with purulent destruction. (See pp. 34-37.)

It is only necessary to add that it is highly probable, giving due weight and place to the evidence adduced by different observers, in various climes, and in successive outbreaks, touching the inoculative as well as natural forms of the Pest, that the largest number of cases would be found occurring and terminating either favorably or fatally in the first stage; and that the residue would be ratably proportioned among the other stages, in a ratio, declining with the advanced complications which they respectively portray.

\section{Treatment.}

The treatment of a distemper so insidious in its attack, subtle and masked in its incubative stage, and if left unchecked, so fearfully fatal in its development, demands a method that shall be prompt and resolute, and based upon the calmest conclusions of science. All empirical modes should meet with a sturdy rejection. Blood-letting, and the vulgar nostrums of farriery, should be discarded. The veterinary who has not thoroughly grasped by careful study the scope and action of this zymotic, should be denied a consultation or a fee. It would be better to trust to nursing and to nature than to him. For his professional blunders might, by the myriads of germs of pestilence created and diffused under his unskilful eye, add to the dumb creature his bungling 
destroys, holocausts of sacrifices to his quackery. It would be otherwise with the instructed and intelligent expert.

Veterinary science is now invoking to its aid the most eminent pathologists and therapentists of the age, in order to secure the mastery of this disease. And this should not only be a cause of gratulation to all agriculturists of whatever nation or clime, aud a source of hope for the future; but it should inspire all further investigation, and the handling of every case, wherever and whenever it may occur, with the same feeling. We do not hesitate then to say, terrible as the pictures of such desolations as have been wrought in Great Britain may be, that the treatment of this pestilence in any new country it may visit, should, from its first onset, be courageous and hopeful. The arm of science thus nerved strikes always for victory. And with the facts fresh in our recollection that the Eczema which broke out in England in 1839, and the typhoid or exudative pneumonia which followed in 1841, have lost all their terrors, and can only be found in a few sporadic cases in enzoötic form; we rejoice that the Edinburgh Committee, through Dr. Wood, their chairman, have proclaimed their faith that this epizoötic is to become milder in its type, and that its fatal ravages will be notably diminished.

Should this disease ever hold an extended reign in this country, not the knife but scientific treatment will check and overturn its empire. If the farming population, and those to whom cattle are a necessity, not only for milk, but for the purposes of labor and breeding, can be duly advised of the latter method, they will not be compelled to resort too unfrequently to the former. But it is not meant by this that science is indifferent to those wise measures of precaution embodied in salutary enactments by the legislative authority. Isolation and quarantine are an essential part of scientific treatment, and unless these can be secured, and, with other approved remedial agencies, applied skillfully and opportunely as to time; destruction and instant burial with the use of disinfectants are the only alternatives left to incaution and ignorance. 
As science cannot accept the rude instruments with which fear always urges ignorance to arm itself, so the common sense of practical men soon revolts from their long continued employment.

The proprietors and tenant farmers of Kincardineshire, by memorial addressed in February, 1866, to the Privy Council, stated that until a then recent period, they were of opinion with a great majority of her Majesty's subjects-

"That stamping out by slaughtering all diseased animals, and those in immediate contact with them, was the only remedy; but that within the last few weeks a great change had taken place in your memorialists' opinions regarding this matter, in consequence of the successful treatment of the Plague in the parishes with which your memorialists are connected .... \&c."

After stating that on certain farms eighty cattle had been cured and only one died, and their belief that by pursuing such treatment, ninety per cent at least might be safely brought through the dreadful Plague; they besought the Honorable Council to act under a proviso for such purpose, expressed in the Cattle Plague Act of 29 Vict., Chap. 2, and to exempt from its operation (i.e., the slaughter of infected animals) for a period of two weeks, all cattle coming under the immediate care of the Inspector whose treatment of the disease had been so successful; to the end that if the experimental trial thus to be sanctioned should have a successful result, a like measure of relief might be extended to other districts. Strange to say, the Council refused to give a beneficent and liberal interpretation to the clause referred to, fell back upon the alleged original understanding of its purport by both Houses of Parliament; confined its interpretation to experimental cases under the direct charge of the Cattle Plague Commissioners, and refused the prayer of the memorialists. We pause a moment to remind the reader that more benign and less ambiguous provisions mark the enactments of law adopted by the State of New York on the recommendation of its Agricultural Society.

The "stamping out" process it is conceded, may effect the end it proposes within certain limits, provided these are suffi- 
ciently extended to comprehend all infected cases. But if the quarantine prove to be an imaginary one, or if the pestilence has broken out through atmospheric agencies and has extended itself beyond the limits of frontier or local cordons, then when the maladroitness of fancied security has been foiled, and all the allied antagonists to scientific methods are prostrated, this brutum fulmen recoils upon its abettors; and the appeal that then comes to the skill they despised loses the full measure of benefit to have been secured at the outset, had better, not baser agencies been employed.

These are the plain practical lessons which the histories of all epidemies in the human family, and of all plagues among the brute races, clearly and invariably teach. They mark the bold uprising and clamor of empiricism, and in its successive overthrows by the strides of pestilence they point to the modest but masterly persuasions and trials of science for true and enduring relief. And if we seem to drell upon such teachings, it is because we are conscious that as "the still small voice" followed the tempest, the earthquake and the fire, and the preparations for it was not until these fearful manifestations had awed the querulous, and doubting prophet; so it always is in the face of mortal pestilences that the howlings of terror, the onslaught of savage phrenzy and the fierce desolations of misguided zeal, precede the calm and benign intuitions of mercy and judgment, which make up what we call science, and give to it the radiance of a divine vision.

Happy are those who aro saved from the period of agitation, tumult and dismay, to witness the return of serene and successful counsels and procedures. Most fortunate is the people who, anticipating this as the natural order of events wherever prejudice and passion hold their course, use all their energy and wisdom to cut short or forestal their sway, and hasten to usher in the reign of order and method.

As above intimated, we have to propose, before we conclude this branch of our subject, a method of treatment to be approved by the Society, and as we hope, also by minds versed in or attracted by scientific investigations. But before 
we proceed to so responsible a venture, we will pass in review the various methods pursued by the different schools in medicine, and by distinguished veterinarians and practitioners of the medical Art; and to avoid repetition, such as contribute to the scheme we may propose will not be particularly dwelt upon in this general review.

The different schools have been fertile in their inventions and modifications of the treatment pursued, whether prophylactic, hygienic or curative. Of these, the Allopathic, as the older and with a larger discipleship, is first in the order of our sketch, and of this school in Great Britain, Smart and Gangee may be rauked as the leading anthorities. In connection with the former, the Edinburgh Committee, made up of highly distinguished physicians and veterinarians, \&c., deserve marked attention.

Dr. Smart, who claims to have had considerable success in the treatment of the Pest, a summary of which we quote from his Report to the Lord Provost and magistrates of the city of Edinburgh, in extenso; has, after insisting upon careful and assiduous nursing, proposed three kinds of drugs as all he found requisite to employ, to wit: *Laxative, with diuretic action - †Stimulant (also possessing diuretic and diaphoretic properties); and as Tonic, one and a half ounces of powdered cinchona bark of the best quality, to be used when convalescence is fully established. This last is given in the early period of convalescence in combination with the stimulant, and at a later period with a quart of good sweet ale, given once daily and at night. He recommends, also, that two table-spoonfuls of laudanum be added to any of the mixtures prescribed or combined with its food, to control excessive diarrhoea, or obviate straining.

His plan of diet requires the use of simple food, and until decided convalescence, well cooked, and given in small portions at regular hours. The full diet, (devised, according to

* Laxative.

$\left.\begin{array}{l}\text { Nitrate of Potash, } \\ \text { Powdered Ginger, }\end{array}\right\}$ of each 1 ounce.

Powdered of sublimed Sulphur, 2 ounces.

Treacle, 1 pound.

Water to make a quart, and well mixed.
+ Stmudlant.

Carbonate of Ammonia, $3 / 4$ of an ounce.

Sweet spirits of nitre, $\}$ of each $1 \frac{1}{2}$ ounces.

Spirit of Mindererus,
Cold water, 9 ounces.

Mix. 
Gangee, by one of the best managers of cows he ever knew, who was in attendance at Smart's experimental byres) is composed of-

"Four handsful each of bran and brewer's draff; one pound of peasemeal; two pounds of mashed turnip (well boiled), not too thick, and given night and morning. At mid-day a gruel is given, of two pounds of oatmeal, well boiled in six quarts of water. In addition to these, some raw turnips (two pounds, for example, of greentops), and one pound of hay, may be allowed in small quantities during the twentyfour hours. To allay thirst, three to four quarts of water, previously boiled and allowed to cool, are given in mouthfuls during the day.* This constitutes the full diet of a decided convalescent. Half of this diet is, in most instances, during the acute course of the disease, too much. In all cases the same kind of food and periods of giving it are followed. There are some animals that for a time refuse all food, not excepting gruel. In such cases the gruel is administered by the bottle thrice daily, along with or after the medicine. The animal should get a little mash so soon as it takes it voluntarily. It is often expedient to miss a meal, especially whenever symptoms of an unfavorable indication appear. These are not of unfrequent occurrence during the course of treatment. Grass is given, and the quantity of hay and turnip increased as there is progress toward more perfect recovery."

\section{His summary of treatment is as follows:}

1. The animal is at once taken from its ordinary food and separated from the rest.

2. It is to be placed in a well-aired byre or house free from draughts, and the temperature of which is maintained at $70^{\circ} \mathrm{Fahr}$. or $75^{\circ} \mathrm{Fahr}$.

3. It is to be well rubbed down, and thoroughly cleaned and covered with a good rug.

4. If there be constipation, begin with the laxative and continue night and morning, or if required, oftener, until there is free scouring.

5. Let there be no delay in giving the stimulant, and, if needful, combine it with the laxative.

6. Defer giving ale and bark until convalescence appears.

7. To obviate straining or excessive purging, two tablespoonfuls of laudanum, night and morning, may be added to other medicine.

\footnotetext{
* Many of the diseased animals evince a remarkable predilection for charred wood ; and as carbon is an excellent antiseptic, it is only obeying a natural indication to supply materials to satisfy this craving. To do so, charred wood may be boiled with the water, and a few small charred branches of trees placed in the stall.
} 


\section{Be careful to avoid overfeeding, as an error in diet may prove} fatal.

9. See that the cow is well milked night and morning (even when there is no yield), during the course of the disease.

10. All the droppings should be at once disinfected by solution of chloride of lime, and quickly removed.

11. The affected animals should be frequently and closely observed, and threatening indications treated as they occur.

\section{We give also in a note,* several examples of successful treatment, which may serve as a guide as well as encourage- ment to the uninitiated.}

* First case.-A cow from an infected byre in the Canongate, admitted on the 21st September ; was very weak, and expected to die the same night; the breathing was labored and sighing, and the animal was cold all over. Had taken no food for five days previously; the milk and cudding quite absent during that period; put under treatment next day, when it was thoroughly rubbed down and covered with double rugs. As there was already scouring, it was ordered stimulants three times a day, and to be fed entirely on gruel. It got worse apparently for two days; scouring became excessive, and mixed with blood. On the $25 t h$ the cow was so well as to be allowed a little mash. The temperature was good, scouring less, and there was abundance of healthy urine. On $26 t h$ and $27 t h$ there was no apparent progress; the breathing was very oppressed; pulso 100 per minute; not strength to rise; breathless and exhausted after every effort. . On the 2sth it was decidedly better; warmer, more animated, looked eagerly for the gruel; urine abundant; the dung more natural. Bottle of ale and stimulant mixture twice daily. On the $29 t h$ the cow eat too freely of hay; relapse of twenty-four hours, accompanied by much diarrhœa and straining; corrected by a tablespoonful of laudanum night and morning. During the next few days some progress toward recovery was made. Had stimulant twice and sometimes thrice a day, and in the evening ale with tonic powder. On the 4th October the pulse was 72 , and getting stronger, and the respirations were 36 per minute; food consisted chiefly of gruel, Convalescence now appeared, and became decided. The cow was more lively-no scouring. Temperature good; the hide over the back and on both sides of the neck was puffed up with air under it (general emphysema of the cellular tissue); when struck emitted a drummy sound. On the 5th, unequivocal sign of advanced convalescence evinced-cudding. Two small mashes with a little turnip and grass, the stimulant mixture twice, and at evening the bark in warm ale and gruel, constitute the daily food and medicine of the animal. Milk returning; pulse and breathing natural; the cow quite recovered. Puffiness of the skin every day getting less.

Second Case.-A cow from an infected byre; put under treatment on the 2sth Sentember; had taken no food, nor been seen cudding for two days previously; pulse, 96 ; constipation, and loaded panch; vagina shewed the characteristic color; treated with laxative mixture night and morning. On the 1st October the pulse 96, weak; respiration 72 and oppressed. Free scouring, lasts all next day ; moderated by a tablespoonful of laudanum night and morning, along with the stimulant. On the $2 d$, signs of convalescence ; takes a little mash night and morning, but mostly gruel ; scouring abated. On the $4 t h$, couvalescence more marked; pulse, breathing and temperature more natural; milk returning. October \%, all signs of returning health now present; takes small mash night and morning, with a little turnip, hay and grass. The milk is returning rapidly; breathing tranquil.

Third Case.-Cow from an infected byre. Admitted on the $29 t h$ September; all the marks of disease present; pulse 100, and weak; breathing oppressed; no appetite; yery depressed and thirsty; reddened vagina and gums-constipation. Had laxative mixture, and freely scoured by a single bottle. To have stimulant mixture three times a day; remains in an undecided state during the next three days, refusing food except gruel and a little thin mash. October 3 , the pulse 60 , and respiration 48 . The cow is more lively; eats a little better; same treatment; to have a tonic powder and ale at night. October 6 , pulse still high -80 ; the respiration 48 ; the breathing 
The Edinburgh Committee, in their Interim Report, made up in a week after their appointment, "deprecate and strongly protest against the system of indiscriminate slaughter," \&c., and regarding Rinderpest as evidently a disease of a low type, and the tendency to death to be by exhaustion, conclude that violent and lowering treatment is wholly inadmissible, \&c. So also with strong saline and gastric purgatives, in the place of which Professor Dick, one of the committee, takes linseer oil in doses of sixteen ounces, to which is added half a mutchin (Ang: pint) of whisky. For the relief of scouring, he recommends the use of lime water in quart doses, to which laudanum, from one-half ounce to an ounce, is to be added. These remedies were to be followed by a stimulant treatment, (or it might be simultaneously administered), to wit, carbonate of ammonia in six drachm doses, three times a day. The tonics promotive of convalescence are, sulphate of iron in half ounce doses, twice a day, or the powdered bark recommended by Dr. Smart.

In a subsequent paper, the committee classify their treatment under four heads :

a. Diaphoretic and Stimulant.

b. Acid Treatment.

c. Restorative Treatment without drugs.

d. Prophylactic Treatment.

Under the first, a vapor bath is administered once or twice a day, and for successive days, according to circumstances; the animal being placed in a box or stall whose sides are an

oppressed; otherwise, not markedly changed. October 9 , signs of convalescence quite decided; appetite restored, takes full meal of a convalescent quite greedily. The milk increased in quantity; improving in quality; pulse and breathing still a little too high. This arises from a slight attack of pleurisy, caught since admission to the byre.

Fourth Case.-From an infected byre. Admitted 26 th September; taken no food for two days; dull; losing milk; oppressed in breathing; pulse 100; signs present, reddened vagina and gums. Laxative mixture given; free scouring next day; stimulant treatment; small mashes twice a day; gruel at mid-day. On the 1 st Octover, the pulse was 96 ; respirations 48 ; temperature natural; animal dull; no appetite. On the $2 d$, improvement; stimulant twice a day, and ale and bark at night. On the $9 t h$, convalescent; milk increased in quantity, improving in quality ; gets full diet; takes it eagerly.

Fifth Case.-Cow from an infected byre, where ten had previously died. Admitted 1st October. Had all distinctive marks; treated on similar principles. For three days, pulse 95 , and respiration 102 ; nothing specially to be noted in treatment. After seven days illness, convalescent, giving full milk, chewing cud and taking full diet. 
inch or so higher than the patient, covered with a tarpaulin thrown over the box so as to tightly enclose the animal except his head, and the hot vapor being kept up by throwing redhot bricks into a tub of hot water, first placed in the box below the level of the floor, and so as to be easily accessible to the operator.

The avowed object of this bath is "to promote the circulation at the surface, to relieve the congestion of the mucous membranes, and to eliminate the poison from the system."

To aid which desired results, and as not incompatible, stimulants are given:

1. Oil of turpentine, four table spoonfuls in a chopin-bottle full of gruel, well shaken, and given twice a day-increasing the perspiratory effort, and superceding the use of a laxative.

2. Infusion of coffee, obtained by digesting two ounces of coffee roasted and ground, in a bottlefull of boiling water, for fifteen minutes, and when sufficiently cool given every six hours.

3. Carbonate of ammonia, administered three times a day in halfounce doses, in a bottlefull of gruel, to which may be added three drachms of nitre.

The Acid Treatment is suggested in consequence of the alkaline state of the secretions, and consists of :

1. Dilute muriatic acid, three drachms, twice a day, in a bottlefull of gruel.

2. Vinegar, also in the gruel, two ounces, given four times a day.

The Restorative Treatment demands full accord with

1. The general sanitary instructions of the commission as to cleanliness, use of disinfectants, regulating the temperature of the byre so as to keep it up to $65^{\circ} \mathrm{Fahr}$, or $60^{\circ} \mathrm{Fahr}$. at least; the banishment of hay, straw and all kinds of fodder from the stall, as well as manger, \&c.

2. The regulation of the cliet, so as only to give oat meal or barley meal gruel, or linseed, hay and bran teas, to which, in the earlier stages of convalescence, well boiled turnips or carrots may be added; not even a handfull of hay being permitted until rumination is re-established, and that first dampened with water which has been salted.

3. The keeping of the animal warm, by rugs or other appliances.

4. The use of good, sweet ale, at the rate of two chopin bottles three or four times a day. 
The Prophylactic Treatment, recommended with a view of preventing the development of the disease, or of modifying the intensity of its symptoms, \&c., consists of:

1. Sulphite of socta, one ounce in a bucketfull of water, and given morning and evening.

2. McDougall's solution, a wine glass in a bucketfull of water, twice a day.

3. The sulphite and solution combined, to wit, a half ounce of the first, and two tablespoonfuls of the second, given as above.

Gamgee, while challenging for his practice as many recoveries as are gained by his opponents, affirms that-

"No known remedy restores an animal once severely attacked, and the administration of medicine is, as a rule, not required to save the small percentage which may recover."

Winding up his hopelessness as follows:

"But if any one wishes to test the effects of medicine in this disease, let him treat at least one hundred animals on any one system, and leave another one hundred to nature, having a proper regard for their comfort and judicious hygienic management."

He proceeds to account partially for the laurels won by the Homøopaths in South Holland, by noting as one of the strange variances of outbreak in Great Britain, that-

"Dutch cattle have suffered less than our own, both in Holland and Great Britain."

In the absence of definite information, we are left to conjecture whether his methods were as numerous as those of the empirics to whose treatment he professes to have given close observation, or as those of the remedies employed and of which he gives an extended notice, though prefaced by the slur-

"Some animals recover despite the mode of treatment."

Alluding to the recent method of subcutaneous injection-

"As of tincture of aconite, belladonna, and other alkaloids which do not irritate and inflame the tissues"-

he next describes the system of injection into veins, in the use of-

"A pint or" quart of water at $100^{\circ}$ Fahr., injected after the like amount of blood has been taken from the jugular vein ...., to be 
tried in the early stage of the disease and .... with result of purgation, action on the kidneys and free exhalation from the skin"-

and passes to the class of External applications, inclusive of the ordinary methods-

"Of applying heat, cold, rubefacients and blisters to the surface of the skin."

Those less known and partially commended (while actual cautery is very wisely discarded as barbarous), are-

1. The vapour bath.-Covering the animal (head excepted) with woolen rugs, propped up and out by sticks, dc., and then heating the air between the rugs and the skin by a spirit or gas lamp ....

2. Mustard poultices. - Which should be large, warm, and applied with a rug to the body, so as to be kept on for three or four hours ....

3. Rugs dipped in boiling water-wrung out thoroughly and applied to the abdomen.

Elsewhere, mention is made of the hot air and vapour baths which have been used with some success in Russia, and were thought to be of sufficient importance to form the basis of a dispatch from Sir A. Buchanan, the ambassador at St. Petersburgh, to Earl Russell, in October, 1865.

The vapour bath, originated by Thaer, who applied it with success in the murrain of 1828 , is taken over a kettle with a plank cover perforated with holes, sunk into the ground and so built up that fire may be kindled under it, and when steam or hot vapour is evolved, the sick animal covered with a woolen cloth next to the skin and a linen one outside, is kept over it from thirty minutes to an hour; then rubbed dry and kept perfectly warm; allowed gruel, \&c.

Many recoveries were detailed by the Russian farmer who communicated its use. Like results also followed the practice used and commended by Mr. Graham, of Capellie, near Glasgow, in his hydropathic application of cold water:

"The diseased animals were packed in three heavy horse rugs, saturated with water, about which were closely applied three other rugs ; and received an internal remedy* during the packing period.

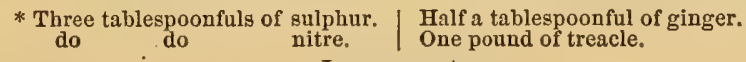




\section{The Internal Remedies, as classified by Gamgee, are as follows :}

1. Purgatives, which in trastic eathartic doses he properly condemns, as mild laxatives he tolerates, though he had as much success in cases where he made no attempt to relax the bowels as where either mild or active purgatives had been preseribed, giving a preseription* not apt to induce much purgation, and to be followed by a bottle of linseed oil.

2. Enemata; too much overlooked as medicinal agencies and as means of nutrition. They may be given first to move the bowels by dislodging contents of larger bowels; second, to restrain them, in the use of a pint of starch emulsion, containing one ounce of laudanum,

3. Diuretics, of which nitre has been principally used, but "it is apt to weaken, and must be prescribed in moderation, and it has no specific action of value." Oil of turpentine is diuretic, as well as stimulant.

4. Diaphoretics, in the use of warm clothing, heated air, \&c. (as before referred to), adding the internal use of liquor ammonice acetatis, to those before mentioned.

5. Stimulants.- Whisky, brandy, spirits of voine, in two ounce doses, every two or three hours, have been frequently administered; "some animals have recovered, whilst others have died."

Carbonate of ammonia, in half-ounce doses, has been largely employed, and "seems to agree as well as anything with the sick animals." Strong ale, porter, port wine, dce, should be used in the stage of convalescence.

6. Seclatives, not resorted to in any great extent. Tincture of aconite in 30 drop doses, has been administered at frequent intervals. Extract of belladonna. and opium hare been principally chosen from the narcotic list, as affording the best chance of regulating the condition of the bowels.

7. Neutral Salts.-The nitrates and chiorates of potash and acetate of ammonic produce farorable effects upon the blood in febrile disorders, and activate the secretion of the skin, kidneys, and mucous membranes generally. They may be administered singly (or combined with carbonate of ammonia) in moderate and repeated doses, and dissolved in a considerable quantity of water.

8. Tonics, regetable and mineral, may be used with benefit in the convalescent stage, if not given in doses so large as to induce derange-

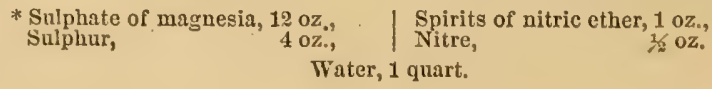


ment of the stomach and bowels. The decoction of cinchona or Peruvian bark, and the infusion of gentian may be given about an hour before fecding, \&c. Sulphate of iron is the best tonic, and should be given in the food in drachm doses.

9. Antiseptics.-Condy's fluid-the red solution of the permanganate of potash-in water alone, or water slightly acidulated with sulphuric acid; two ounces of the fluid every two hours diminished the fotor of the excrement. Small doses of carbolic acid, sesquichloride of iron, or of chlorine voater, produce similar effects.

10. Mineral acids.-Mydrochloric (formerly known as muriatic) acid, and sulphuric acid, more frequently have been vaunted as specifics. Nitro-muriatic acid is serviceable in the convalescent stage.

Mr. Priestman (whom we may remember as the veterinary surgeon first consulted by Mrs. Nichols) has suggested a mode of treatment which, according to the statement made by Dr. Hayes, and found in Sequel to First Report, page 13, has proved most successful.

The same hygienic conditions and mode of diet as commended by Smart are preserved; half-ounce doses of carbonate of ammonia and nitre are given night and morning in cold water, as a prophylactic, and when symptoms of the Pest appear, two ounces of chloric ether are given in gruel three times daily, and when they abate, two ounces of a mixture consisting of equal parts of tincture of gentian, tincture of ginger, and aromatic spirit of ammonia are given night and morning.

A chalybeate remedy for the Pest, based upon a large experience in Poland, was brought to the knowledge of the Royal Commissioners through a dispatch from Major Mansfield, the Consul-General at Warsaw, to the British Secretary for Foreign Affairs.

On a Polish farm there existed a chalybeate spring, and the cattle drinking of it

"were either but slightly affected or recovered after drinking profusely of it, while on the adjoining farms the beasts died in large numbers. It was then found that by putting old iron into the cattle troughs, so as to produce a highly chalybeate water, the same result ensued, and the cattle recovered."

Hence, doubtless, has followed the suggestion of pouring into the drinking trough for cattle a little sulphur and 
a drachm of sulphate of iron and a half pound of salt every day, for each large beast.

Dr. Druitt recommends the tincture of the Sesquichloride of iron, the Trisnitrate of Bismuth as a deodorizer of the alimentary canal, and yeast in large quantities in addition to those we have previously noticed. Fourteen out of twenty Dutch bullocks were cured by Mr. J. Hutton through the agency of ammonia and tonics.

"Stimulants were administered as required. All the water used for drinking was medicated with mineral acids, and the beasts frequently washed with water impregnated with ammonia."

Prescriptions have been confidently recommended by veterinary chemists and doctors of medicine, of which we may quote two specimens:

Chlorate and nitrate of potash, of each one ounce; Hydrochloric (muriatic) acid and powdered opium, each one drachm; to be mixed in a pint and a half of a decoction of linseed.

Chlorate potash, common salt and nitre, each one ounce, to be dissolved in a pint of hot water, in which an ounce of dilute hydrochloric acid has been mixed; the dose to be administered in gruel, \&c.

Mr. Moffat's prescription consisted of :

Chlorate of potash, three drachms, tartar emetic five grains, and carbonate of iron, fifteen grains.

Those of Mr. Crotch, M. A., Dr. Carr and Mr. Wilson severally commending,

the injection into the venous system of antiseptic and parasiticide salts, of which the hyposulphite of soda, the permanganate of potash and the perchlorate of soda are specified-the fiequent washing of eyes, face, \&c., with vinegar, and the internal administering of a pint or more daily-a pint of fresh yeast, added to a like quantity of beer,-put in two quarts of gruel, and given three times a day;electricity, the electro-voltaic pile, ..... cod liver oil balls; bleeding to fainting, and giving a bottle of brandy to revive ; calomel and fumigation with mercurial vapor; prescriptions having cayenne pepper for their bases,* complete the list of allopathic nostrums, after we have given that of Mr. Heatley, of Market Drayton, as follows :

* Gamgee's Cattle Plague (et ubi sup.), p. 104-116. 
Take of spirits of turpentine one ounce, and of castor oil seven ounces, to be given only once as the first dose; take sesquicarbonate of ammonia and powdered Peruvian bark, each one drachm, powdered ginger thirty grains, and peppermint water six ounces, to be taken three times a day. Boil one ounce of mutton suet in a half pint of new milk, strain and give every night; and give four ounces of brandy in a half pint of linseed tea every morning. Each of the above doses to be increased or decreased according to circumstances.

The limits of this Report will not permit an extended review of these various prescriptions; and it is doubtful whether it would be possible to assign any satisfactory reason for the successful action of many of them, if such could be truly predicated.

It would be unwise for instance to rely upon a remedy as a mere de-odorizer of the alimentary canal, inasmuch as such an agent would be unnecessary if convalescence were once established, and useless, if it did not exert a decided influence in mitigating the fury of the disease. It is also to be observed on the most cursory examination of the list of therapentic formulæ we have given, that many neutral salts, such as the chlorates and nitrates of potash, \&c., and others of which sodium is the base, enter as chief ingredients; their combination with acids, stimulants, sudorifics or narcotics, promising to their authors some remote chance of relief. We are far from asserting that these salts could not be supplied at certain stages of the Pest with decided benefit; but we point to these recipes more as exhibiting the sheerest empiricism, at least in the motley admixtures proposed by each enthusiast, and according to his fanciful conceit of their essential value. It is in this and not in any invidious sense, that we have as we think, very fairly designated them as nostrums.

Further on we will notice such of the remedies cited as from other analogies may claim to have specific virtue in arresting the peculiar ferment of the Pest; but now let us pass to the consideration of those which if given in a state of health in large and repeated doses, would tend to the development of a morbid action, very similar to that we are considering. This we need hardly remind the intelligent reader, brings us to the consideration of the homœopathicity of cer- 
tain drugs, as curative in this distemper; and to the second branch of this review, that of the treatment pursued by the school, whose fundamental axiom is "similia similibus curantur."

The Homœopathic school has not been without ardent advocates, lay as well as professional, for its superior efficiency in the handling of the Pest. Its doctrines and method of cure, though hotly contested and decried when first announced, as bald quackery, have by undeniable success in a vast number of cures in the human subject, gained for it high commendation among the common people, and by gradual advances have exturted from opposing schools this high commendation,-that they have moderated the heroic treatment formerly in vogue. The "infinitesimal doses," derided as addressed only to the imagination, or only suited to ailments where "bread pills". would have been equally available, were gladly tried by Russian serfdom, during the terrible scourge of cholera which visited Eastern Europe in 1830 ; and we may add, approved by and through them, as the reports made to Admiral Mordinow, and since published by him, of large percentages of cure, sufficiently attest. The superior efficacy of the Homoeopathic treatment of cholera to that relied upon loy its opponents, was further demonstrated. in the public contest instituted under the auspices of the Austrian Cabinet at Vienna. And since that day its marked success with many people in different climes, and in all the varieties of disease "which flesh is heir to," has given the system a popular acceptation, against which it is in vain for prejudice or self-interest to contend. Its doctrines have withal been accepted by experts whose scientific attainments and high probity place them above the suspicion of sciolism and imposture. And while deprecating the absurdities to which many have practically carried its teachings, it is yet to be urged in the behalf of pure science, which holds all medical systems as at present in a tentative posture, that no hindrance should be interposed by the dogmatists of any school to the establishment and acceptance of facts of cure in any disease by any method; to the end that these may 
undergo the rigorous scrutiny which the inductive method demands, and by which alone medical as well as other physical sciences are to be permanently advanced. And this claim we may the more freely advocate, and with the high certainty that such advocacy will be sustained and shared in by all generous spirits who seek to pursue humane ends by scientific means; as the sequel will show, that we propose no blind adhesion to any system, and as the transition period, in which all present systems of medicine now stand, indicates a new and a higher eclecticism based upon a more perfect classification of disease, and a more thorough demonstration of the agencies which afford the most prompt and certain, if not specific relief.

Attention was first attracted in Great Britain to the successful cure of the Rinderpest by Homoopathic remedies, through the Report made on the Cattle Plague in Belgium, by M. Barron, Her Majesty's Secretary of Legation at Brussels, to Lord Howard de Walden. In this Report, after a review of the recent outbreak in Belgium (not theretofore visited by this scourge since 1814), and which, principally from the vigorous system of quarantine noticerl in our first Report, was comparatively light, the successful cures of Messrs. Seutin and Gaudy in Holland were brought to the notice of the English Government, with a strong recommendation that these gentlemen, one a chemist and the other an Ex-Professor in a Veterinary College, should be permitted to verify their practice in England. Despite the alleged malevolence of the Dutch Veterinary Corps, the carelessness of the farmers whose cattle were under treatment, and the absence of proper assistance, a large per centage (from 70 to 80 ) of cures was gained; the results of the practice being officially certified in one commune, that of Mathenesse, as of forty-six cures in sixty-three cases. The proposition of these experts being based on an indemnity moderate in amount, to cover expenses and remuneration, was not accepted by the British Government, and no opportunity was afforded for a direct inspection and test of the practice. But as appears from an address of Lord Bury, Treasurer of the Household, \&c., before 
the General Cominittee of the Norfolk Cattle Plague Insurance Association, the friends of Homœopathy, requested Dr. Hamilton to go to Holland to investigate and report upon the treatment pursued by both schools. The Doctor was furnished with suitable credentials from Earl Russell to that Government. He found the Allopathic practice mostly confined to the use of dilute muriatic acid (in doses of one or one and a half drachms), combined in linseed tea, given four or five times a day, sometimes with gentian, tormentilla, and ginger; occasionally recourse was had to dilute sulphuric acid combined with sulphate of quinine in equal parts. By the use of these remedies, and with the external use of carbolic acid in proportion of eighteen drachms of the acid to forty quarts of water, or of vinegar and tepid water, used four or five times a day, there had been a saving of 45 per cent. The Homøopathic treatment at Matterness, within a mile of Kethel, in the very center of what had become to be styled the "black district," as reported by Dr. Hamilton, is also given by his Lordship, coupled with the allegation that the Royal Commission had refused to examine the Doctor as a witness, and the assertion of the consequent duty incumbent on the orator in common with every individual, to give as much publicity as possible to this fact.

The Homœopaths commenced their method of treatment on the $22 d$ day of September, 1865 , when eighty beasts sick with Rinderpest, as first vouched for by the certificate of veterinary surgeons, were put under their care; of which number sixty recovered. Besides these, two hundred and thirty beasts were put under Homœopathic prophylactic treatment, twenty-five showing the outbreak of the distemper before the preventive treatment bad time to work; but up to the fourth week no other case had occurred, and on the 21st day of October, the commune was pronounced free from disease; the remedies employed being Arsenicum, Phosphorus, Phosphoric Acid, Rhus Toxicodendron and Sulphur.

Another able exposition of this method of treatment is given by Dr. Pope,* from whose well digested review of the

* See Monthly Homœopath Review, Feb. 1866. 
symptoms of the Pest as they passed under his own eye we have elsewhere quoted (see pp. 24, 26). His observations were gleaned from over one hundred and seventy cases which had occurred in his immediate neighborhood. Accepting Smart's view of the morbid anatomy of the Pest, he adopts his system of diet and care, and finds that-

"Certain features of the Rinderpest are very like those of scarlet fever. Its toxæmic character, the congested state of the mucous surfaces, and the extensive desquamation of epithelium are resemblances of some importance."

And it is doubtless because of this similarity, that Dr. Pope seems to rely upon Belladonna as of prime value; an instance being given of its efficacy, in the hands of Mr. George Hope, a much respected citizen of York, who was determined to use his best efforts, and as we judge, without any pecuniary reward, to mitigate the losses of his neighbors.

"An animal .... was so far advanced in the disease, that on Mr. Hope's visiting her, he found that the Inspector had been sent for, to give an order for her shooting and burial. It was late at night and as the order could not be carried into effect until the following morning; the owner was persuaded to allow medicine and gruel to be administered during the night. Belladonna was the medicine given, and by the morning the animal had so far rallied that all thoughts of destroying her were abandoned, and she made a complete recovery."

Another exceptional case of recovery in a late stage of the disease is given, in which

"the cow was completely despaired of, when first seen, and though she suffered to a very great extent from emphysema of the subcutaneous cellular tissue of the trunk, completely recovered."

Dr. Pope very wisely recommends Belladonna, in tincture, two to five drops to be administered every two, three, or four hours. He says:

" 1 st, $2 d$ and $3 d$ dilutions were tried in our early cases, but they were by no means so satisfactory in their action as the pure tincture."

The other remedies advised by Dr. Pope with their correspouding indications we will give in his own words; remarking that they substantially correspond with those recommended by The Association for the trial of the Preventive 
and Curative Treatment in the Cattle Plague, \&c., Sc., of which His Grace, the Duke of Marlborough is announced as Chairman :

"Arsenic has been useful chiefly in meeting the prostration about the fifth or sixth day. As a prophylactic I question its value. If it have any, it is not in the sense that vaccination is prophylactic to small pox; but it simply acts by keeping the animals in good condition, and so enables them the better to resist the contagion, giving rise to the disease.

"Rhus tox.-The chief indication for this remedy has been found in the muscular twitchings which characterize the disease in some of its stages.

"Mercurius sol. has been found valuable when the mouth has been long congested, and the patches of desquamation are general.

"Ammonium caust., 1st dec., is of service where there is much abdominal distention, with heavy breathing and painful moaning.

"Turpentine, 1st dec., has been of signal service in checking hæmaturia, a symptom which did not yield to Cantharis at all.

"Secale cor., tinc., Mr. Emerton thought useful in one case of subcutaneous emphysema, and its proving shows that it deserves attention in this condition.

"Phosphoric acid, 1st dec., Mercurius sol. and Arsenic have appeared to control the diarrhœa more than any other remedies; but they have not proved altogether satisfactory. In any future case I should be disposed to try Muriatic acid or China. It has been a more difficult symptom to meet than any other.

"Mercurius cor. 1, has checked several cases of dysentery in very marked manner.

"In one case of apparently impending metastasis, the acetate of copper, in grain doses of the first trituration, appeared to prevent its development; but it was the only case in which it was resorted to, and therefore much additional experience is required before its value here can be estimated correctly.

"In addition to medicines, much good has accrued from exposing the animal's muzzle to steam from boiling water or scalded bran. The nasal discharge is thus promoted, and large lumps of coagulated mucus are passed, to the great relief of the patient." ....

In brief review of this method of treatment, it is to be observed in all frankness, that inasmuch as the present foundation of the Homœopathic system lies in its Symptomatology, no little difficulty must be experienced in applying it 
to the dumb creation. Besides the drug-provings which have been made on the human race, cannot with any certainty, or in some cases, eren of probability be transferred to the brute races. This is more especially true of the ruminant orders, whose complex arrangement of the digestive organs would render the disparity of symptoms relating to the functions of assimilation, and of the reflex action upon the brain and cord from the direct influence of drugs acting upon the stomachic apparatus, more than probable. No such result might however be expected, when once the influence of the drug was felt. after it had been absorbed and entered into the blood circulation. Besides, as in this disease the function of the first and second stomachs is quite suspended, and medicines carclessly administered (especially in large quantities) and thrown into the paunch, are as inert as if lying in their original packages; so it might happen in the administration of different drugs to obtain their provings, that different results would follow if these were thrown into the first or the fourth stomach. And after all, what could we know of their symptomatic indications so pregnant of suggestion in the various morbid states of the human subject, derived from provings on a nervous expanse, not only so delicate as to register at once every, the most trivial departure from the normal state, but so secure and protected in such registry as to confirm it by an unequivocal and audible tell-tale; - what could we know except by the loosest inference, when we seek the same intelligence from those to whom nature denies the power of speech. Hence, we are thrown upon the more tardy method of watching our provings of medicaments introduced into the system of any auimal, by experiments on those doomed to slaughter, or massing the drugs, and leaving the proving to go on until death supervenes. So that not only as Dr. Pope remarks-

"Any nicety in the selection of a medicine to meet a particular case, seems well nigh impossible."

-but all our reliable knowledge of the various scope of drugs irritative or destructive of nerve or tissue, alterative of the blood structures for a brief period, or exerting power until the 
full measure of poisonous disintegration is established, must be principally gained from post mortem observations.

We are not to be understood, however, as holding the view that in drug-provings on the lower races, there can be no symptomatology. We only insist that in the case before us, that of the ruminant tribes, it must be extremely limited, and that before such knowledge can be extended, a very elaborate system of drug-provings upon these tribes should be first instituted.

We are not left, however, wholly in the dark as to the fatal action of drugs in poisonous doses upon the brute races, as our toxicologists have made fiom time immemorial, frequent experiments illustrating such action, although mostly in dogs, rabbits and animals of small size and little value. From the records then they have given us, and until other more reliable data are furnished, we have to indicate as best we may the pathognomic signs, which point, on the Homœopathic priuciple, to the selection of the chief remedial agents which are best fitted for the cure of the Pest. We will detain the reader with a few examples:

Let us take in the first instance Ammonium Causticum and its ally of the same base, the Carbonate, which have in the hands of Dr. Sunart and others, furuished many examples of its specific worth, and whose action we can best understand by the study of the main features of the poisonous action, or what may for want of more familiar phrase, be styled the Pathological Anatomy of the former drug. In men, we find its scope of action evinced as follows :

Redness of the Schneiderian membrane (covered in cases of intense poisoning with an albuminous membrane), also of the velum pendulum palati, of its arches, and of the posterior wall of the buccal cavity. The uvula is dried up, and covered with a mucous (epithelial ?) layer. Redness also of the posterior surface of the epiglottis, and the rima glottidis, also of the trachea and bronchi. A few intensely red streaks in the mucous membrane of the æsophagus and stomach. Red spots in the ileum. (In dogs) the contractile power of the muscles extinct after death. Dark redness of the middle portion of the stomach toward the cardia .... Great fluidity of the blood, \&c. 
After examining the symptomatic provings of this drug, and especially its power to produce-

"violent oppression of the chest; want of breath; desire to draw a deep breath (prevented by a pain in the region of the œesophagus).... excessive exhaustion and muscular debility, \&c.; trembling; chilliness; pulse at first small, afterwards becoming more rapid, \&c.;"

-or those of its congener, the Carbonate, in producing as additional symptoms-

"swelling, itching and burning of the pudendum; painful varices of the rectum, with bloody discharge; burning pimples of the size of a millet grain, with a scarlatina rash over the upper part of the body; red, itching eruption (fluid and then becoming sometimes fetid), disappearing in a few days, \&c.;"

- we can hardly fail to find some counterpart of the Pest in this drug. But we cite from the Elinburgh Medical and Surgical Journal for 1841, this interesting case :

"A young man who usually slept in a chemical laboratory, was poisoned by the fracture of a vessel containing nearly fifty pints of volatile alkali (liquid ammonia). The accident occurred in the night without his knowledge, and he was exposed to the vapors nearly au hour. He was roused by violent constriction of the throat and dyspnoea. He arose, but felt suffocated .... The mucons membrane of the mouth and nostrils appeared to be destroyed, and bloody, frothy matter flowed from the mouth and nose. The tongue was of a bright red color, and had lost most of its cuticular covering .... The dyspnoea was extreme; great thirst ... deylutition almost impossible, \&c."

It is difficult, at least from the stand-point of the Homœopath, to couceive how Smart's stimulant mixture, as he is pleased to style it, in which Ammonium appears in another form also, that of the Acetute (Spiritus Mindererus), conld have had any special efficacy, unless $A$ mmon. Caust. sustains a special relation to this disease. Nor is it easy for a disciple of Hahnemann to conceive how the secretions from the eyes, nose, borvels, skin, should be alkaline, unless the morbific influence should hold a close similarity in its action to that of an alkali.

We confess that we cannot find in Arsenicum anj true rapport with the Pest. It corresponds in most of its provings 
too closely with certain stages of cholera to sustain a Homœopathic relation with the distemper we are considering. It seems to have quite as destructive power over the peritoneal as over the mucous coat of the intestinal canal, and the common srmptoms of erosion of the latter, of great prostration and fluidity of the bloorl, will hardly suffice as Homœopathic equivalents. Yet there may be cases as in the inoculations of Jessen, where the tendency to lymph extravasations, or others where extreme prostration and tendency to gangrene might justify its use as an intercurrent remedy.

With greater diffidence we venture the opinion that Belladonna can only be deemed a specific in cases where cerebral disturbances are manifest at an early stage. True, we have the redness of the throat, \&c., but not its swelling; nor the rash upon the skin, as in the human eruption of scarlatina, thongh there doubtless exists epidermic desquamation. And unless in addition to its action over the pudendum of the female, and the hæmorrhoidal veins of the male, it could be shown that Belladonna produced a true rubescence* throughout the alimentary canal, we should expect it to fail in many instances, except where it was needed to assnage the excited condition of the cerebral vessels. We ought not, however, to have neglected to admit, as a common sign, the horrible smell produced in the cadaver.

If we are to look at the reddened aspect of the throat and fances as a principal sign, why not turn to Bromine. Yet no one could confound the violent congestion of these parts, covered with coagulable lymph, with the exposure of these denuded surfaces in the Pest, except where protected by scales of epithelium; any sooner than a like mistake in the degree of rubescence in the stomach or bowels would also permit us to ignole the gangrenous ulcers, barely hid. And

* The post mortem of this drug shows in men at least, the coats of the bowels inflamed, and parts not only red, but black; blue spots on the duodenum here and there; the jejunum, ileum, cœenm, and processus vermiformis, lead colored and soft in many places; lead colored spot of the size of a dime on the ileo-cocal valve; the colon filled with hard foces. The pancreas and liver have the same blue or lead color, the former softened, the latter crumbling and put:efied. The spleen is also crumbling and decayed. The lungs are dark blue, otherwise healthy; the heart livid and softened. The abdomen, penis and genitals are hard as a stone, cmitting a frothy and fetid water when opened. 
for a further illustration of the deceptiveness of the color of congested mucous surfaces, we may advert to that presented by the provings of Bryonia, where the cherry brown color of the mucous membrane of the large intestines might easily be allied with that of the rectum in the Pest (though the absence of all inflammatory appearances in the rest of the bowels might serve as a means of discrimination), or a similar appearance of the stomach advise the homœopathicity of this drug to eczema epizoötica. It would be interesting to trace the points of similarity exhibited in the action of. Cantharis, Croton tiglium and Helleborus, with doubtless many others that might be named, in their different action as to color and intensity of inflammation, with epithelial destruction in the mouth, fauces, bowels, \&c. It is worth noting as we pass, that in the first and last of these remedies, we have the additional mark of the gall bladder filled almost to bursting, while in the second, the correspondent redness of the rectum is not to be wholly distinguished from extravasation.

The plants of the Ranunculus order, demand greater study than they have received. R. sceleratus is known to produce the affection termed by the German shepherds "cold-fire," the cattle declining to eat, tremble and shiver, and their abdominal veins become distended. $R$. repens, eaten by a flock of sheep, caused them to fall as if struck by lightning, their eyes rolled, their breathing was hurried and aggravated. Depletions were injurious. The mucous membrane of the eyes was injected; the mouth dry; abdomen slightly distended, and rumination ceased. Five ounces of the juice of $R$. acris introduced into the stomach of a dog, developed a post mortem redness of the mucous membrane of the stomach, \&c. R. flammula eaten by horses in large quantities produces distention of the stomach and inflammation and gangrene of the abdominal organs.

In this connection we may properly advert to Aconite, (whose tincture, as we have seen, in 30 drop doses, Dr. Gamgee recommends as a sedative), as this plant is also classed in the botanical order just alluded to. Its provings, like those of Arsenicum, adapt it to the choleraic brauch of zymoties, 
although to different stages. The deep inflammatory biush it produces on the mucous surfuce of the oesophagis, stomach and bowels, as far as the coecum, is accompanied with dark colored patches (these organs containing a viscid blackish green fluid), attended at the same time with an enormons distention of the cerebral vessels, which in the development of the drug symptoms have caused restlessness, dimness of sight, stupor, and partial insensibility, accompanied with trembling, cold extremities, bathed (with the forehead in men) in cold sweat, and blueness of lips and skin as if asphyxiated. The gall bladder is not distended, while the kidneys are somewhat engorged.

Dr. A. T. Thomson says :

"It acts first on t'ie stomach, then on the nervous system, producing vomiting, hypercatharsis, vertigo, cold sweats, delirium and convulsions, which terminate in death .... It resembles Strychnic in its effects on the posterior extremities when administered to quadrupeds." *

In cases such as those described by Egan and Pope and by Prof. Simonds as occurring in Galicia (see pp. 23-27), this remedy in the tincture, and in doses of tive to ten drops, might be prescribed until the nervous twitchings and excessive diarrhoea were arrested.

Acidum Muriaticum, which in its dilute form was largely employed by the Dutch veterinarians, corresponds somewhat in the corrosive smarting, slight inflammation aud agglutination of the eyes and eyelids, in coryza with an acrid discharge, and in the painful varices it produces, with some of the prominent symptoms of the Pest. Its ralue is not to be denied in acute disease (especially of a septic character), with rapid sinking of the vital force, and when the tongue is dark red, dry or covered with a viscid phlegm, lips dry, blackish and cracked, and the other symptoms last noticed occur. Its power also of assisting the gastric juice (perhaps of restoring it), must be conceded. But in the absence of any sure experiments it may be conjectural, whether its use in the early stages of the Pest would bring back to the stomachs their 
suspended activity. It may be that this acid may supply to the blood the loss, or may arrest the decomposition it undergoes, when the chlorides begin to pass off. Dr. Thomson is nuable to determine whether its tonic effects in diseases in which he had successfully employed it, is to be attributed to its action on the nervous agency, or to its decomposition and the action of its chlorine; although from the effects of this ingredient in its uncombined state, he thinks there is reason to incline to the latter opinion.**

We cannot find any proper correlation of Secale Cornutum with the Pest. This drug produces in countries where rye is used as a principal cereal, ergotism, both gangrenous and convulsive; as also a congenital form of this disease. The skin affections seem to us wholly different from the desquamatory or papular stages of the Pest-ferment, both as to color and action; and with the lungs and cerebral vessels turgid with blood, the ureters and bladders filled with watery, inodorous urine, almost to bursting, we have hardly a common sign except in the distended gall bladder. We cannot, therefore, concur with Dr. Pope as to the propriety of its use; unless where with an unusual disturbance of the skin function threatening its gangrenous destruction, we have colliquative diarrhoea, with spasmodic breathing.

Tartar-emetic or stibium, though used in some of the allopathic prescriptions, has no correspondence whatever in its symptoms or morbid anatomy with those of the Pest. Its most marked action is in producing inflammation and consequent hepatization of the lungs, and also thickness and opacity of the membranes of the brain. The mucous membranes of the mouth and intestines are unusually pale, while the peritoneal coat is of a brick red color throughout, thus reversing the usual appearances as to color in the Pest. These, however, may be the appearances in the slow operation of frequent and small doses, while in the rapid poisoning (of dogs) the mucous membrane may be highly reddened.

Phosphorus (gout-producing?), with its specific nourishment for an impoverished vitality, shows also miraculous power over 
the cerebro-spinal system when depressed or threatened with paralysis, in pleuritis, pneumonia, typhus abdominalis, acute exanthemata, \&c. In its pathological anatomy, it intensifies the redness of the stomach and small bowels to a purple hue (sometimes in the ileum of a dark-red brown); and though the lining membrane of the stomach is easily separable, there is also revealed an intense redness (sometimes perforation) of the muscular coat (peritoneum and omentum also) with greenish thick fluid; that in the smaller bowels being ink-colored. Its power to destroy fibrin is so great when exhibited internally (in dogs) that no trace of it can be discovered, even with the aid of the microscope. Unless the Pest in its early stages had more than usual symptoms of typhus degeneration, or was marked with icteric coloration of the eyes and skin, its exhibition would be without reason or benefit. So too with Phosphoric Acid, available for zymotic affections, only in scurvy and in choleraic diarrhoea.

Cuprum Aceticum produces bright red spots near the pylorus, bit these are accompanied by black spots of the size of a pin's head. While the mucous membrane of the stomach and bowels is almost entirely destroyed under its action, the epithelium is not destroyed but thickened, with a tendency to gangrene through the entire track of the digestice canal; the spleen and lungs empty; the liver and kidneys congested; the lungs crepitating, and dotted with rose-colored spots, ecchymosed too, as also the bowels; the blood in the smaller veins thin and of a cherry-red, while the large, veins and right ventricle are full of thick black blood; we have in addition to the bright red spots on the stomach above noticed, only a large gall bladder turgid with dark green bile with yellowish tinge, to tally with the abnormal coursings of the Pest. The principal sphere of this remedy is in the irritation of the ganglionic centers and of the medulla oblongata.

To pass, however, to other drugs, such as we have shown to be in extended empirical and allopathic use, for instance, the nitrate of potash, better known in common parlance as saltpetre. The redness which it produces in the stomach is not that of simple congestion of the capillaries, but it 
would seem of their destruction, as the blood is poured out upon the organ and then vomited up. Its homoeopathicity lies in cerebral congestion, spinal irritation, and the like, and though besides what we have noticed, it produces sensitiveness of the pulse, causing it to flutter, it has no other correspondence with the symptoms of the Pest, unless such may be found in a dropsical odema of the body.

Of the chlorate of potash we have but few provings; and these find no illustration from observed phenomena supervening from its use in poisonous doses.

In like manner we may dismiss Terebinthina oleum (turpentine), whose symptomatic action in this distemper has been given by Dr. Pope; Sulphur, whose potency in chronic ailments is brought out by the higher attenuations; Iron, valuable as an auxiliary to the blood in debilitated or cachectic constitutions; and the host of drugs, such as ginger, gentian, tormentilla, which in large doses may serve as temporary stimulants in many affections, but are without specific efficacy in this.

Quinine produces in animals an enlargement of the solitary glands in the upper portion of the intestinal canal, which is very dry. The glands are somewhat inflamed. Some portions of the canal are slightly reddened, the muscular as well as the mucous coat of the smaller bowels is softened, and can be scraped off down to the peritoneum; that of the large bowels is similarly affected, but in a less degree. Its disturbing power in the human subject, when given in large doses, results in congestion of the brain and cord, red and white softening of the medullary substance and serous effusion; the softening and dissolution of the spleen, and blood congestion of the liver. It would be of principal value after the force of the disease is expended, in the palliation of the symptoms of marked exhaustion.

Rhus toxicodendron, $R$. radicans and $R$. vernix, valuable in paralytic affections of the extremities, in skin desquamations or hæmorrhages, and in zymotics of the typhus type are without massive provings revealing their power over the mucous surfaces. Analogy alone can guide to their prescrip- 
tion after Pope's indication of symptoms, or where the burrowing of the Pest under the skin leads to the conclusion that it is directing its force upon this secernent expanse.

Here we may briefly notice Chloric Ether, prescribed by Dr. Priestman. It may be the Chloral of the modern school which is obtained by the prolonged action of Chlorine upon Alcohol; hence the composition of its name, chlor-al. This is a transparent, colorless liquid, of a greasy aspect; has an irritating odor, is quite tasteless, somewhat caustic in its action on the skin. It must be dropped into water and heated to effect its solution. If brought into contact with a few drops of water, a white crystalline solid is formed and heat is evolved.t Sometimes the term Chloric Ether is applied to the chloride of hydrocarbon; the olefiant gas of the Dutch chemists, and most probably the ether used by Dr. Priestman. Its formula is $\mathrm{C}_{2}\left(\mathrm{Cl}_{1}\right) \mathrm{H}_{2}$. Beyond their power of etherization, but little is known of the therapeutic properties of either of these so-called ethers, and their use, until further scientific investigations of their medical action, must be wholly empirical.

We may be permitted in closing this part of the discussion of remedies proposed, viewed or not from a Homœopathic stand-point; and after presenting thus crudely, the little that is known of the Morbid Anatomy revealed by the action of leading poisons upon the inferior creation; to state by way of apology for so imperfect a sketch, that it is designed mostly to show how much lies yet unexplored in this domain of provings in large doses upon domestic animals. We say large doses, and we mean, moreover, frequently-strenuously repeated; so as to enable the observer to compare the narrow range of symptoms, to which he must

\footnotetext{
* Alcohol, represented by the chemical formula, $\mathrm{C}_{4} \mathrm{H}_{6} \mathrm{O}_{2}$, in the presence of oxidizing agents which take up two atoms of its hydrogen, becomes Aldehyd $\mathrm{C}_{4} \mathrm{H}_{4} \mathrm{O}_{2}$. A similar action takes place when three atoms of chlorine replace in aldehyd as many of hydrogen, and the result chloral is reprisentcd by $\mathrm{C}_{4}\left(\mathrm{H}_{1} \mathrm{Cl}_{3}\right) \mathrm{O}_{2}$. Soubeiran, Liebis and Guthrie of $\mathrm{N}$. Y., by distiling ehloral mixed with lime and water, or with a solution of potassa, obtained a liquid which, when shaken with sulphuric acid, then separated and rectified over baryta in a perfectly dry retort, yielded chloroform; which is now more easily obtained by distilling a mixture of $1 \mathrm{lb}$. chloride of lime, $3 \mathrm{lbs}$. of water and 3 ounces of alcohol in a capacious retort.
}

† Brande's Manual of Chemistry, p. 1305. 
be confined from the inability of the subject to express its sensations, with the lesions revealed by the autopsy. In this way alone can we find a specific for any epizoötic, and we insist, that before any drug can make a fair claim for specificity, it should be shown to be capable of at least simulating the major part of the lesions as well as symptoms of the distemper to which it claims a therapentic affinity. And until such or other more judicious experiments shall have been conducted to a successful issue, the veterinary art will be confined to its present system of palliatives. Every disease will run its course ; and the issue of recovery or death will be determined by the balance between the germinal power of the poison absorbed, and the receptivity of the blood-fluid weakened, or recruited by empirical bungling.

We have yet in reserve, as before announced, the consideration of those remedies, for which it has been claimed that they severally exercise a specific influence in arresting the peculiar ferment of the Pest. Incongruous as the list may seem, they admit of an easy and scientific classification, and may be arranged in three classes :

1st. Those which are essential or concomitant elements of blood-food, and which may be exhibited to supply the waste of these elements during the progress of the distemper; these as opposing forces may be regarded as anti-catalytic.

2d. Those which may be supposed to set up a new ferment supplanting the morbid one, and thus act as apo-catalytics.

3d. Those generally known as antiseptics, which arrest the putrefactive process, by rendering the fluid or tissues, in and on which the ferment is operating, incapable of putrescence -or even of fermentation; and are thus a-catalytic.

In this first class, as it is not our purpose to refer to those which are ordinarily embraced under the head of hygienic preparations; further than to say that Dr. Smart's method of preparing and exhibiting food for the sick animal meets every contingency which the most skillful and assidnous nursing could provide against: we will note a few instances, of which the most important is the Chloride of Sodium, or common 
salt. This chloride is found in the blood, gastric juice, urine, bone, cartilage,* \&c. It exists also as a necessary element of vegetable food; seeds and grain containing the smallest amount, while green vegetables and meadow grasses (especially Lolium perenne, or common rye grass) hold it in largest proportion.t The common experience, of those who are engaged in the rearing of domestic animals, is familiar with the necessity of an artificial supply of this element of the blood, in order to obtain their highest perfection; to secure thrift in growth, or even the appearance of health. Boussingault's experiments are very happy and instructive. He took six oxen and divided them into two lots; - to the one he gave salt at stated intervals, while he entirely refused it to the other. No perceptible difference in the appearance of these lots was, on the most careful scrutiny, manifest at the end of fourteen days; but at the close of the month it was revealed to the most unpracticed eye. In both lots the skin under touch was sound aad fine; the hair of those, to whom salt had been supplied, was smooth and shining; of the others dull and staring. At the end of a year the hair of the second lot was matted, or in places had fallen out, and the animals were listless and inanimate, while the first lot had the sleek and fine coat of stall-fed beasts, and proved their high condition in frisky and rampant attitudes. It seems strange on first thought to learn besides, that the supply of salt had exercised no influence on the quantity of flesh, fat, or, again in other trials, of milk obtained; but the marvel disappears when we understaud that salt plays no part in the flesh-forming economy, but, according to Liebig, merely neutralizes

"the injurious action of the conditions which must be united in the unnatural state of animals fed or fattened in order to produce flesh."

A clearer statement is, that

"salt serves in the organism to assist and promote the general changes without taking a share by its elements in the formative process."

It appears that a chemical action takes place in the system, by which chlorine (not found in chemical combination in any 
organized part or tissue, but ever present in every fluid of the body) leaves its base (sodium) in the common salt supplied to the animal, and unites with potash forming the chloride of potassium; the soda set free uniting with carbonic acid, and forming the carbonate of soda.*

Time will not suffice to follow these changes as far as chemical and physiological research has carried them; it may suffice to add that the chlorine derived from salt, and uniting with the salts of potash, is found as a principal inorganic constituent of the muscles; that the soda as an oxide is found in the secretions of the liver; as a carbonate in the blood of the herbivora (although the ashes of their food yields hardly a trace of it), twice or thrice in excess of the carbonate of potash; $\dagger$ while all excess of salt furnished is carried off rapidly in the secretion of the kidneys. It is important to note that the carbonate of soda (found also in the saliva) imparts to it as well as the blood their alkaline properties; that the tendency of this carbonate (as also that of potash) is to maintain the fluidity of the fibrine and albumen of the blood, that it assists in preserving the form and consistence of the blood corpuscles; and also performs an analogous function with reference to the other semi-solids of the body.t

When we consider that all vital phenomena, or manifestations of those actions which take place in the body in a condition of health; though they may be said to be primarily dependent upon the organic nitrogenized elements of the tissues or fluids for the power of appropriating materials for their nourishment, or of self-regeneration to repair waste; are still, if secondarily, yet as essentially dependent upon the inorganic constituents of such tissues and fluids in order to keep up their play, and so maintain health and life; we find but little difficulty in concluding, that when any of the proximate principles, or elementary constituents, organic or inor-

\footnotetext{
* Soda unites also with Oleic and Margaric Acids (the acids fonnd in fat), forming the Oleate and Margarate of Sodä, which are found in minute quantities in the blood, bile and urine-and with Pneumic Acid (the acid found in the lungs) forming Pneumate of Soda, which is not discharged from the body.

t In the milk of cows four and a half times (according to Berzelius), and six times (Pfaff and Schwartz) more than in human milk.
}

† Flint's Physiology, pp. 36 and 44; supporting Liebig's view, ut sup. p. 426. 
ganic, are in excess, or in deficient supply, their harmonious motions are disturbed, and the charm of vital play and healthy action is broken. The elements, which by too large supply in the first instance, or by the deficiency of their coördinates, and in the effort of nature to maintain a just equilibrium become so, must remain as clogs upon vital action, until they are thrown off, or agencies employed to restore the balance. And it is in this view that Liebig, in commenting on the condition of those animals which in the experiments of Bonssingault were deprived of salt for a trvelvemonth, is both convincing and eloquent, when he says that their bodies were,

" in regard to disease, like a fireplace, heaped with most inflammable fuel, which only requires a spark in order to burst into flame and be consumed."

If the inquiry should now be deemed useless or visionary, whether those animals who succumbed so easily to the Pest had been denied or not a proper modicum of salt; or whether this agent was of any specitic worth in the treatment of the murrains of the 17th and 18th centuries;* one conclusion will not be gainsaid, that in all future prophylactic and remedial treatment of the Pest, salt should be largely supplied in the food, and in the absence of other remedies might be relied upon as palliative if not curative. $t$

We shall embrace under the general division in which we have placed the chloride of sodium, two other agents, although we are far from insisting that either exists so largely as a constituent of the blood-elements, or has been traced as such; or that the latter has any existence in these elements except by conversion or as a product of disease. And in order that we may not give their consideration an undue prejudice, by reason of the classification we have previously made, we will

\footnotetext{
* See page 56 of this Report, and note.

$+\Lambda$ illustrative of the frequent agreement of the tentative experiences of iustinct in our race, and the deliberate conclusions of men of ssience. it is not improper here to notice the fact that the Indians of this Continent, whose nomad life impelled them to the chase for the sustenance of life, and limited their supply of food to that mostly deficient in salt, should have used salt snccesfully as a cure for the bite of the rattlesnake. Sequel to 1st Report, p. 17. See also cases of cure by this agent, in Trans, of the Royal Soc., Vol. XII of Abridgement, p. 244; with white oak bark and vinegar, Vol. IX, p. 230.
} 
for the present urge their disposal at this time as a matter of personal convenience; and with this apology we may be permitted to announce a summary view of the uses of Oxalic and Acetic Acids in the treatment of the Pest.

Oxalic Acid is known to exist in vegetables eaten by man, as in the Rbubarb plant (Rheum rhaponticum), and in the Tomato (Lycopersicum esculentum.)

It obtains also in vegetable food consumed by cattle, of which we will only specify the sorrel tribe, either the mountain variety, oxyria reniformis (R. Digynus, L.), or the common Dock (Rumex acetosa), and the equally common sagittate plant. According to Liebig,* it exists in roots, barks and leaves to which cattle are frequently found to turn, leaving, when opportunity offers, their richer pastures for such relishes. True, the acid is found in nature mostly in combination with potash and lime. As produced by art, however, it is the only vegetable product which in its anhydrous form contains no hydrogen, and thus as the analogue of Carbonic Acid, deserves a careful study. The experiments made on animals by Christison and others, mostly by injections into the veins, exhibit its immediate control over the motor nerves evinced in walking with a peculiar stiff gait, in jerking or drooping of the head, and paroxysmal action of the muscles of the chest. The bright scarlet spots, observed by Smart, are brought ont on the external surface of the lungs, unless death has been very rapid. Though no reliable deduction can be made from these injections into the venous trunks, whether femo. ral or jugular; yet the post mortem appearance in men, who have been poisoned with this acid taken into the stomach, show the same reddened (sometimes brownish red) appearances of the mouth, gullet and windpipe (stomach in parts black, in parts red), duodenum and jejunum ; with easy detachment of the epithelium and villous coat, as in the Pest. The high affinity this acid has for lime and potash might justify its use, as a chemico-physiological experiment, at the period when there was reason to believe that the bases of these salts were passing off in the general disintegration of the 
bloot-thids. It could only be exhibited in dilnte form in small doses, frequently repeated; as in a eoneentrated solution it rapidly destroys the coats of the stomateh, inducing gangrene-or aflecting the brain by sympatly-eonvulsions and rapid dissolution. But wo only design to indieate it to bo worthy of provings such as we have previously sugerested; with the eantion applicable alike to most acids and corrosive drugs; that in its administrative trials every effort should be made to avoid as far as possible those local lesions in tho digestive canal, which induce death before the general eonstitutional disturbance is produced f for it is this alone which it is of importance earefully to study, both in the consequent changes induced in the lining or enveloping tissues of tho principal organs-in their substance, and in that of the fluids of the body.

Acilum acetienm (radical vinegar, as it was formerly called), may prove of more value than any other acid in this disease, and, if so, is of realy use in domestie vincgat. By doses of four tablespoonfuls a day of the latter given to adults, Dr. Parrot, of Dorpat, Russial, suceessfully treated many cases of epidemic typhus in 1812; and this where the ferer was aceompanied with obstinate diarhori. In this latter symptom its use is always admirable.

Dr. 'Thomson salys that it has been aministered in combination with salt in dysentery, ehecking the purging and correcting the footor of the stools.*

Its existence in the sweat has been shown by Thenard, and when the acid is combined with a base, the addition of the perehloride of iron to a solution of the salt, produces a deep blood red color, an effeet not observed, when tho fireo acid is alone employed.†

In this view, as well as of the combination commended by Dr. Thomson, its use would be more eflicacious in a ' Zymotic,

\footnotetext{
* Materia Medica, Vol. II, p. 56. In the presence of the more fashionable remedieg of the age, this has amost pased into oblivion as an chlefent arent in Phthisis, for which Galen prescribed it, and Oriental physiclans now use it. In the form of vincgar its uso is mostly contined to domestic cooking, unless when some young lemale, ashamed of her obesity, uses it so freely as to induce hemoptysis and cousumption.
}

†Simon's Chemistry, Vol, I, p. 86. 
when saturated with salt, the compound to be administered largely dilnted with water.

It may be also urged that this acid represents chemically the fruit acids-at least the one most common in this climate and country-Malic Acid. Liebig regards all the organic acids as having an analogous constitution, and decoms it

"the most, natural supposition that they contain in each case a compound raclical, of which Ifydrogen is an element; in such a manner therefore that the conversion of (arbonic $\Lambda$ cid into an organic argid has been effected by the rejlacement of a part or of the whole of the oxygen of the radieal, by hydrogen."

In this way, and on this supposition, he makes the formulat of Acetic and Malic Acids the same, and adds:

"It is easy to see that the formula of $\Lambda$ cetic and Malic $\Lambda$ cids correspond to that of Oxalic $\Lambda$ rid (omly being doubled), and that Tartaric $\Lambda$ cid is Carbonic $\Lambda$ cid, in which half the oxyogen of the radical has been replaced by hydrogen, while one-fourth of the oxygen external to the radical has been separated or expesled without replacement." ${ }^{2}$

It is not to be inferred, however, that the chemical theory of equivalents as thus expressed, is to serve as a foundation for equivalent medical action; or that any such experience as is found in the laboratory would bes repeated in the stomach of either man or beast. But the manipulations and conclusions of the chemist may serve as our sufficient authority for introducing these acids uncler the general classification and at the point we proposed at first on grounds of convenience.

And here it may meet a scientific requirement, to bring to notice other primordial elements of blood-food. In such way this branch of our inquiry may take to itself a more perfect unity. We have cited common salt as the representa-

- Anlmal Chemintry, p. 68, Amer'n (3d London) edition. The formulas are as follows:

$$
\begin{aligned}
& \text { Carbonic Acid, } \left.\mathrm{C}_{2} \underset{\mathrm{U}}{\mathrm{O}}\right\}+\mathrm{O}_{2}=2 \mathrm{I}+2 \mathrm{O} \text {. } \\
& \text { Oxalic } \left.\Lambda \text { cid, } \mathrm{C}_{2} \mathrm{O}_{\mathrm{O}}\right\}+\mathrm{O}=2 \mathrm{R}+0 \text {. } \\
& \text { Malic Acid, } \left.\quad \mathrm{C}_{4} \mathrm{H}_{2} \mathrm{H}_{2}\right\}+\mathrm{O}_{2}=4 \mathrm{R}+2 \mathrm{O} \text {. } \\
& \text { Acetic Acid, } \left.\quad \mathrm{C}_{4} \mathrm{O}_{0}^{\mathrm{H}_{3}}\right\}+\mathrm{O}_{2}=4 \mathrm{R}+2 \mathrm{O} \text {. } \\
& \text { Tartaric Acid, } \left.\mathrm{C}_{4} \underset{\mathrm{O}_{2}}{\mathrm{H}_{2}}\right\}+\mathrm{O}_{3}=4 \mathrm{R}+3 \mathrm{O} \text {. }
\end{aligned}
$$


tive of the mineral constituents of the animal economy. TVe might, harl our limits permitted, also have adduced the salts of potash and lime; of which nitre and the iodide and chlorate of potash and the phosphite of lime are the representatives in medical practice now most commonly in use. But of the nonmineral constituents, it is understood that the carbonaceous element of the animal frame (through vegetables) is derived from Carbonic Acid, two of whose analogues, as therapentic agents, we have adverted to ; that the non-nitrogenized element (as in sugar, starch, oils, \&c.) derives its hydrogen from water; while the nitrogenized elements (as in muscle, gluten, \&c.) take their nitrogen from Ammonia.

But as the uses of water are well kuown, and we have previously expressed our views as to the value of ammonia as a medicinal agent, we may be considered as having sufficiently dwelt upon the typal forms of blood-food, and may pass to the second class, of those for which the claim has been made, of specificity in the Pest.

On this class, the one which embraces antagonistic ferments, we shall not divell long; as we will not undertake to discuss and do not care even to point to those which in putrescent cheese or meat (as in badly prepared Bologna sausage), when introduced into the human stomach, hare produced such subversion of the natural fermenting power of that organ and its adjuncts, as in many instances to baffle all medical skill.

It is our purpose to treat in this class only of yeust, which, as we have seen (p. 100), has been said to have been successfully tried as a remedy for the Pest; and our view of it as a remedy will be chiefly by way of comparison.

Yeast deports itself in the presence of many agents and re-agents, as the ferments of zymotic disease are believed to do, and may in this respect be regarded as their type. As familiar as the common mind is with this substance, its scientific definition may not find such ready discernment. It is a compound of nitrogen in the state of putrefaction or eremacausis (slow combustion or decay), possessing the power of causing fermentation in sugar or non-nitrogenized 
organic bodies, of which sugar and starch are the commonest instances, and carbon the chief coustituent. The presence of water is necessary to sustain its power of exciting ferment, and this is lost under pressure, or when the yeast is desiccated and dried.

It is alone its soluble part, however, that possesses the property of inducing fermentation, and this only after it has received oxygen from the atmosphere to which it must be first exposed. It then developes in its mass carbonic acid. Like vaccine or purulent matter-if not kept dry too long, and under attendant circumstances which ensure its own decomposition-when again moistened, it starts afresh on its destructive mission.

The fermenting process is easily carried forward to putrefaction in bodies containing nitrogen, of which, in the animal organism, blood is the primum mobile. And as nitrogen has so low an affinity for the simple bodies, that it is said to be in a state of indifference to them, its evolution is always attended with an easy transposition of atoms. When acted on by alkalies, by acids, or increase of temperature ; organic compounds, containing nitrogen in the presence of water, throw off all that element in the form of nitrates; but if the azotised animal matter first moistened, be exposed to the action of the oxygen in the atmosphere; then in the form of ammonia. When gluten, the vegetable equivalent of albumen, is subject to the putrefactive process; after the evolution of carbonic acid and hydrogen commences, the ammonia takes on its forms of phosphate, acetate, caseate and lactate, which are produced in large quantities; so that for the time being the decomposition of the gluten ceases. But if water is freshly added, the process is renewed, and then in addition to the products just mentioned, we have carbonate and hydrosulphate of ammonia and a mucilaginous substance coagulable by chlorine, \&c. Those who desire to follow the labyrinthine changes of which nitrogen is capable, will find that subject elaborately treated by Liebig,* from whom we have freely taken the views above expressed. We must turn, 
however, to the brief consideration of the agencies by which fermentation is arrested.

These are embraced in a long catalogue known as antiseptics, of which we may mention the most important; to wit, boiling water, alcohol, salt, an excess of sugar, the mercurial salts, nitrate of silver, volatile oils ; the mineral, pyroligneous, sulphurous and carbolic acids.

"Alcohol and common salt, in certain proportions, check also all putrefaction, and consequently all processes of fermentation; because by these means the putrefying body is deprived of a certain condition of its decomposition, namely, the presence of a certain quantity of water."

The action of these antiseptics, in arresting yeast ferment, and also the putrefactive process in animal substances, is of the highest interest in the pathology and treatment of zymotic disease, and will readily furnish to the enthusiastie student of medicine most valuable suggestions. His aim in their applications in medical and veterinary practice, will be to select such as will produce the least disturbance, transient or permanent, on the vital force. We will only add, that from the similarity of the action, while in the state of propagation, of yeast and morbid poisons, and the identity of the means by which it may be arrested, that it is not improbable that yeast may exert a curative action in the Pest; thongh even such probability requires that more numerous trials should be successfully instituted than those previously noted.

The old school of medicine has long since exhausted its ingenuity in the use of mercurial salts and the like, in the treatment of epidemics, and has passed from the general use of the mineral acids; and the present school rejoices in the discovery of the efficacy of those last named in our list, to wit, sulphurous and carbolic acids.

This brings us to the consideration of two of the most valuable antiseptic remedies; which are embraced in our third division of specific agencies.

The farmer has long been familiar with the fact, that if he burns a little sulphur in a barrel which has been rinsed out with water, and confines the fumes produced, so that they are 
absorbed by the wet surface of the staves; the cider he may subsequently pour into the vessel, will remain sweet for a long period and will not undergo the fermentation ordinarily induced. This preserving power is one of the attributes of the sulphurous (not sulphuric) acid generated in the combustion of sulphur, and has been taken as the starting point for some exceedingly ingenious researches by Dr. A. Polli, of Milan. This learned professor adopted the catalytic theory of disease, as applicable to those maladies in which the blood having absorbed some poisonous morbific germs, undergoes marked constitutional changes; and though he was met at the threshold of his investigation by the dogmatic assertion of the celebrated Bernard, that any substance capable of destroying a catalytic poison in the blood, would so affect that fluid, that it would be thereafter incapable of vital function; persisted in his inquiries, until he satisfied himself that not only did sulphurous acid possess this power, but that its compounds with soda, lime, or magnesia whether hyposulphites, simple sulphites, or bi-sulphites also exercised the same function, and could be exhibited in large doses and with perfect impunity. Two animals of the same kind, size, and condition, and fed alike for a few days, except that one received a certain amount of a sulphite in his food, were slaughtered; when it was discovered that the latter gave evidence of the existence of the drug in every tissue, organ, and secretion; and furthermore, remained perfectly fresh though the weather was that of summer in a tropical clime; while the former, to which no sulphite had been given, rapidly passed after death into an advanced stage of decomposition. This experiment being confirmed by many others equally satisfactory, the deduction naturally followed, that as no fermentation could exist in the presence of a sulphite, and as this remedy could be administered without any injury to the vital function, and permeate every part of the living structure, that it was only necessary to saturate the system with a sulphite, in order either to prevent, or arrest the catalytic action in all zymotic maladies. 
But further to establish this deduction by facts, the Professor next selected two dogs of equal size and weight, and in perfect health; fed and treated them alike for four or five days, except that to one was administered a certain quantity of the bi-sulphite of soda. Some very fotid pus obtained from an ill-conditioned ulcer was then injected into the fernoral veins of each dog (about a drachm to each), the experiment being repeated on the next day. After the first operation, both laid down, refused food, and remained prostrated for twenty-four hours. The effect of the second injection was more marked. They were seized with stupor, their pulses were rapid and feeble, and their respiration greatly accelerated; when made to rise they tottered and reeled across the room. The one to whom the bi-sulphite had not been given grew worse, his wound in the thigh became gangrenous, and in ten days he died with all the symptoms of typhus; while by that time the other, receiving his daily dose, and having regained in four days his appetite, was entirely well.

Like experiments have been conducted in a vast number of cases by the Professor and his compeer, Dr. De Ricci; sanious matter from ill-conditioned and phagedenic sores,defibrinated blood exposed to the air until it has become putrid-the discharge from the nostrils of glandered horseshave been employed, and in all cases proved fatal withoutand wholly innocuous with-the concomitant use of the sulphites. Conversely De Ricci has exhibited the bi-sulphite in an alarming case of septicæmia, produced by a lady's kissing the lips and face of a dear friend who had died very suddenly; giving nearly twenty grains of the bi-sulphite in infusion of quassia, \&c., every half hour at first, and then every hour; and with the most perfect success. Since that time the use of the sulphites has been extended to cases of scarlatina ; measles; phlebitis, originating from the stinging of the back of the hand by the spines of a cactus; the malignant epidemics of the Northeru Coast of Africa ; puerperal fevers, \&c.*

* Dublin Quart. Journal, August, 1864; Glasgow Medical Journal, October, 1865. 
In most if not all these diseases, the administration of the sulphites has also proved prophylactic.

When the fermenting process is arrested by sulphurous acid, the rationale of such action, according to Liebig, is that atoms of oxygen are taken up from the liquor of ferment, and combining with those of the sulphurous acid, form Sulphuric Acid. If this transposition in inorganic, is also realized in organic fluids, and takes place during the administration of the sulphites in zymotic diseases; the resultant acid being formed in very minute quantities and generally distributed throughout the circulating media, could not exert its ordinary local effects, which are primarily escharotic and destructive of the tissues. Indeed, Pereira's statements in regard to the constitutional action of all mineral acids may be adopted here, that they become neutralized by combination with bases (of salts), and are not absorbed as free acids which operate topically only. In this view we may be spared any extended discussion of the constitutional disturbances produced by the use of sulphuric acid; and for the further reason that its lesions do not correspond with those of the Pest.

The Sulphite of Potassium develops in the treatment of zymotics, action equally beneficial with that of the like salt of soda. It is more expensive, and for that reason not so well fitted for general use. Nevertheless, it should be employed as we may recommend in experimental trials; and in all desperate and long neglected cases, where it is probable that the salts of potash have begun to leave the circulation.

Carbolic Acid sometimes called Phenic Acid, but chemically, Phenic Alcohol, or Phenol, is said to occur as a natural product in the secretion of the beaver, castoreum, whose peculiar odor is that of this acid; it is also found in the oil of cocl-tar. Its aqueous solution has an acrid taste, and an odor like that of wood smoke or creosote, of which last it is 
probably a homologue.* Its formula is $\mathrm{C}_{12} \mathrm{H}_{6} \mathrm{O}_{2}$. It is obtained by the decomposition of Salicylic Acid $\dagger$ (an acid of the benzoic group), which is itself derived from several species of Salix (willow), and from the flowers of Spirce ulmaria (queen of the meadow). As it is highly poisonous, it is to be administered with discretion, and largely diluted with water. In this form it is very valuable as an application to the skin, where wounds and sores reach a putrescent stage, $\neq$ and like the sulphite of soda, thus dissolved, is readily absorbed. The latter so diluted and applied with a wet bandage, we have known to discuss the formation of ordinary boils; the former of erysipelatous swellings. Whether this acid will act as readily or more effectually in arresting the Pest-ferment than Sulphurous acid, in its administration through the sulphites; time and experimental trials will best determine.

As we have progressed (though wearily, we fear, to some of our readers) in this extended review of the potential action of remedies propounded by various authorities as available in the cure of the Pest; some light has been incidentally thrown (as we imagine) upon the pathological course of this distemper. We have seen the important and curious part which the chloride of sodium plays in the animal economy (p. 119) in the preservation of its equilibrium, or what we ordinarily term the state of health. Inferentially we are able to approximate at least to the nature and order of those disturbances which must take place, when this essential element of the fluids and semi-solids of the body is withheld in times of scarcity, or through neglect to supply it at stated intervals; or when, in the progress of the fermenting processes of disease, it is decomposed or forced out of the circulation. Then its normal function must be deemed to be wholly negatived; especially, we conclude that

* Silliman's Chemistry (Organic by Hunt), § 789.

t The common wintergreen (Gaultheria procumbens), contains in its essential oil the ether of this acid-to which, or the oil of wintergreen, if strong nitric acid be added and the mixture boiled as long as red vapors appear, trinitric phenol (nitropicric acid), is obtained on cooling. Ib., §795.

$\ddagger$ Also in the treatment of compound fractures of bones and in burns, as recommended by Prof. Lister; and in the treatment of burns of the first and second degree, by Prof. Pirrie, \&c. 
the fluidity of the fibrinous and albuminous elements of the blood, and the form and consistence of the blood corpuscles, are impaired.

At such a juncture (though science may not as jet have demonstrated the order of the successive stages) we may also infer that the transposition of the atoms of nitrogen, which in their allotropic forms make blood, fibrine, \&c., commences; the probability being that they take their departure in the form of ammonia, and that some of those subsequent combinations are formed in the body, which have been previously sketched (p. 125).

We can thus see how the secretions, not as in cholera, largely made up from watery constituents, but surcharged with alkaline carbonates, are poured out upon the mucous surfaces, with excoriating power ; bringing with them the first products of decomposed nitrogenized matter, to be in their turn fresh elements of corruption, if communicated to other animals; or, if reabsorbed, additional exciters of the putrid fermentatiou. And we can readily infer, that when the bases (salt, potash, \&c.,) of the inorganic constituents are withdrawn from the circulating media in certain measure, the ferment of the organic elements reaches the stage where putrid exhalations, the evidence of their accelerated decomposition, are first the harbingers and then the accompaniment of death.

But as in organized structures we have not only to consider the play of elementary bodies, such as are reproduced in the laboratory, and thus display the chemical laws to which they are subject; but also the power, countervailing doubtless in many ways, which vitalized membranes and structures exert in limiting or enlarging such laws; and also that mysterious agency lying behind all possible phenomena, the vis vite itself: so the views we have just advanced on the function of the saline constituents of the blood, and its easy disintegration in their absence, total or partial, need further elucidation in the light thrown by physiological research on such topics. We can only glance at one or two illustrations.

The mineral acids have been generally regarded (p. 126) as antiseptic agents. But they exert their porver in various 
degrees of manifestation, and do not all deport themselves as pure chemical solvents. In some cases they can hardly be said to exert any direct, if any influence whaterer, on the fermenting fluid. Take, for instance, arsenious acid (common arsenic). Its action is wholly confined to the membranes and membranous tissues with which it is brought in contact. It does not exert the slightest influence, according to Liebig,* on the fermentation of sugar in vegetable juices; the action of yeast on sugar, or even the putrefaction of the blood; its scope of action on the tissues being explained by the fact that the gelatinous tissues form a combination with this acid, similar to that which tanuic acid forms with the skin. The prudential use to be made of this discovery of the chemist, and as corroborating what has been previously advanced (p. 110), is that this acid has no relation to the Pest; and that neither this nor any other acid should be employed in the treatment of any zymotic, whose force is expended in part or in whole on the membranes with which it is brought in contact, unless it has the further peculiarity of ensuring for, or restoring to them a more active power of absorption.

But a more pertinent illustration is to be drawn from the behavior of common salt in the phenomena first observed by Dutrochet, when exploring the mutual action of two liquids on each other through a membrane. This action was named by him and is now generally known as endosmose.

If a glass tube about six inches long and with an aperture of one-quarter of an inch, be covered at one end with a piece of fresh membrane, taken from an intestine, bladder or stomach; and after being filled with a solution of salt, is held in a vessel containing pure water, so that the level of the two fluids is the same: in a short time there will be perceived an elevation of that contained in the tube, which is to be regarded as the result of a force exerted against the law of gravitation, and at its height is equivalent to and may be measured by a column of mercury two or three inches in height. 
If to the water in the vessel there be added salt enough to make it of the same saline strength as that in the tube; in an equally short time, the fluid in the latter will go back to its original level. But if again, more salt be dissolved in the vessel, the fluid in the tube will soon be found at a lower point. The law of these changes of level may be thus expressed."

"The spring water flows towards the saline water, and the weaker solution of salt towards the stronger; as if forced by an external pressure to pass through the pores of the membrane, in opposition to the law of gravitation."

Water also flows towards blood, when into the tube is poured ox-blood, deprived of its fibrine, and the experiment is conducted in the presence of water heated to blood heat or $100^{\circ}$ Fahr. ' But this flow is dependent upon the existence of salt in the liquor sanguinis.

If again to either fluid, as in the original experiments, there be added a free alkali (carbonate or phosphate), the change in level is more rapidly produced. And finally, if the outer liquid be made slightly acid, then

"the flow of the acid to the alkaline liquid takes place with the greatest velocity."

The philosophy of digestion in the flow of the alkaline fluids of the blood toward the stomach, which, when distended with food, secretes an acid, and the general percolation of fluids through the membranes of the body find an easy illustration in these experiments. The latter may also explain how an acid judiciously selected and employed so as not to impair the susceptibility of the membranes, may be so moved by the swift propulsion of osmose, as not only to neutralize the alkali in excess, but also to arrest the attendant decomposition. But aside from such conjectural views, we have at this time a practical purpose in drawing attention to the action of saline drugs. When these are introduced into the alimentary canal, to induce catharsis, the flow of fluids not so highly charged with saline ingredients,- 
as in the experiment with the glass tube, covered with membrane-is toward the more concentrated solutions; and the bowels thus distended soon relieve themselves by purging. A moment's reflection leads to the conclusion, that as by this operation the circulation has been deprived more rapidly of its saline constituents than it would have been by the force of the disease, the latter has received fresh augmentation of its power, and not the amelioration of condition anticipated. Another deduction and we have done. Salines introduced even indirectly into the circulation to repair waste, should never be in a concentrated, but a highly dilute solution; as it is only in this way we can institute an endosmosal current by which they may be carried into the circulating media, and reverse the morbid current which tends to carry them out.

We are now in a position where we may essay what we have proposed, and propound a method of treatment that may best accomplish cure. We would gladly avoid the responsibility which must always attend the proffers of those who challenge an untried enemy. But if we are clothed in the armor of science, and avail ourselves of the promptings of a wise instinct inspired by her teachings and instructed by the errors of those who have preceded us, we can hardly fail. If we should, however, we are satisfied that thus we will prepare the way for more successful overtures in future.

We trust, however, that we may not be ranked with those who have at first counted without their host, or at the last, made false alliances. We do not propose to shield our methods under any special theory, however fashionable. We will not espouse all the conclusions of the chemicophysiologist, to the disgust of the humoro-pathologist, or the disciples of the vital school. We "take the good the gods provide" us. We essay only a common-sense solution of the foremost intricacies in the problem before us; and will be content, if we succeed thus far, to leave what remains to the fancy or skill of the theorists of all 
creods. But that we may not seem to be trifling with the honored and well earned confidence which the teachings of the different schools have inspired, we interpose an explanation. If one were bitten by a rattlesnake, it would be held by men of ordinary judgment to be the most reprehensible bravado in him, to refuse all the methods of relief proposed, and to trust entirely to the peculiar strength of his constitution to quell the poisonous invasion. And it would present a temerity entitled to but little less of blame, if he were wittingly to allow the poison "swift as quicksilver" to course through-

"The natural gates and alleys of the body ........................ posset, And curd like eager droppings into milk The thin and wholesome blood;"

- that at the last he might either prove himself in possession of a talismanic charm, strong enongh to foil its enmity; or by a succession of charlatan-remedies to bafle his antagonist, or by countermoves, to weary him out. The instinct, or if you will, the common sense of the race, demands that no dalliance be held with such a mortal foe. The bane must receive its antidote, if to be found, and that without a moment's unnecessary delay.

In this view, the end proposed is to act as if the Pest germs were the poison of an asp, at once to be rendered inert; or some baleful dose swallowed, whose corrosive action is instantly to be neutralized. The first and great point then is to get rid of the toxic effects of the poisoned germs which are developed in this zymotic, and to this end, if one may quote a homely but expressive proverb, "not to let grass grow under our feet."

As a guide to the unskillful-a hand-book also to the learned-we will indicate our proposed method of treatment in a series of rules.

RuLE I.-In apprehension or in the presence of an outbreak of the pest,

a. Apply the thermometer (see p. 65) to the vulva or rectum; and if the heat of the parts (the females not 
being in a state of sexual excitement, and none overheated by driving, \&c.) rises to $102^{\circ} \mathrm{Fahr}$.; or-

b. If no such instrument can be readily had or reliably used; observe the appearances of the inner mouth (see p. 74). If to the eye or by the aid of a magnifying glass there appear small round nodules (knobs) no larger than a millet seed, red at the point or head, or some of them broken and discharging a yellowish or yellowish-grey matter, and the thin membrane which covered the swelling and those adjoining peeled or rolling off:*

All animals exhibiting these signs are at once to be put under treatment as in Rules II, \&c.

RuLe II.- $a$. Let all such animals be separated at once from the herd, and placed in an out-building which is to be used as a hospital-in suitable stalls or boxes-from which all hay, grass, straw, litter, loose dirt, cobwebs, \&c., are to be removed. Sawdust, tan bark, or dry sand is to be their bed.

b. Dissolve 2 oz. of Sulphite (not sulphate, which is Glauber's Salts) of $S o d a$, or 1 oz. of the Bi-sulphite, in 12 quarts of pure spring or clear rain water.

(If the treatment of the case has been long deferred, or the outbreak be deemed an alarming one, double the quantity of the salt may be employed, not otherwise). Administer 1 pint of this solution every hour (or half hour), after Gamgee's plan. $f$ A tin twisted cup in the shape of a horn, with its mouth well rounded off, is to be employed to the exclusion of glass bottles. "The operator should go up to the right side of the animal, pass his hand over the face into the angle of the mouth in the left side. The head is bent round, not elevated, except to a slight extent; .... the person giving the draught to plant his feet well on the

* Those who apply the thermometer in time will SAVE THE WHOLE PERIOD OF INCUBATION, or at least five days of burrowing of the pest-germs through the membranous tissues, and of their ferment in the fluids of the body. Those who watch the first signs in the mouth may save from tivo to four days. Those who are so indolent or inobservant, as to wait until they find the disease in full blow, should "go farther and fare worse." Let them hunt up other indications which may serve to alarm them. We have no patience for such a task.

+ Cattle Plague, p. 98. 
ground, with his back against the animal's shoulder, .... and holding the horn in his right hand, pour its contents by degrees into the animal's mouth."

c. Take one-half ( 6 qts.) of the solution as above, and add to it 12 qts. of warm water $\left(120^{\circ} \mathrm{Fahr}\right.$.), so that the mixture when used may be at least ten degrees above blood heat.* : Take a coarse cotton sheet, folded to four thicknesses, and wetting it with this warm solution, (wringing the edges of the folds so that the water will not drip), lay it on the middle of a coarse woolen blanket (previously fitted as to size, and with straps to fasten it, \&c.); then apply to the abdomen and fasten the blanket over the back. (Apertures may be made in the blanket if long enough, so that the hind as well as the fore legs may not be restricted in their motions, and so as to protect the chest and buttocks from the air) $\nmid$.

d. If no Sulphite or Bi-Sulphite of Soda can be procured, or more than one animal is to be treated, use Carbolic Acid, 4 drachins to 12 quarts, pursuing the same method of internal as well as external treatment as in $(b$ and $c)$.

e. For like reasons as in last rule, employ $1 \mathrm{oz}$. of $A q u a$ Ammonia to 12 quarts of water, as in ( $b$ and $c)$, or,

$f .1$ pint of alcohol with as much salt as it will hold in solution as in ( $b$ and $c)$, or,

g. $1 \frac{1}{2}$ quarts of vinegar saturated with salt as in ( $b$ and $c$ ), or,

$h$. Other remedies, the specificity of which is to be proved by the same methods.

$i$. As an independent experiment with the sulphite of soda (or if the sulphite of potassium can be had, with it also), 20 gr. powders might be thrown every hour under the tongue, to be dissolved in the saliva which is rapidly secreted and then to be swallowed.

* This temperature will meet the requirement of the fourth law of absorption by osmose as laid down by Matteucci in his fourth Lecture on the Physical Phenomena of Living Beings.-Am. Edit., p. 89. See also p. 133 of this report.

+ As the object of this application is to induce endosmose of the saline solution by the abdominal organs, and not a general perspiration, the blanket must not be too tightly secured. 
RULE III.-If the symptoms do not indicate that the ferment has subsided, twelve hours after the medicinal dranghts as prepared have been entirely taken, or if they recur, commence anew with a fresh portion of the remedy selected, and proceed as in Rule II ( $b$ and $c)$.

RULE IV.- $a$. If nervous twitchings or the like make their appearance, apply pounded ice in a bladder or bag, to the base of the brain and the spinal cord (from between the horns for a few inches along the neck). If this application does not soon relieve, and the Homœopathic treatment is preferred, in the choice of intercurrent between the doses of the anti-septic remedies, as above to be employed; give 10 drops of the tinct. of Belladonna in four table spoonfuls of water, or if the Allopathic methods are chosen, and diarrhoea has supervened, add a table spoonful of laudanum* to a pint of starch emulsion (or warm water) and inject as an enema into the rectum.

$b$. If after twelve hours from the commencement of the treatment, symptoms of aggravation appear, the dose may be doubled. Otherwise if evidence of improvement appears, it may be less in quantity and given at longer intervals.

c. When it appears desirable to remove the bandage from the bowels, the portion of the body wet by it may be gently dashed with water from the well $\left(60^{\circ}-70^{\circ}\right.$ Fahr.), then rubbed perfectly dry, and the body covered with a fresh blanket so as to exclude the action of cool air.

d. If the bandage is not used, still the animal is to be covered with a blanket, and the temperature of the stall

\footnotetext{
* It would be useless to give morphia or opium in any of its forms, while a medicinal endosmose is being instituted-as it is well known that these first check and then reverse the process (see Matteucci's Lectures, p. 79). They can be exhibited only when the morbid osmose has filled the bowels and brought on diarrhcea. If the brain conditions indicate the use of opium in coma, stertorous breathing, and upturned eye and contracted pupil (or a pinched eye), a warm solution should be applied and rubbed in, along the face or the under part of the neck, or one-half of a grain of morphine, or 5 grains of first decimal Homœopathic trituration may be thrown in under the tongue. It will be readily admitted as unwise, in the present state of our knowledge, to hope for alleviation of symptoms by putting opium in any of its forms, in the stomachs, while they are in a state of suspended activity. Otherwise we admit, if scientific experiments could show that when the normal endosmosal current towards the stomachs had completely ceased, opium could exert an antagonistic power, and renew the current.
} 
kept not lower than $60^{\circ} \mathrm{Fahr}$. If the covering is sufficient, fresh air may be more freely admitted.

RULE V.- $a$. When the patient gives signs of hunger, dilute milk or boiled gruels (as in Smart's method, p. 92), to which a free allowance of salt has been added; or when thirst is manifest, water from which all chill has been taken, may be given a half hour before the administration of the medicine.

b. Should any unpleasant odors arise from the body, breath or droppings, dilute sulphuric acid may be added to a small portion of chloride of lime, and after the early escape of chlorine, and when the caustic smell of lime is perceived, the vessel is to be removed; and the contents, added to the droppings of the sick beasts, also to be removed, and covered with six inches of earth. Or carbolic acid may be used in dilute solution, and the sides and floor of the building sprinkled with it. And so. with any disinfectant, such as carbolate of lime, sulphate of iron, dissolved in water, \&c. Carbolic acid may be dissipated through the building by throwing from time to time a few grains of it upon a hot plate-dipped for a few minutes in boiling water and then wiped dry.

c. If constipation show itself so as manifestly to make the animal uncomfortable (and not otherwise), give two quarts of an injection of blood warm water, to which a couple of tablespoonfuls of salt have been added.

d. Should any disposition to swelling (emphysema) show - itself along the back from the beginning, make the wet bandage large enough to go around the trunk; if it be only partial, or occur at a late period, shift the bandage, \&c.

$e$. If any viscid or glairy secretions from the eyes, nose, mouth or vulva begin to flow, the parts are to be frequently bathed with a weak solution of carbolic acid, or with vinegar to which an equal portion of water has been added. 
RuLE VI.-The sequelce of the disease must be treated according to their indications.* If the medicines have not been pressed with too much activity, there need be but little apprehension of any violent reaction on their use. And if no such reaction manifests itself, the animal is best left to the "vis medicatrix naturce."

RULE VII.- $x$. When convalescence is established, the diet as given by Smart may be followed. Before being admitted to the herd, the patient should be carefully washed with a weak solution of carbolic acid, into a stronger solution of which the feet first washed out in the clefts very carefully have been allowed to stand for a time. After this operation a quarantine of seven days would be advisable.

b. To cleanse the premises boiling water may be sprinkled frequently and copiously over the stalls, floors, \&c. If cold water is employed, the common washing soda of the shops should be added, and all boards, \&c, carefully scrubbed. The clothing of attendants may be treated in either of the above ways, or may be washed with water to which carbolic acid has been added, or they may be hung up in a barrel, and sulphur slowly burned under them, \&e.

This method of treatment will, we trust, be received by candid minds as fulfilling our pledge, not to commit it obsequiously to the interest or dogmas of any school. It will be doubtless considered in this respect sufficiently catholic. In the variety of agencies offered in Rule II, opportunity is offered to determine experimentally which is most efficacious. If the so called antiseptic remedies prove their superior virtue, they will furnish additional proof that this zymotic acts as a true ferment. If ammonium causticum takes the lead, it will afford another illustration of the Homoeopathic law. If the absorption through the wet bandage (and we

\footnotetext{
* The constitutional disturbances produced by the force of the disease-perhaps also by the remedies-may require further medical treatment. This must be determined according to the preferences of the practitioner and the methods of the school to which he belongs. The foregoing pages $\mathrm{m}$ iy prove a sufficient guide to indicate which medicines in especial contingencies cover the case most completely.
} 
would like to see isolated trials of this method), should work successfully, this would draw just attention to the practicable adaptation in disease of the law of endosmose, and would ameliorate the heroic use of the water treatment.

In conclusion, whichever of these remedial methods should give the greatest percentage of cures, would best indicate the selection of a prophylactic agent; though we imagine that even the use of this would not excuse the farmer or stock-grower who did not, in the presence of this epizöotic, give to his cattle at least their ordinary quota of salt, as often as twice a week.

P. S. Thanks are due and very cordially expressed to Alonzo $\mathrm{H}$. Clark, M. D., of New York, for access to the plates, \&c., of Perigoff; to S. O. Vanderpoel, M. D., and E. P. Hun, M. D., of Albany, for the studies of Lebert and Cruveilhier; to Sam'l Lilienthal, M. D., of New York, for translations from Jessen; to John L. Vandervoort, M. D., Librarian of the New York Hospital, for transcriptions from Rammazini and Lancisi ; and to the Committee of the New York Medical Society, of which D. D. Smith, M. D., is Chairman, for marked courtesy and very valuable suggestions. It is not to be inferred, however, that either of the above named gentlemen, celebrated for their mastery of Pathology and Therapeutics, are committed to any of the conclusions in this report. These, hastily sketched in intervals of leisure, must stand as the independent conclusions of the writer, and as they have been put forth with much diffidence, a kindly criticism is solicited for them. 
WI $, 27,4$ 


\title{
APPENDIX,
}

Giving the descriptions of symptoms, and post mortem appearances, \&c., of the epizöotic of 1711 , as described by RAMMAZINI and LANCISI; as in the original text.

\author{
Symptomata-RAMMAzINI, p. 787.
}

"Affectiones genus, quod Bubulo generi bellum ad internecionem usque videtur indixisse, ex frigore, rigore, horripilatione, mox ex calore acri, et vehementi per universum Corpus diffuso, cum pulsus frequentia, febrem esse satis liquet, malignam vero, exitialem, pestilentialem etiam, si mavis, esse aperte testantur, quæ illam comitantur symptomata; qualia sunt, magna anxietas, et gravis anhelitus, etiam cum STERTORE, et in principio febris, stupor et species quædam veterni, continuus ex ore, et naribus graveolentis materia descensus, fœtidissima alvi proluvies, interdum etiam cruenta, anorexia, et abolita penitus ruminatio, pustulce quinta vel sexta die per totum corpus erumpentes, ac tubercula variolarum speciem referentia, communis tandem omnium eodem modo circa quintam, et septimam interritus, cum Boves paucissimi evadent, iique forte potius quadam, quam remediorum dynami. Hæc quidem ex se patent, quid vero intus patiantur miserandi Boves, cum jacent anxii, ac stertentes, ac dum stant immoti, capite usque ad terram demissio, conjectare quidam possumus, sed ex mutis animantibus, quæ per nutus nihil significare possunt, nil certi rescire possumus, quod forsan in causa est, ut difficilior sit curatio. Causam igitur hujusce malignæ febris pro viribus perscrutemur.

Omnibus epidemiis, si a sporadicis affectibus differre debent, id peculiare inest, quod communem causam habeant, sive ab Aëris vitio, sive a corruptis alimentis, aut ab aliquo contagioso fomite prognata fuerit, qui ab uno corpore in aliud transinigret illique eandem labem communicet."

Observatum in Dissectis Cadaveribus, p. 791.

"In Boum cadaveribus, quotquot Lanionum secespitæ subjecta fuere coram Excellentissimis Anatomes Professoribus D. Molinetto, et Viscardo, id singulare in omnibus repertum est; in Omaso nempè, corpus quoddam durum et compactum, ventriculi parietibus fortiter adhærens, magnae molis, et intoleranda graveolentice; in aliis vero partibus repertæ sunt hydathides, in cerebro, pulmonibus, sicuti etiam ingentes vesica solo flatu plenæ, quæ dissectæ diram Mephitim exhalarent, ulcera in radice linguc, et ad illius latera vesiculce sero plenœ. Illud vero corpus durum, et compactum ad instar calcis, quod in Omaso observatur, primum productum esse contagiosi miasmatis, pro certo habeo, dum tacite sævitiem suam exercens, stomachicum fermentum labefactat, et corrumpit; non enim est credibile, post febrem excitatam, conflari hoc corpus intra paucos dies, dum Boves ubi primum febrire cœperint, quodcunque alimentum aversantur, nec quidquam, nisi liquidum per os infundi potest: cætera vero, quæ memoravimus, malignæ febris producta esse, facile crediderim, sed omnium Phœenomenorum exactam rationem adferre velle, non patitur unius horæ ambitus; ampla enim materia suppeteret, ad integrum tractatum conscribendum." 


\section{Symptomata-LANCIsI, p. $11 \%$.}

" Utique vidimus interdum in nonnullis bobus primum indicium contractæ pestis fuisse, fugam arripere, ululare, stertere, ac mille modis quasi subito terrore percitos se se agitare; scilicet quod venenum, cum in iis volatilium salium ubertatem, miramque fibrarum nervearum in spasmos proclivitatem invenisset, diversos statim convulsivos qua externos, qua internos motus induxit. Alios etiam spectavimus, tametsi rarius, prccoci morte, quasi fulmine tactos interiisse, eos videlicet, qui natura sua jam enerves, spirituque fuerant destituti. Sed in plerisque præcipua exceptæ luis signa extiterunt subito mœrere; caput demittere; e languidulis oculis lachrymas, e naribus, et ore mucum, et salivam fundere; atque interim febri cum horrore, vel horripilatione correptos, nauseantesque humi jacere ; semper autem phlogoses, pustulce, ut innuimus, hydatides, et ulcera linguam et fauces summo cum. ardore obsidebant. Principio ut plurimum sitientes multum bibebant ; postea vero a potu, ciboque penitus abstinebant; et idcirco cum deglutire, ac ruminare non possent, inedia, sitique celerius etiam, quam natura forte morbi factum esset, ad interitum adigebantur ; alvo sæpe sæpius Iubrica, dejectisque fœtidis, variegatis, et interdum cruentis humoribus. Plerique tandem omnes putidi, gravique cum anhelitu, non raro etiam cum tussi intra primam hebdomadem occidebant. Qui autem ad alteram pertingerent (erant autem perpauci) evadere consueverant; præsertim si cadentibus pilis corium exasperaretur, aut facto ad nates, et ad crur a decubitu, ne libere possént incedere, prohibiti fuissent.

Vermes interim in naribus, ad cornuum radices, in labiis, atque ore comperiebantur, quibus scilicet locis muscarum agmina poterant confluxisse."

\section{QUID OBSERVATUM FUERIT IN DISSECTIS CADAVERIBUS.}

"Quod vero spectat ad ea, quæ in boum cadaveribus detecta fuerunt; illud prænosse convenit, raro in peste denatis certas, et perpetuas apud illorum viscera affectiones deprehendi ; etenim lues a liquidis primo excipitur, et ab iisdem postea aut hæc, aut illa membra pro varia eorundem conditione corripiuntur. Id sane evidentissimum apparuit in tribus extispiciis, quæ nos fieri curavimus; nam prater oris, fauciumque ulcuscula, atque asophagi, omasi, pulmonumque a rubore subnatum livorem, seu gangraenam; quas yuidem res in unoquoque pene similes comperimus, diversce in singulis occurrerunt viscerum losiones. Etenim in primo, qui tertia morbi die perierat, animadvertimus in omaso tum fœni duriusculam massam, tum pilam illam, quam Plinius Invencarum tophum apellat, ortam scilicet ex abrasis lingua pilis, et $\operatorname{mox}$ deglutitis, subinde vero peristaltici motus ope in modum filtri accedente saliva coactis; cotera viscera parum a statu sanitatis abfuerunt. In altero deinde, quoniam interierat 6 die, cum hepar et intestina tum pulmones sphacelo tentatc erant. In tertio cor etiam, et cerebrum corruptum pene diffuebant Neque quidquam in ipsorum liquidis constans, et memorandum observare licuit ; ob peculiares enim fluidorum crases variam quoque illorum fluiditatem, et colores offendimus." 


\section{ERRATA.}

Page 11, line 5 and 6, for "constitutioxris," read-constitutio-æris.
" 37, " 15 , for "Gambee," read-Gamgee.
" 38 , " 26 , for " in one case," read-in the same case.
" 39 , " 27 , for "irridescence," read-iridescence. 



\section{DESCRIPTION OF PLATES.}

\section{PLATE I.}

Frg. 1. Lower jaw of a Rinderpest cow. Under lip everted. Showing characteristic congestion of the superficial membrane. Also its peeling off at a more advanced stage of the disease, from the gum, exposing the raw surface of the mucons coat,............ See p. 31 .

FrG. 2. Microscopic view of the epithelium from same membrane, partly rolled up into scrolls and cylindrical forms, partly presenting its proper flattened and nucleated appearance; also showing mucous corpuscles, starch cells, \&c. The epithelial scales are very granular, and evidently undergoing retrograde degeneration,............ See p. 32 .

\section{PLATE II.}

Fro. 1. Giving the equally characteristic capillary congestion of the mucous membrane of the swollen vulva, the aphthous eruption on the upper part of the left labia near the integuments, the inflamed clitoris and ropy discharge from the orifice,...................... See p. 36 .

FIG. 2. Section of the 4 th stomach of steppe calf No. 14 near the pylorus, show. ing the ulcer-like depression beginning to heal,........... See p. 29.

\section{PLATE III.}

FIG. 1. Section of the $3 d$ stomach, exhibiting the scarlet rings frequently found in its gastric folds with theî denuded and dusky centres,.... See p. 32 .

FIG. 2. (a.) A single papilla attacked, and the capillary congestion commenced and beginning to spread.

(b.) The same seen under the microscope, and the minutest capillary vessels engorged and branching off towards the adjoining papillæ. See p. 33.

\section{PLATE IV.}

Fir. 1. Mucous coat of the 4th stomach, contrasting its earlier and more advanced stages of degeneration, .................... See pp..33-4.

Fro. 2. Same from 4th stomach of inoculated cow, No. 6, showing ecchymoses shining through the violet colored membrane,.......... See p. 28.

\section{PLATE V.}

FIG. 1. Showing complete injection and arborescent forms of the capillary vessels when fully congested in the small bowels.

FrG. 2. Characteristic mahogany appearance of the same after such extreme congestion, .......................................... See p. 35 .

\section{PLATE VI.}

Fig. 1 and 2. Sections of the duodenum in steppe cow No. 8, showing yellow fibrinous masses from Peyer's glands (fig. 2, showing one Peyer's gland and two Solitary Follicles, the exudation being removed from the former at both eads), ............... See p. 30 . 


\section{PLATE VII.}

Fir. 1. Section of jejunum in steppe cow, No. 6, mucous membrane colored blackish by pigment. Peyerian glands strongly injected, ....... See p. 28.

FIt. 2. Section of jejunum in steppe calf No. 32, with one Peyer's gland, the exudation being separated from it. The solitary follicle, hyperæmical

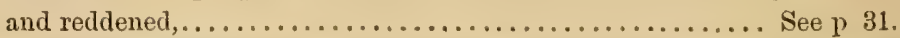

FIG. 3. Section of the large intestines, showing the "zebra appearance" of Boulay as the result of the extreme congestion of the larger vessels of its

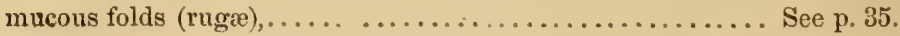

\section{PLATE VIII.}

Fit. 1. Section of the mucous membrane of the crecum of the vaccinated cow No. $6, \ldots \ldots \ldots \ldots \ldots \ldots \ldots \ldots \ldots \ldots \ldots$. See p. 28 .

Fi®. 2. Free exudations (like polypus, with depressions, \&c.), poured out in great multitude, in the concavity of the small bowels of the steppe calf No.

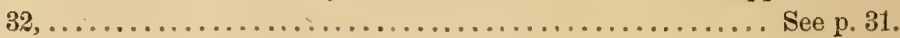

\section{PLATE IX.}

FrG. 1. Appearance of the hæmorrhoidal congestion of the rectum, ... See p. 35 .

FIc. 2. Highly vascular engorgement of the capillary vessels of the mucous membrane of the wind-pipe,.................... See p. 37.

FIG. 3. Section of 4 th stomach in eczema opizoötica, showing in the dark irregular patches the hæmorrhagic or sub-mucous effusions in that disease; (observe contrast with appearance of same stomach in the Pest in

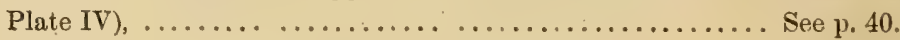

\section{PLA'TE X.}

Fig. 1 and 2. Colors of newly drawn blood from (1) healthy ox, and (2), from Rinderpest cow $\ldots \ldots \ldots \ldots \ldots \ldots \ldots \ldots \ldots$. See p. 38.

Fra. 3 and 4. Microscopic field (3) of (1)-(4) of (2), showing in (3) a fero red corpuscles corrugated from sudden transference of blood when. warm to the unheated slide of the instrument; the proportion of white to red cells; the absence of granular matter, and the free almost isolated position of each cell; in (4) the smaller size of the red, and greater abundance of the white corpuscles, their distention, rupture and shedding of contents; their stellar form; the number of granules from broken cells, and the cohesion of the corpuscles in irregular masses, ............. See p. 38.

FIG, 5 and 6. Crystals (with white corpuscles), as seen by GArGEE,... See p. 63.

\section{PLATE XI.}

FrG. 1. Rinderpest milk, in most advanced stage of the disease, under the microscope, the fatty cells elongated and crowded.

FrG. 2. Healthy milk, the butyric elements floating freely, \&c....... See p. 39.

\section{PLATE XII.}

FIG. 1. Flesh of Rinderpest cow, freshly slaughtered with fat, \&c.

Fic. 2. " after exposure to light and air for 24 houx, showing change of color and shrinking mostly in the fat.

Fre. 3. Flesh of healthy ox, after like exposure, ........... See pp. 39, 40. 


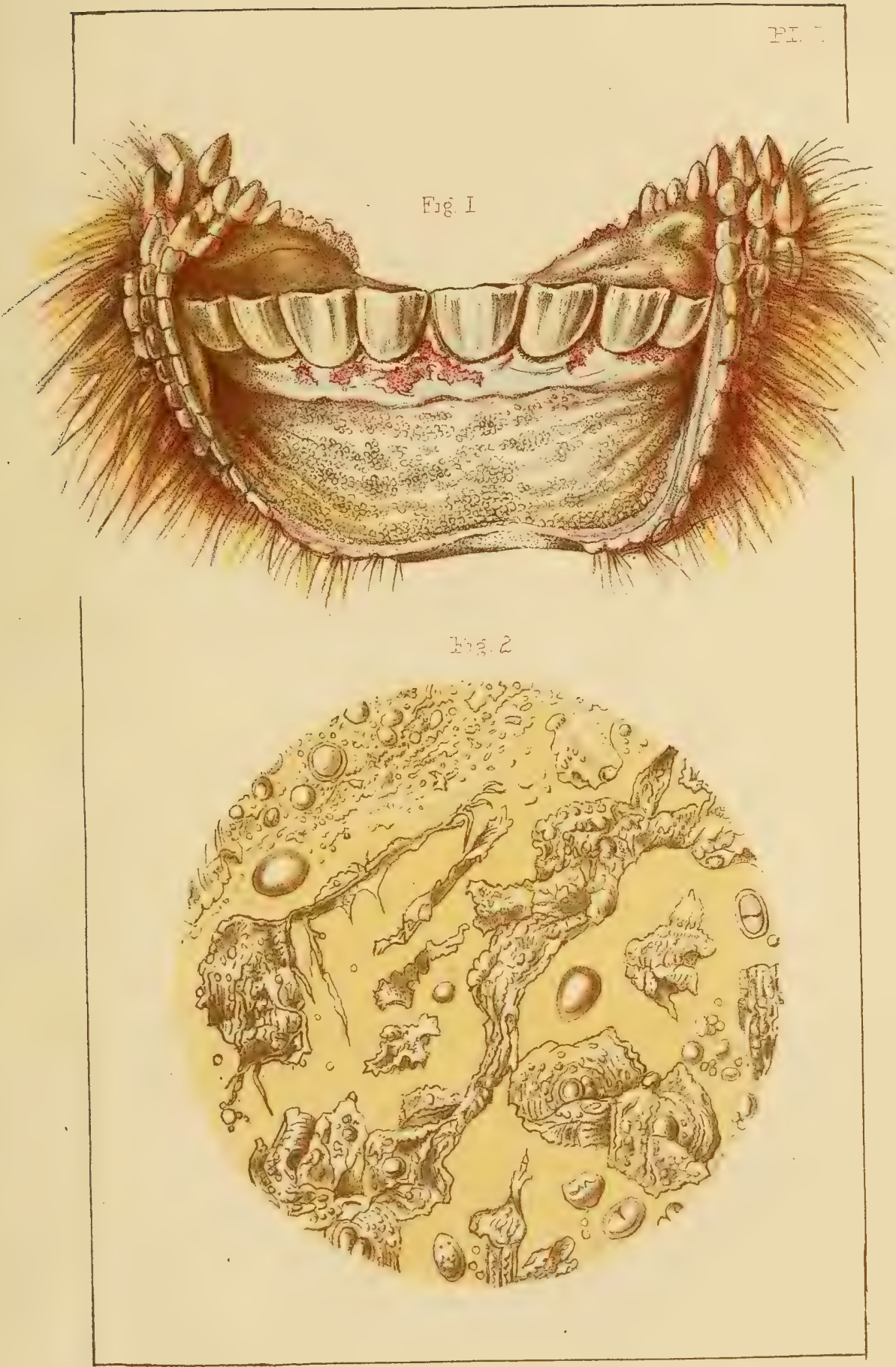





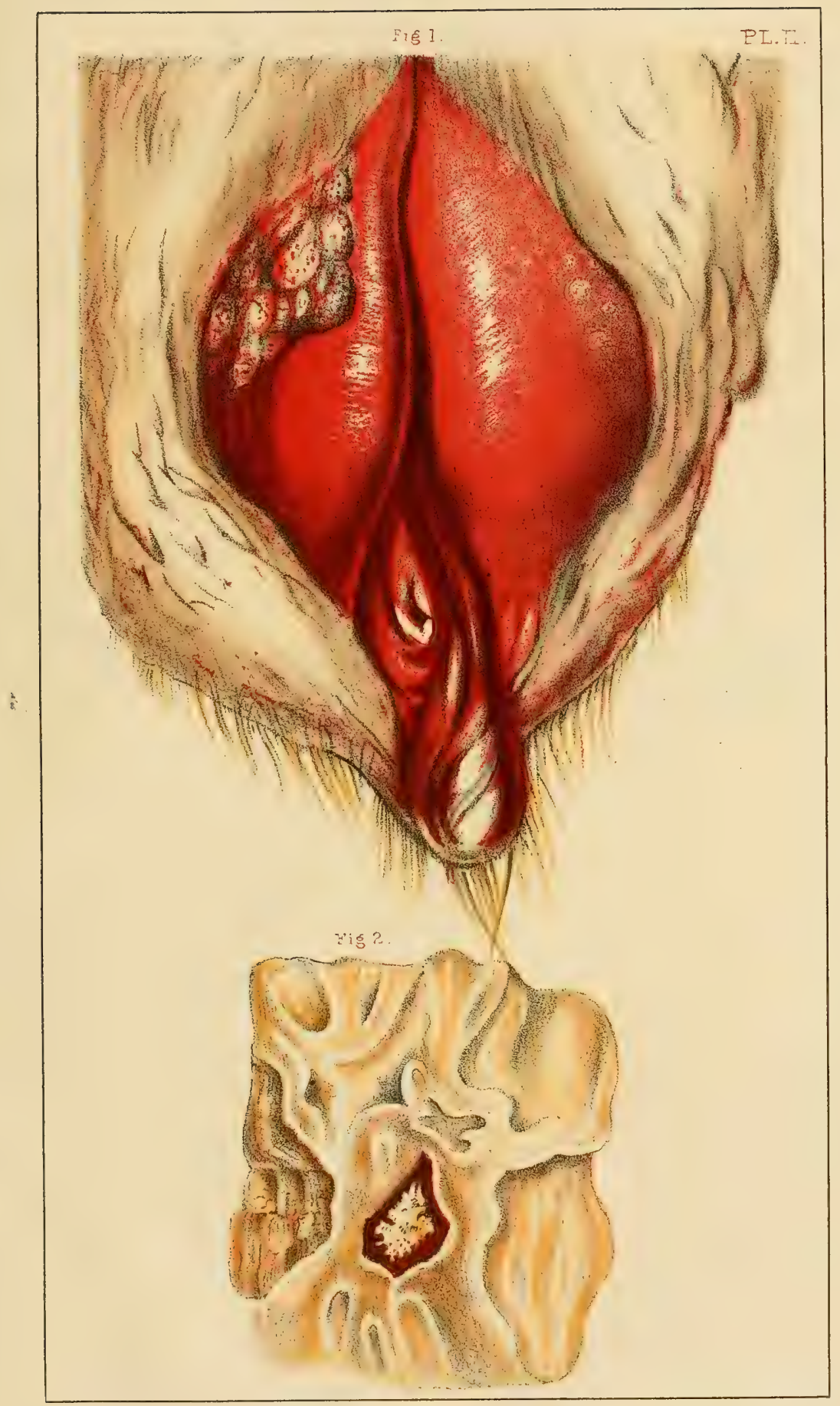





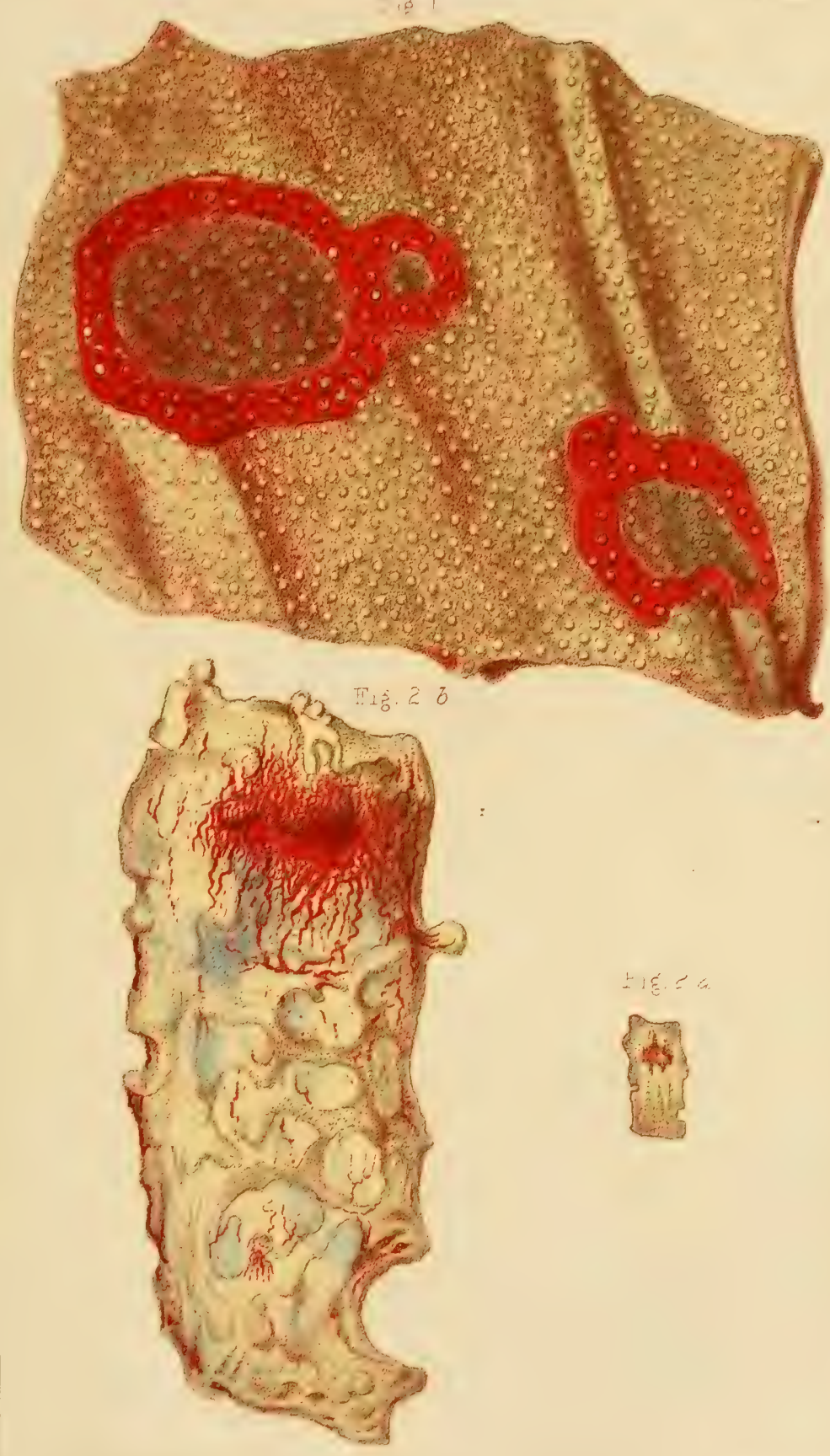





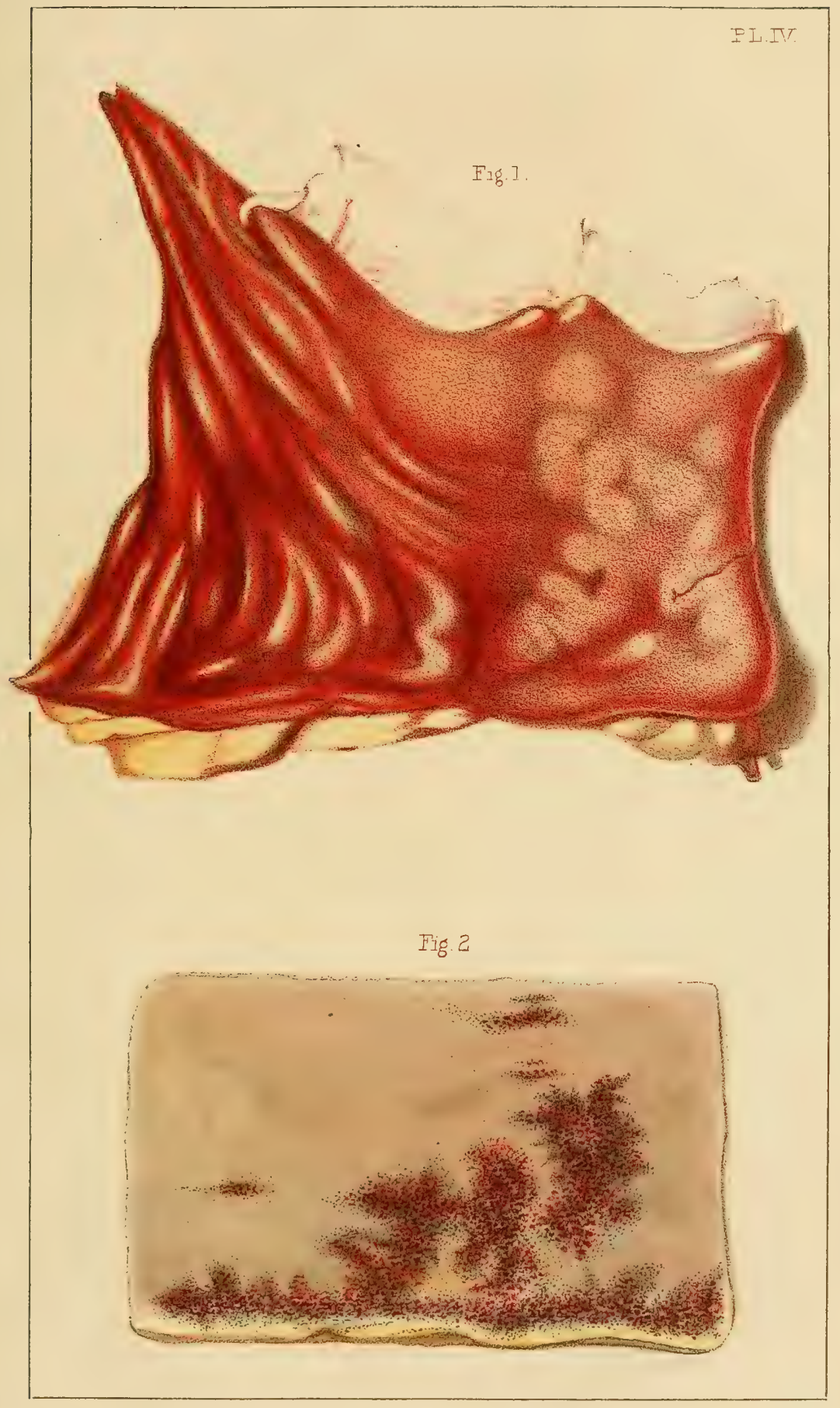





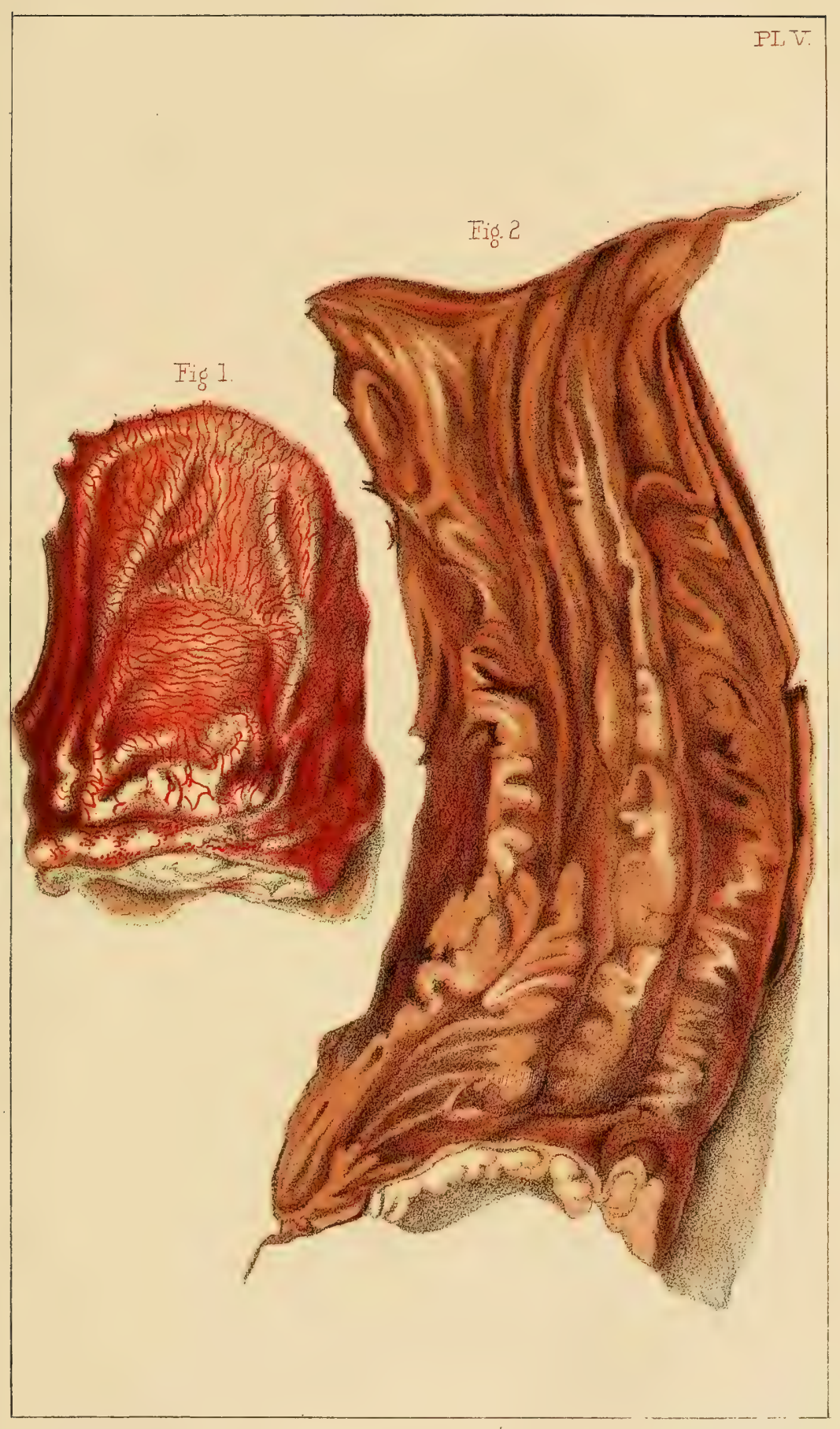





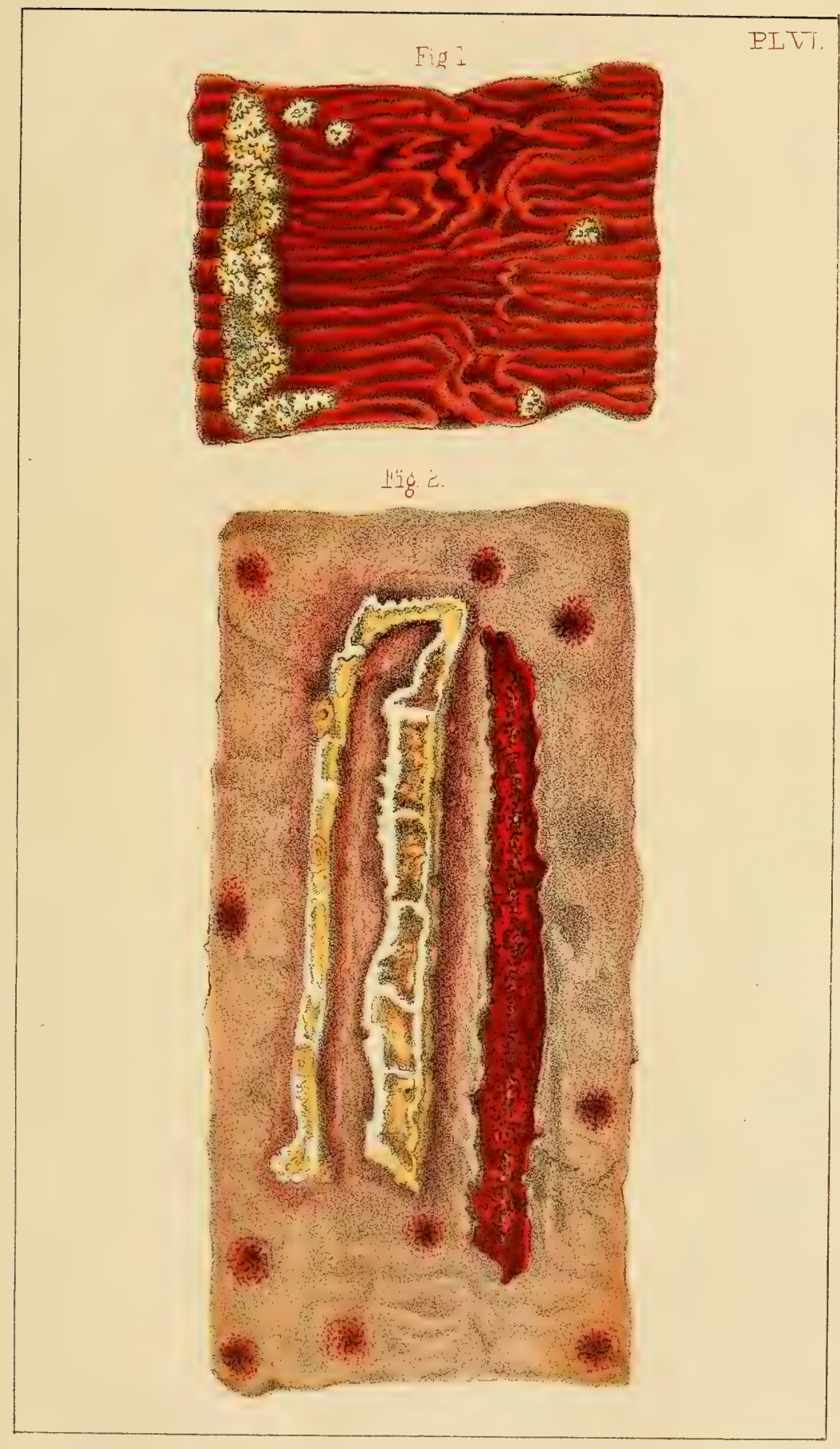





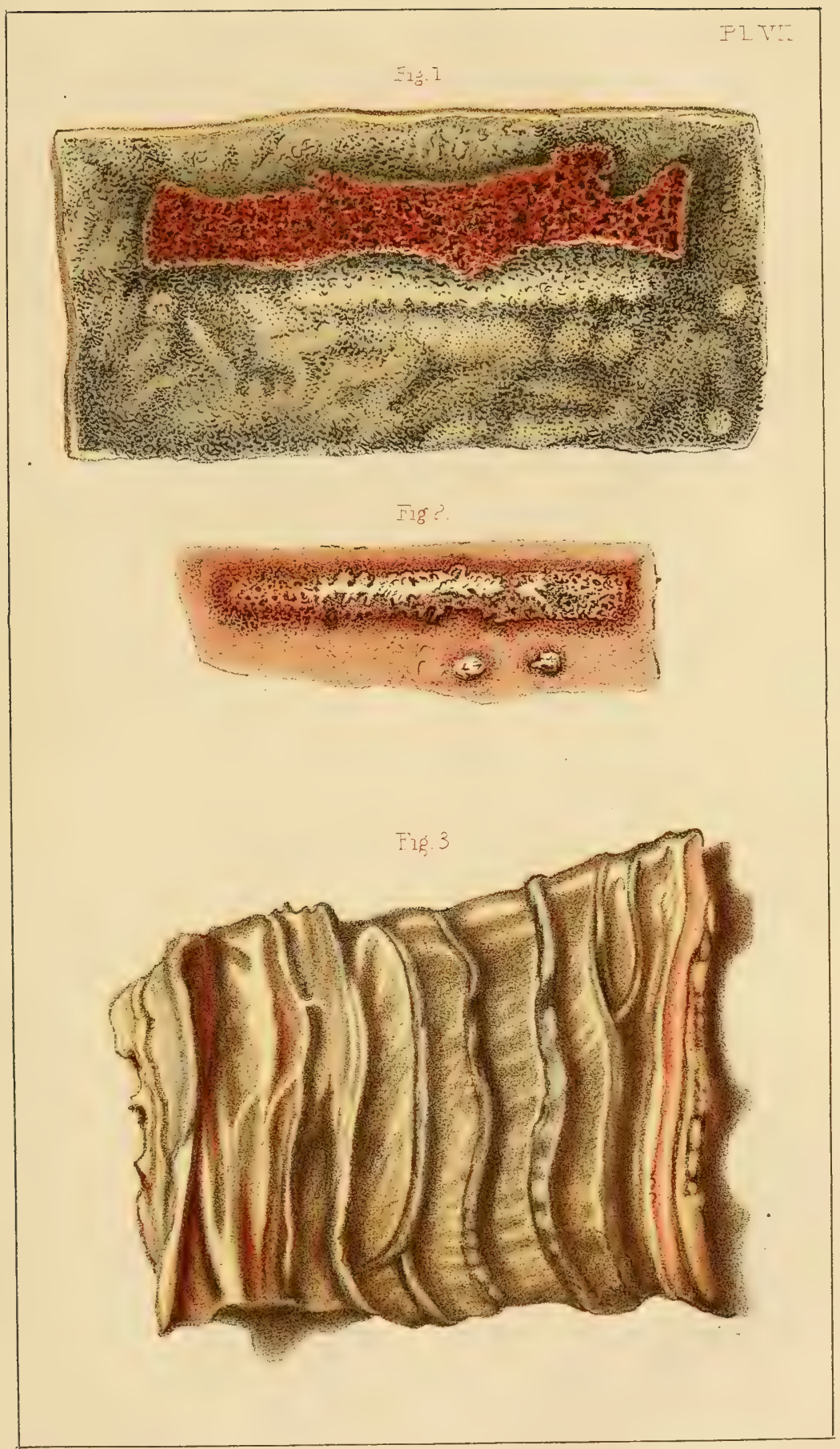





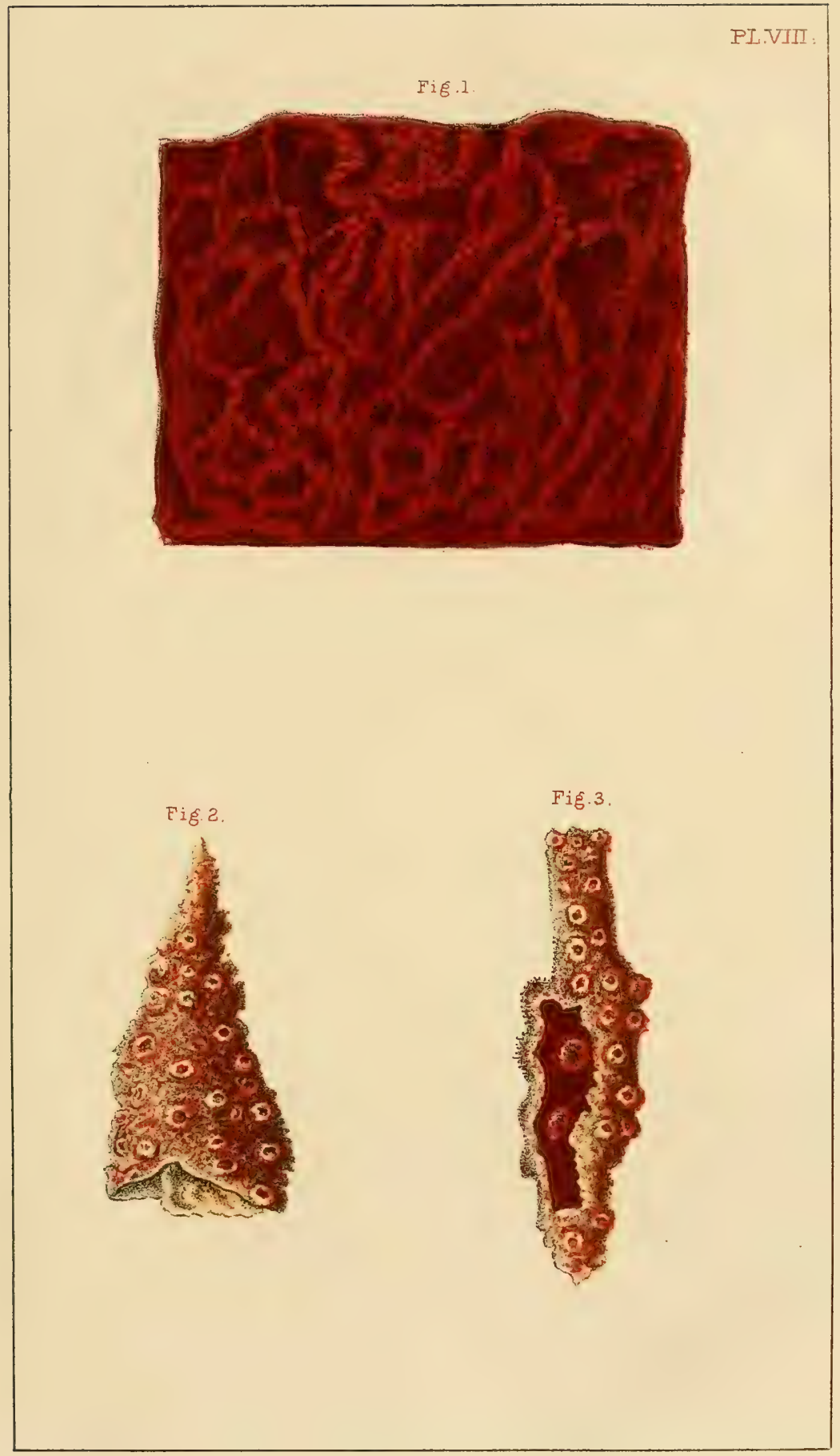





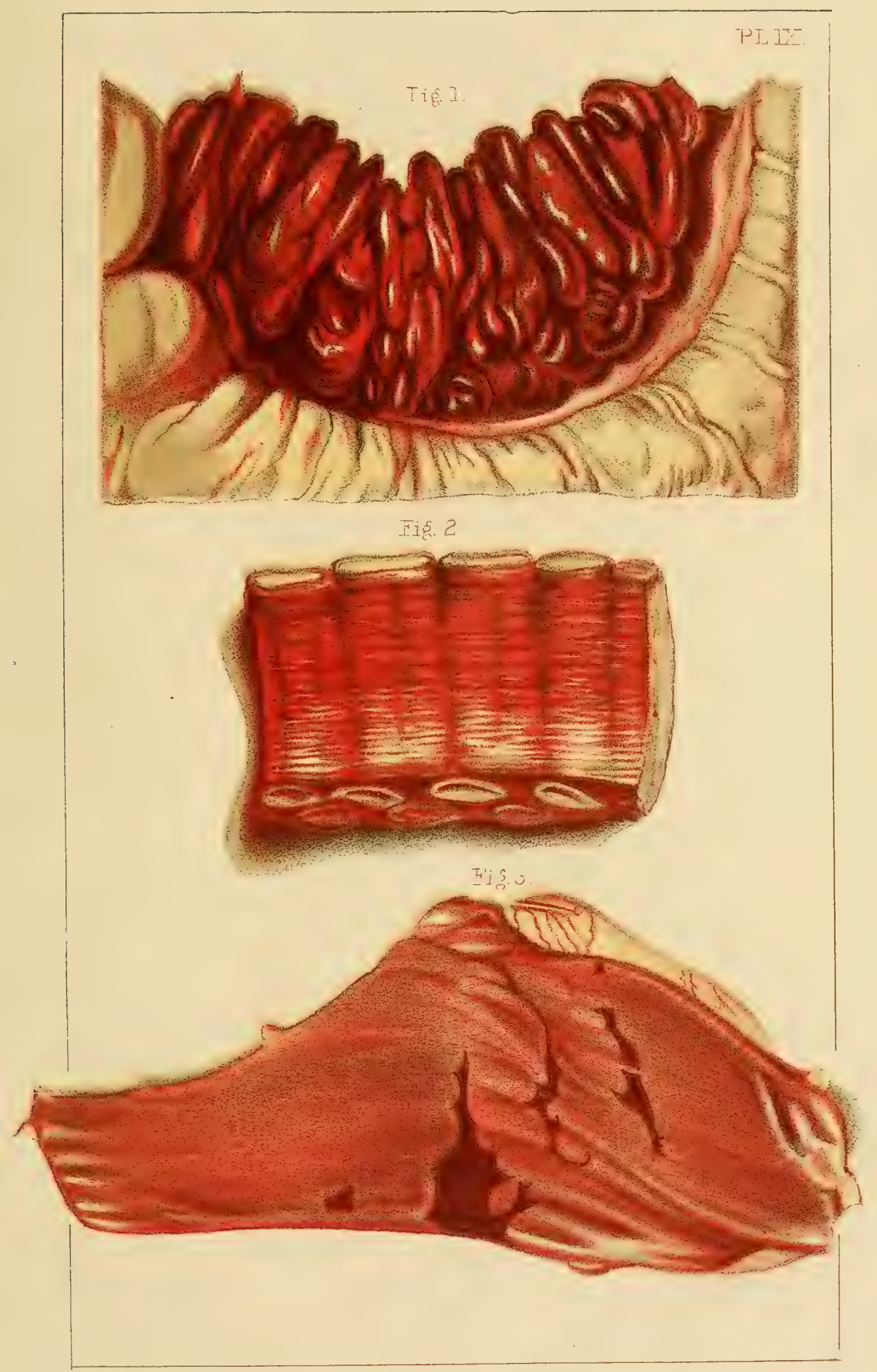





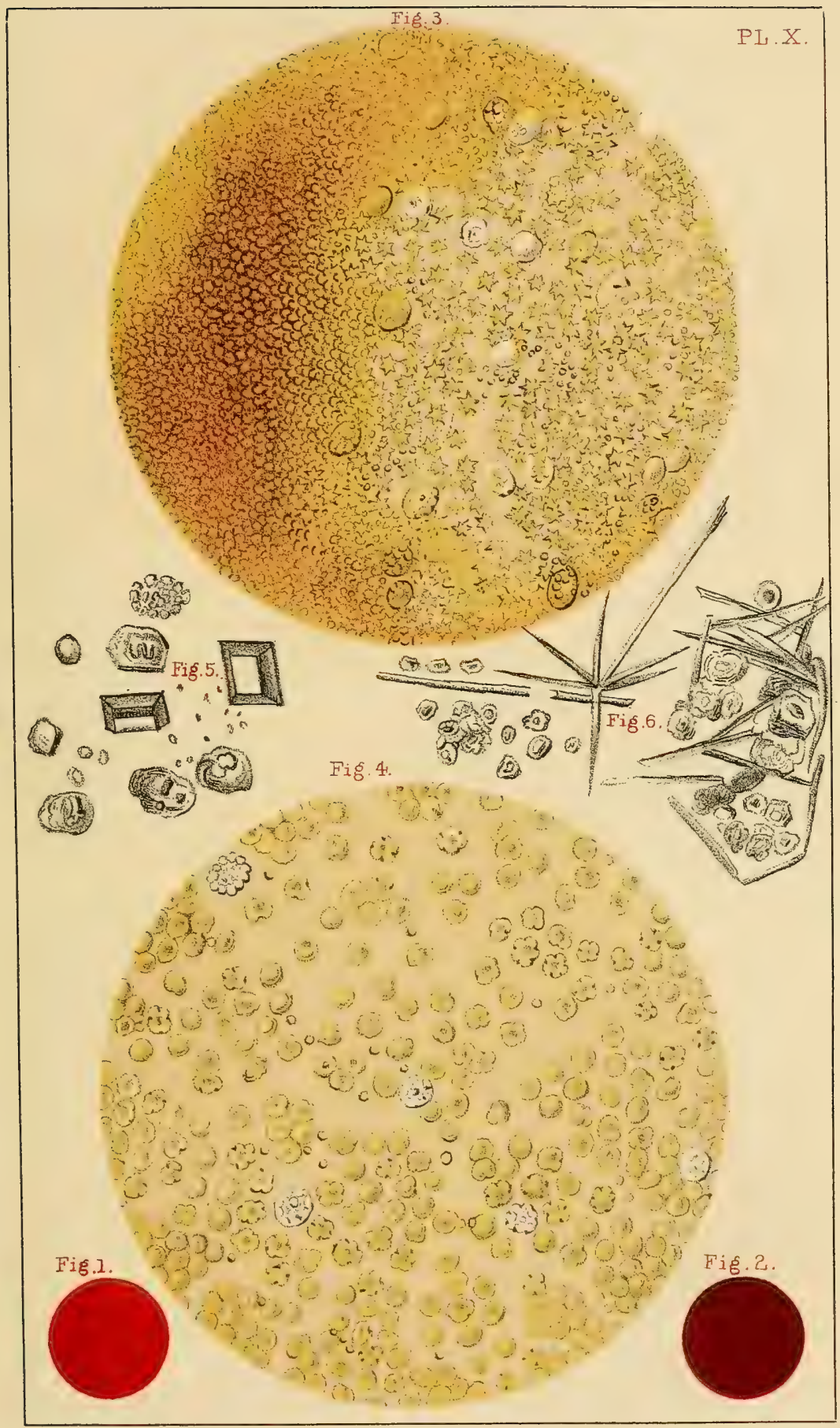





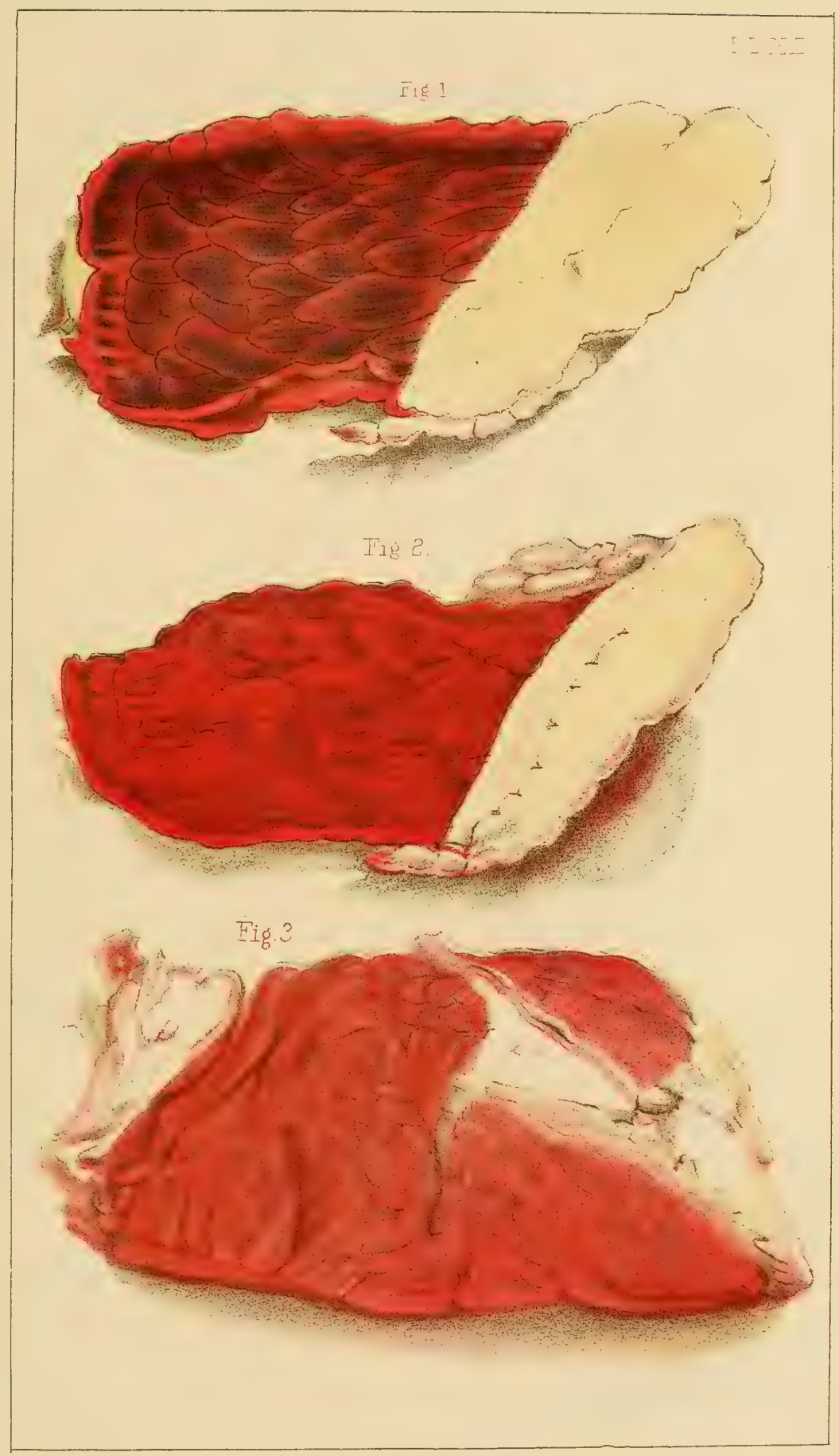





\section{,}

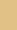






LIBRARY OF CONGRESS

||||||||||||||||||||||||||||||||||||||||

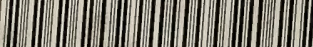
| || || || ||| || || || || || || || || || ||||||||||||| 00028651764 